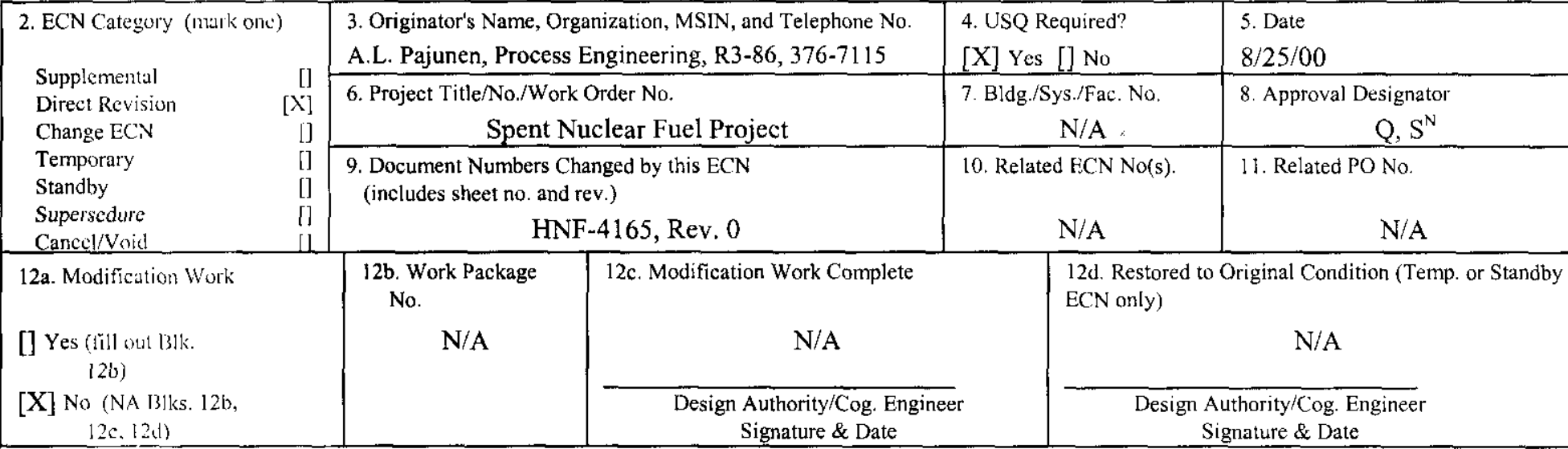

13a. Description of Change

13b. Design Baseline Document? [] Yes [X] No

1. Complete document revision

2. Minor text revisions in Introduction (Section 1.0)

3. Text nodifications and added table of recommended enhancement factors to Summary (Section 2.0)

4. Text modilicitions and added figure clarifying basis for conservatism of stoichiometry selected for uranium-water reaction (Section 4.0)

5. Text modilications and added figures to: (a) clarify basis for conservatism of stoichiometry selected for the uranium-moist aur reaction, and (b) model for predicting reaction rates (Section 5.0)

6. Minor 1ext changes clarifying uranium-dry air reaction discussion (Section 6.0)

7. Complevision to provide a simplified method for predicting rates at transition conditions between regions of applicability for correlutions (Section 7.0). Previous transition method description moved to Section 10.3.

8. Minor text revisions to reflect new references on crumbling (Section 8.0)

9. Updated and added references (Section 9.0)

10. Moved previn's transition method to Section 10.3 and added figures/text demonstrating prior transition region reaction rate predictions in Rev. 0 are equivalent to reaction rate predictions produced by the simplified method now presented in Section 7.0 .

USQ Screnim $K-00-1164, C V D-00-1703, C S B-00-1220$

\begin{tabular}{|c|c|}
\hline 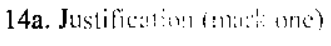 & 14b. Justification Details \\
\hline Criteria $(1,1,1, \cdots, \quad\{X\}$ & This revision incorporates peer review comments based on a review of Rev. 0 of this document and \\
\hline Design 1:1:?: & Design verification method is by Independent Review as documented on EDT 629788. \\
\hline
\end{tabular}

Enviromm:":at |

Facility D):alitictiu: |

As-Found

Facilitate Cint i. í

Const. Errork) (1)

Design Eatu:

15. Distrit)

See distribu: an iist 


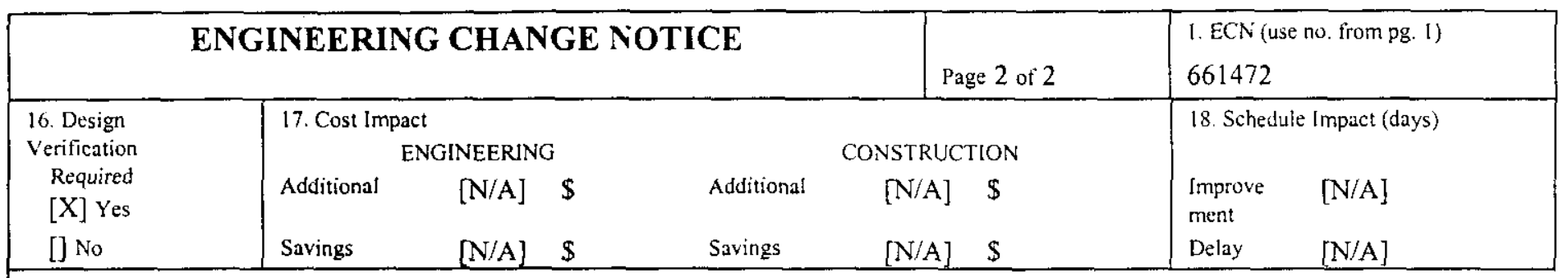

19. Change Impact Review: Indicate the related documents (other than the engineering documents identified on Side 1) that will be affected by the change described in Block 13. Enter the affected document number in Block 20 . N/A

SDDDD

Functional Design Criteria

Operating Specification

Criticality Specification

Conceptual Design Report

Equipment Spec.

Const. Spec.

Procurenient Spec

Vendor Information

OM Manual

FS.ARSAR

Safety Equipment List

Radiation Work Permit

Enviromuncotal Impats Statement

Environmental Report

Environmental Pernit

[]

[]

[]

[]

[]

[]

[]

[]

[]

[]

[]

[]

[]

[]

[]

[]
Seismicistress Analysis

Stresi Design Report

Interfuse Control Drawing

Calitration Procedure

Instal:ation Procedure

Maintenance Procesure

Enginetring Procedure

Operasing Instruttion

Opersting Procedure

Operscional Safety Requirement

IEFD Drawing

Cell Aтапgement Drawing

Essescial Material Specification

Fac proc Samp. Sihedule

Inspetion Plan

Inver:ory Adjustment Reques
[1 Tank Calibration Manual

[1] Health Physics Procedure

[] Spares Multiple Lrit Listing

[] Test Procedures/Specification

[] Component index

[] ASME Coded Item

[1] Human Factor Consideration

[1] Computer Sotware

[1] Eletric Circuit Schedule

[] ICRS Procedure

[] Process Control Manualiplan

[] Process Flow Char

[1] Purchase Requisition

[1] Tick!er File

[] See below
[]

[]

[]

[]

[]

[]

[]

[]

[]

[]

[]

[]

[]

[]

$[\mathrm{X}]$

20. Other Affected Documents: (NOTE: Documents listed below will not be revised by this ECN.) Signatures below indicate that the signing organization has been notified of other affected documents listed below.

Document Number/Revision

Document Number Revision

Document Number Revision

HNF-SD-SNF-TI-015, Rev. 6

21. Approvals

Design Authority

Cog. Eng. A. L.Pajunen

Signature

Date

Cog. Mgr. J. R. Frederickson

QA D.W. Smith

Asafety C. T. Miller

Environ.

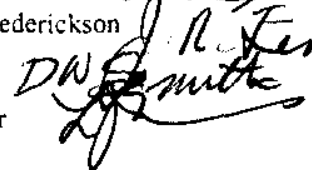

Other D. R. Olander
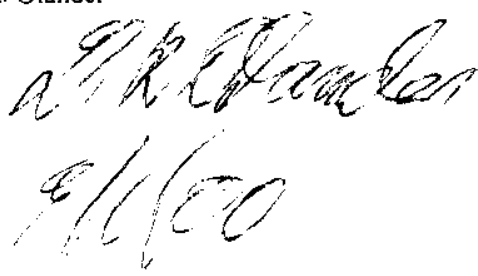

Signature

Date

Design Agent

$8 / 25 / 2-20 \quad P E$

$9 / 1 / 2000$ QA

9/18/00 Safety

$9 / 16 / 0 . \quad$ Design

Environ.

Other

DEPARTAENT OEENERGX:

Signature or a Control Number that tracks the Approval Signature

ADDUIONAL 
DISTRIBUTION SHEET

\begin{tabular}{|c|c|c|c|c|c|}
\hline \multirow{2}{*}{$\begin{array}{l}\text { To } \\
\text { Distribution }\end{array}$} & \multirow{2}{*}{\multicolumn{3}{|c|}{$\begin{array}{l}\text { From } \\
\text { Process Engineering }\end{array}$}} & \multicolumn{2}{|l|}{ Page 1 of 1} \\
\hline & & & & \multicolumn{2}{|l|}{ Date $9 / 8 / 00$} \\
\hline \multirow{2}{*}{\multicolumn{4}{|c|}{$\begin{array}{l}\text { Project Title/Work Order } \\
\text { Uranium Oxidation Rate Summary for the Spent Nuclear Fuel Project (OCRWM) }\end{array}$}} & \multicolumn{2}{|l|}{ EDT No. N/A } \\
\hline & & & & \multicolumn{2}{|c|}{ ECN No. 661472} \\
\hline & MSIN & $\begin{array}{c}\text { Text } \\
\text { With All } \\
\text { Attach. }\end{array}$ & Text Only & $\begin{array}{l}\text { Attach./ } \\
\text { Appendix } \\
\text { Only }\end{array}$ & $\begin{array}{l}\text { EDT/ECN } \\
\text { Only }\end{array}$ \\
\hline
\end{tabular}

Spent Nuclear Euel Project

J. Abrefah

G. S. Barney

R. D. Crowe

D. R. Duncan

J. R. Frederickson

P. G. Loscoe

C. T. Miller

F. W. Moore

L. H. Olguin

A. L. Pajunen

K. L. Pearce

L. R. Pederson

M. A. Reilly

R. A. Sexton

J. P. Sloughter

J. A. Swenson

D. J. Trimble

SNF Project

$\begin{array}{ll}\text { P7-27 } & \text { X } \\ \text { T5-12 } & \text { X } \\ \text { R3-86 } & \text { X } \\ \text { R3-86 } & \text { X } \\ \text { R3-86 } & \text { X } \\ \text { R3-81 } & \text { X } \\ \text { X3-78 } & \text { X } \\ \text { R3-86 } & \text { X } \\ \text { X4-01 } & \text { X } \\ \text { R3-86 } & \text { X } \\ \text { G1-23 } & \text { X } \\ \text { K2-50 } & \text { X } \\ \text { R3-86 } & \text { X } \\ \text { R3-86 } & \text { X } \\ \text { K9-49 } & \text { X } \\ \text { R3-11 } & \text { X } \\ \text { H0-40 } & \text { X } \\ \text { R3-11 } & \text { X }\end{array}$


HNF-4165

Revision 1

\section{Uranium Oxidation Rate Summary for the Spent Nuclear Fuel Project (OCRWM)}

Prepared for the U.S. Department of Energy Assistant Secretary for Environmental Management

Project Hanford Management Contractor for the

U.S. Department of Energy under Contract DE-AC06-96RL13200

Fluor Hanford

P.O. Box 1000

Richland, Washington 


\title{
Uranium Oxidation Rate Summary for the Spent Nuclear Fuel Project (OCRWM)
}

\author{
A. L. Pajunen
}

Fluor Hanford

Date Published

August 2000

Prepared for the U.S. Department of Energy Assistant Secretary for Environmental Management

Project Hanford Management Contractor for the

U.S. Department of Energy under Contract DE-AC06-96RL13200

Fluor Hanford

P.O. Box 1000

Richland, Washington
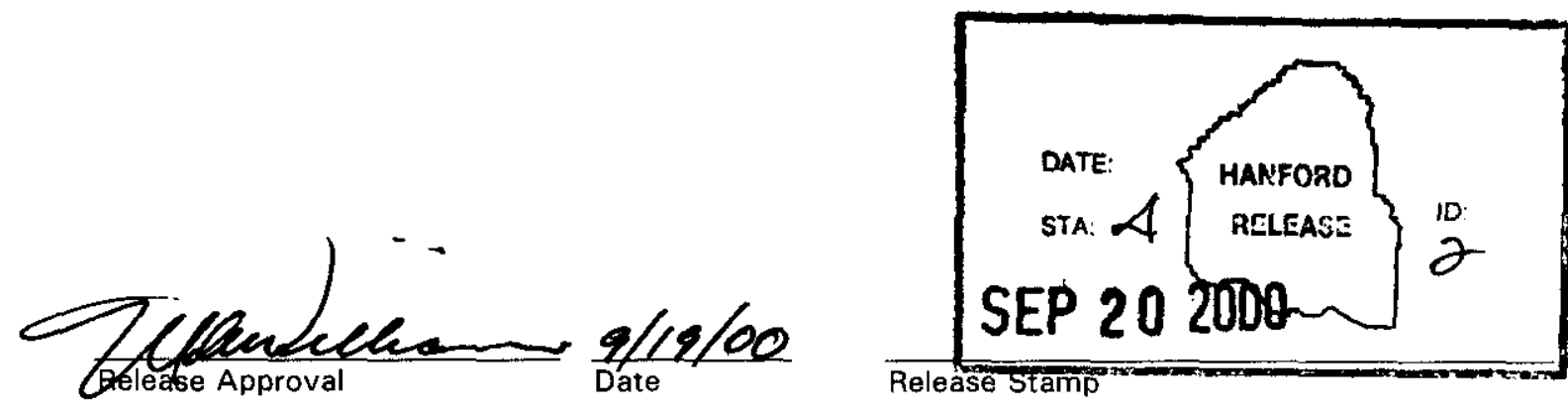
TRADEMARK DISCLAIMER

Reference herein to any specific commercial product, process, or service by trade name, trademark, manufacturer, or otherwise, does not necessarily constitute or imply its endorsement, recommendation, or favoring by the United States Government or any agency thereof or its contractors or subcontractors.

This report has been reproduced from the best available copy. Available in paper copy and microfiche.

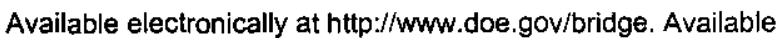
for a processing fee to the U.S. Department of Energy and its contractors, in paper, from:

U.S. Department of Energy

Office of Scientific and Technical Information

P.O. Box 62

Oak Ridge, TN 37831-0062

phone: 865-576-8401

fax: 865-576-5728

email: reports@adonis.osti.gov(423) 576-8401

Available for sale to the public, in paper, from:

U.S. Department of Commerce

National Technical Information Service

5285 Port Royal Road

Springfield, VA 22161

phone: $800-553-6847$

fax: 703-605-6900

email: orders@ ntis.fedworld.gov

online ordering: http://www.ntis.gov/ordering.htm

Printed in the United States of America

Total Pages: 103

HNF-4165, nWl 


\section{RECORD OF REVISION}

(2) Title

Uranium Oxidation Rate Summary for the Spent Nuclear Fuel Project (OCRWM)

CHANGE CONTROL RECORD

(3) Revision

\begin{tabular}{|l|}
\hline 0 \\
\hline${ }^{1} \mathbf{R S}$
\end{tabular}

(4) Description of Change - Replace, Add, and Delete Pages

(7) EDT $625822,3 / 24 / 99$

ECN 661472, August 2000, Complete document revision to incorporate peer review comments.
(1) Document Number

HNF-4] 65, Rey, $]$
Page 1

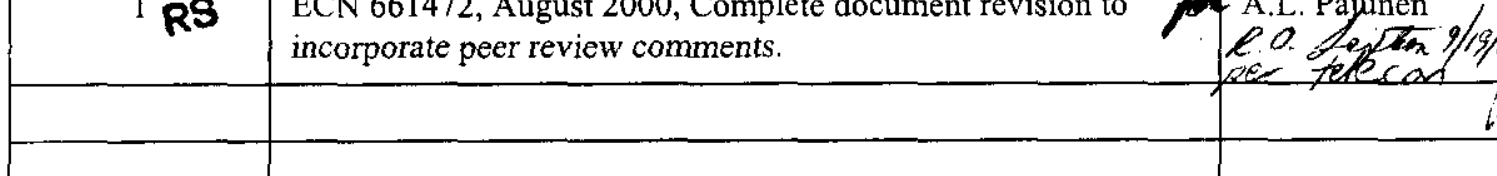

Authorized for Release

\begin{tabular}{|c|c|}
\hline (5) Cog. Engr. & (6) $\mathrm{Cog} . \mathrm{Mgr}$ \\
\hline A.L. Pajunen & J.R. Frederickson \\
\hline $\begin{array}{l}\text { A.L. Pajunen } \\
\text { Q.O. Lejten }\end{array}$ & $\begin{array}{l}\text { JR. Frederickson } \\
\text { ql }{ }^{t} \text { estim }\end{array}$ \\
\hline
\end{tabular}




\section{URANIUM OXIDATION RATE SUMMARY FOR THE SPENT NUCLEAR FUEL PROJECT (OCRWM)}

\section{Table of Contents}

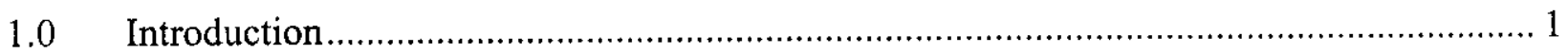

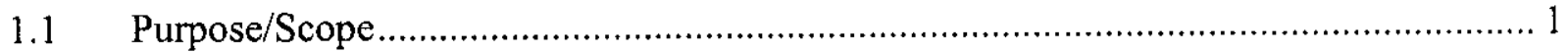

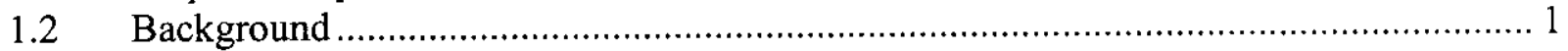

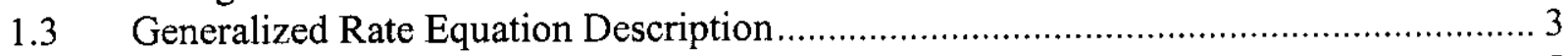

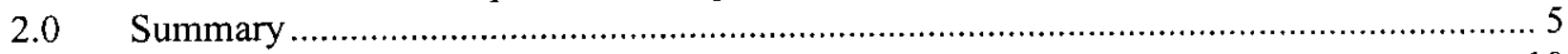

3.0 Primary Conditions of Interest to Project Processes............................................ 10

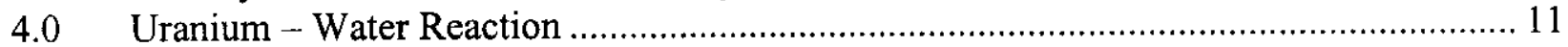

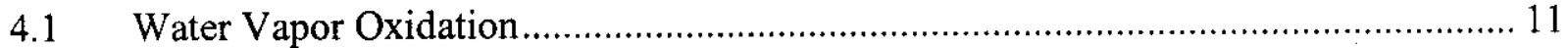

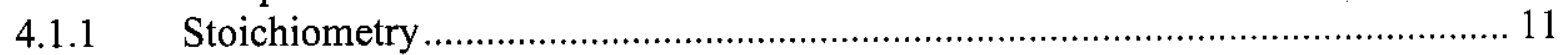

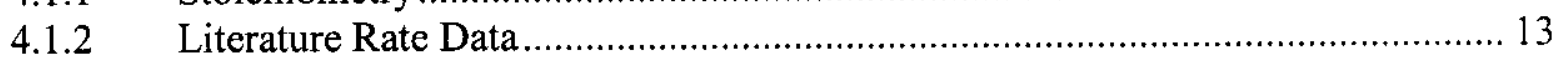

4.1.3 N Reactor Fuel Reaction Rate Observations ......................................... 15

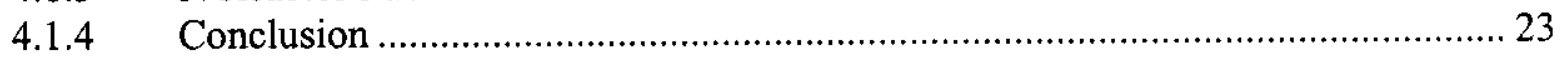

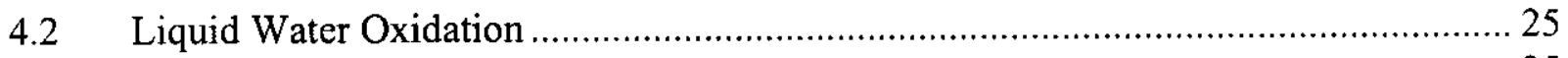

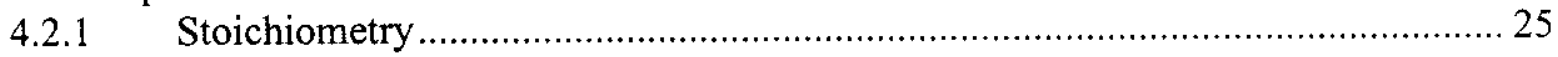

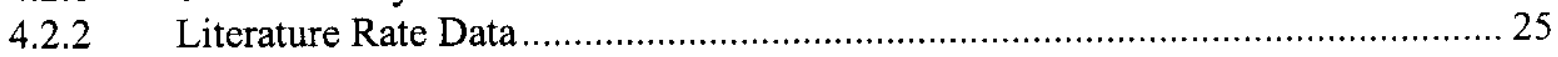

4.2.3 N Reactor Fuel Reaction Rate Observations …..................................... 27

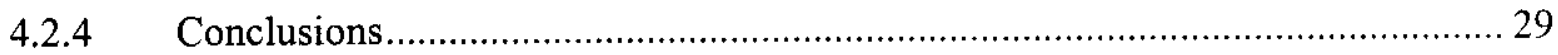

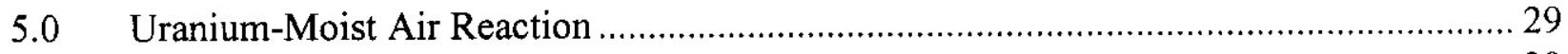

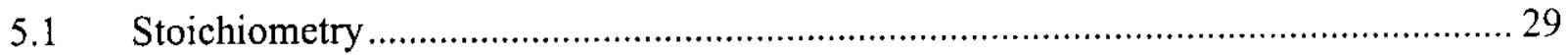

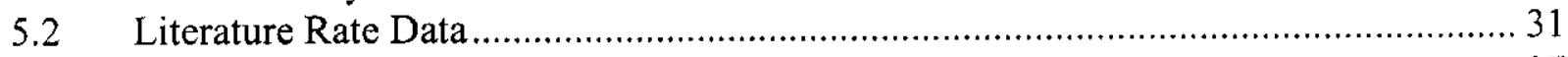

$5.3 \quad$ N Fuel Reaction Rate Observations .............................................................. 37

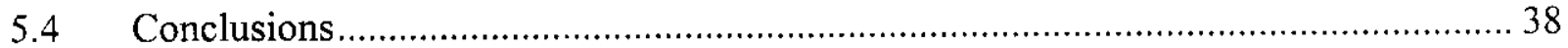

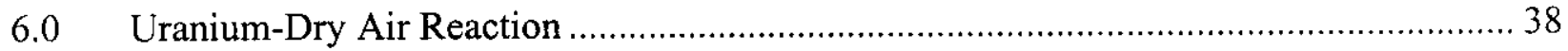

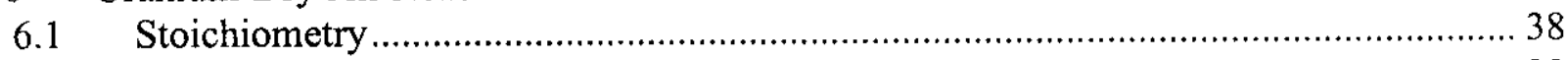

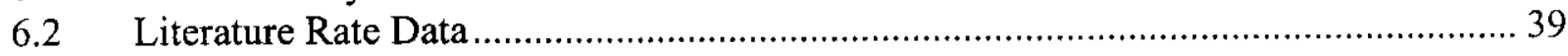

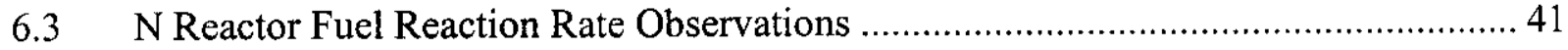

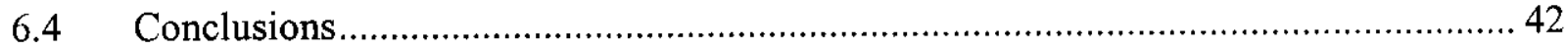

7.0 Basis for Transitions Between Reactions .......................................................... 43

8.0 Other Reaction Rate Considerations ............................................................... 49

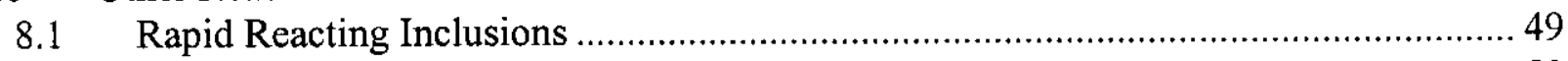

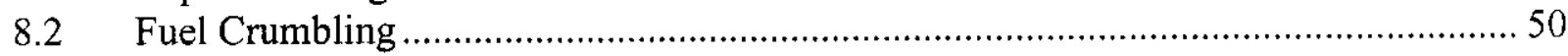

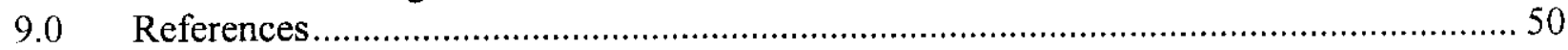

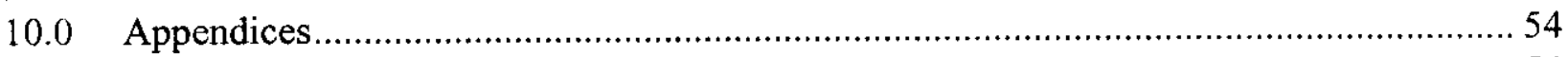

$10.1 \quad$ N Reactor Fuel Characterization Shipping Observations ...................................... 54

10.2 Sensitivity Analysis of MCO Thermal Stability in Dry Air ................................. 76

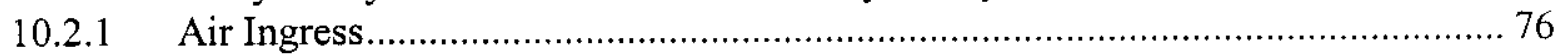

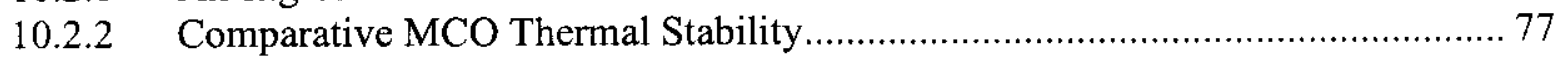

10.3 Alternate Method of Evaluating Transitions Between Reactions .............................. 84

10.3.1 Alternate Transition Description......................................................... 84

10.3.2 Transition Temperatures for Alternate Linear Interpolations ........................... 87

10.3.3 Comparison of Oxidation Rate Predictions in Transitions ............................. 91 
10.4 Uncertainty Estimates for Enhancement Factors from Single Element Drying Tests .. 94

\section{List of Figures}

Figure 2-1. Comparison of Uranium Oxidation Reaction Rate Correlations...........................6

Figure 2-2. Example of Conservatism Produced by Enhancement Factors ............................... 8

Figure 4-1. Water Vapor Oxidation Reaction Characteristics Variation with Stoichiometry .... 12

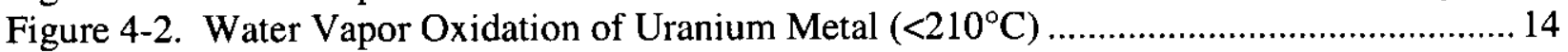

Figure 4-3. Water Vapor Oxidation of Uranium Metal Compared with Saturated Water Vapor

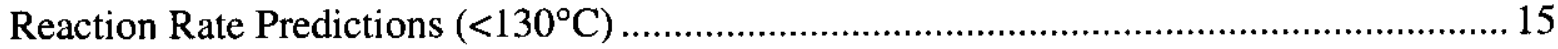

Figure 4-4. Comparison of Bounding MCO Reaction Rates with Single Element Drying Observations

Figure 4-5. Comparison of Bounding MCO Scrap Basket Reaction Rate with Single Element

Drying Observations ......................................................................................... 21

Figure 4-6. Comparison of MCO Fuel Basket Reaction Rate with Single Element Drying

Observations

Figure 4-7. Reaction Rate Dependence on Water Vapor Indicated by Single Element Drying

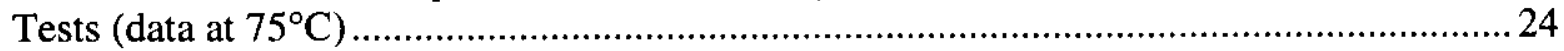

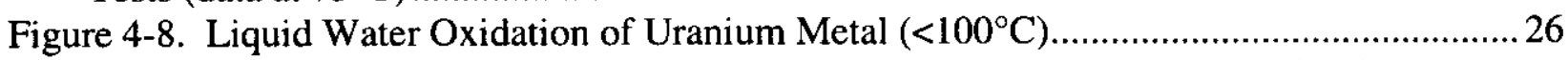

Figure 4-9. Comparison of Bounding Reaction Rates in Liquid Water with Single Element

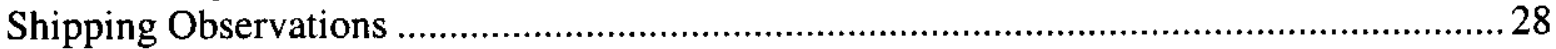

Figure 5-1. Heat of Reaction Variation for Uranium Oxidation by Oxygen with Stoichiometry 30

Figure 5-2. Moist Air Oxidation of Uranium Metal at $100 \%$ Relative Humidity $\left(<100^{\circ} \mathrm{C}\right) \ldots . . .32$

Figure 5-3. Moist Air Oxidation of Uranium Metal at $11 \%$ to $75 \%$ Relative

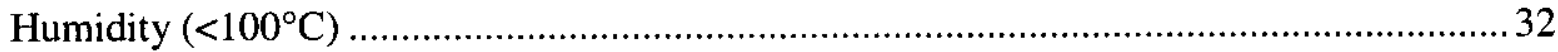

Figure 5-4. Comparison of McGillivray Correlation to Moist Air Oxidation Rate Data............ 35

Figure 5-5. Comparison of Uranium Metal Moist Air Oxidation Correlations $\left(<100^{\circ} \mathrm{C}\right) \ldots \ldots \ldots . . . .37$

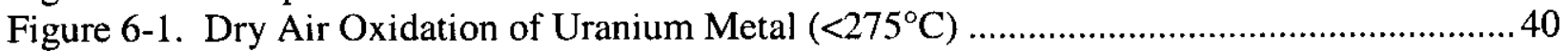

Figure 7-1. Comparison of Uranium Oxidation Reaction Rate Correlations ...........................4 43

Figure 7-2. Uranium Oxidation Reaction Transitions.....................................................45

Figure 7-3. Variation of Moist Air Oxidation Rate with Partial Pressure Water Vapor at $50^{\circ} \mathrm{C} .47$

Figure 7-4. Variation of Moist Air Oxidation Rate with Partial Pressure Oxygen at $50^{\circ} \mathrm{C} \ldots . . . . .48$

Figure 7-5. Variation of Moist Air Oxidation Rate with Temperature and Water Vapor Partial

Pressure ....................................................................................................... 48

Figure 10-1. Temperature Limit for Stable Air System Assuming Dry Air Reaction Rates from

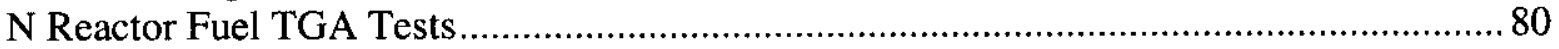

Figure 10-2. Water Vapor Partial Pressure and Enhancement Factors Indicating Air System is

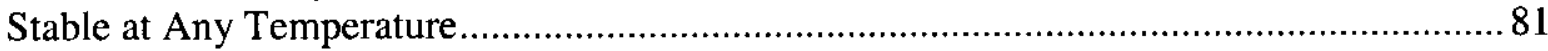

Figure 10-3. Basis for Alternative Transitions between Air Oxidation Reactions .................... 85

Figure 10-4. Composition Basis for Alternative Transitions between Oxidation Reactions ....... 86

Figure 10-5. Variation of Moist Air Uranium Oxidation Rate Based on Interpolations ............ 87

Figure 10-6. Correlation for Predicting Water Vapor Saturation Pressure ................................89

Figure 10-7. Transition Temperature between Moist Air Oxidation Correlations .................... 90

Figure 10-8. Comparison of Moist Air Oxidation Rate Predictions at $1 \mathrm{kPa}$ Water Vapor........ 92

Figure 10-9. Comparison of Moist Air Oxidation Rate Predictions at $10 \mathrm{kPa}$ Water Vapor.......92

Figure 10-10. Comparison of Moist Air Oxidation Rate Predictions at $50 \mathrm{kPa}$ Water Vapor..... 93 


\section{List of Tables}

Table 2-1. Uranium Oxidation Rate Enhancement Factor Recommendations ............................ 9

Table 3-1. Reactions and Conditions of Interest to Spent Nuclear Fuel Project Processes ......... 10

Table 4-1. Low Temperature Reaction Rate Estimates from Single Element Drying Data ........ 17

Table 4-2. MCO Configurations for Comparing Single Element Rate Data ............................... 19

Table 4-3. Uranium Oxidation in Oxygenated Water ..............................................................2

Table 5-1. Moist Air Uranium Metal Oxidation Rate Data [from Ritchie (1986)]....................... 36

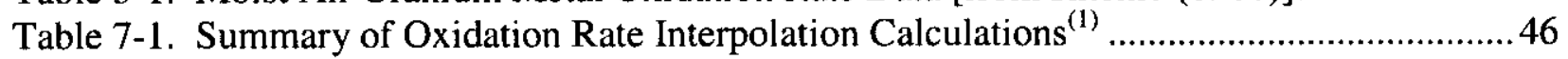

Table 10-1. Oxidation Rate Estimates from Element Shipping Observations ......................................5 54

Table 10-2. Water Vapor Oxidation Rate Enhancement Factor Estimates for N Reactor Fuel from Single Element Drying Tests.................................................................................99

Table 10-3. Enhancement Factor Uncertainty Calculation .........................................................95

Table 10-4. Uncertainty Estimate for Partial Pressure Water Measurements in Single Element

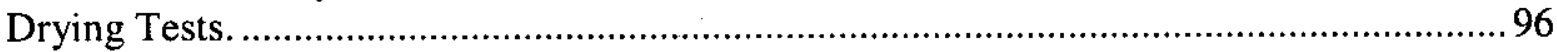

\section{List of Acronyms}

$\begin{array}{ll}\text { CSB } & \text { Canister Storage Building } \\ \text { CVD } & \text { Cold Vacuum Drying } \\ \text { MCO } & \text { Multi-Canister Overpack } \\ \text { PNNL } & \text { Pacific Northwest National Laboratory } \\ \text { RH } & \text { Relative Humidity } \\ \text { SNF } & \text { Spent Nuclear Fuel } \\ \text { TGA } & \text { Thermo-Gravimetric Analysis }\end{array}$




\section{URANIUM OXIDATION RATE SUMMARY FOR THE SPENT NUCLEAR FUEL PROJECT (OCRWM)}

\subsection{INTRODUCTION}

\subsection{Purpose/Scope}

The purpose of this document is to summarize the uranium oxidation reaction rate information developed by the Hanford Spent Nuclear Fuel (SNF) Project and describe the basis for selecting reaction rate correlations used in system design. The selection basis considers the conditions of practical interest to the fuel removal processes and the reaction rate application during design studies. Since the reaction rate correlations are potentially used over a range of conditions, depending of the type of evaluation being performed, a method for transitioning between oxidation reactions is also documented.

The document scope is limited to uranium oxidation reactions of primary interest to the SNF Project processes. The reactions influencing fuel removal processes, and supporting accident analyses, are: uranium-water vapor, uranium-liquid water, uranium-moist air, and uranium-dry air. The correlation selection basis will consider input from all available sources that indicate the oxidation rate of uranium fuel, including the literature data, confirmatory experimental studies, and fuel element observations. Trimble (2000) summarizes literature data and the results of laboratory scale experimental studies. This document combines the information in Trimble (2000) with larger scale reaction observations to describe uranium oxidation rate correlations applicable to conditions of interest to the SNF Project.

\subsection{Background}

The uranium oxidation rate defines parameters important to the evaluation and design of fuel removal processes. A simplified description of the four major parameters defined by the uranium oxidation rate is as follows:

- Heat generation rate $=($ decay heat $)+($ heat of reaction $) \times($ oxidation rate $)$

- Hydrogen generation rate $=\left(\frac{\text { hydrogen produced }}{\text { uranium reacted }}\right) \times($ oxidation rate $)$

- Particulate generation $=($ oxidation rate $) \times($ time $)$

- Oxygen gettering rate $=\left(\frac{\text { oxygen reacted }}{\text { uranium reacted }}\right) \times($ oxidation rate $)$

Reaction stoichiometry defines the ratio of hydrogen produced or oxygen reacted as compared to the uranium reacted. 
The parameter relationships described above for heat generation, hydrogen generation, and oxygen gettering are generic to systems evaluating the oxidation of uranium metal fuel. However, the linear relationship between particulate generation and oxidation rate is an assumption specific to design of fuel removal systems for the SNF Project. Typically, uranium oxidation products will build up on a metal surface. Oxidation of clean metal surfaces produces an adherent oxide, which thickens under highly strained conditions. Oxidation products spall off the metal surface to produce an oxide layer that reaches an equilibrium thickness. This effect is thought to be at least partially responsible for the para-linear (combined parabolic and linear relationship) nature of kinetic expressions describing experimental reaction rate observations. The SNF Project fuel removal systems handle uranium metal fuel that has been stored in water for extended time periods ( 10 years to 20 years). Based on the extended storage time, it is assumed that an equilibrium oxide layer has been established on metal surfaces such that any additional metal oxidation causes part of the established oxide layer to spall off as particulate. This results in a linear relationship between oxidation rate and particulate generation.

Reilly (1998) is the required reference of reaction rate correlations for SNF Project design and evaluations. The databook relies on reviewed and approved reference studies as a basis for the reaction rate correlations presented for use in project design and includes correlations for all the uranium oxidation reactions applicable to the process systems.

Cooper (1998) describes the oxidation reaction rate correlations identified from a literature review for initial use in design studies. These correlations were selected from the relationships developed by investigators in the literature. Confirmatory experimental studies for selected reaction systems were performed to verify that $\mathrm{N}$ Reactor fuel exhibits corrosion reaction rate characteristics similar to that of uranium metal samples used by studies reported in the literature.

More detailed summaries of the literature data available for the dry air, water vapor, and liquid water reactions were developed in Trimble (1998a) and Trimble (1998b). These generally record the data available from literature reviews that formed the initial correlations presented in Cooper (1998) and present regression analyses of the data.

Confirmatory reaction rate data for $\mathrm{N}$ Reactor fuel are available from three general sources:

(1) Laboratory studies on small fuel samples specifically designed to confirm reaction rates in dry air, moist air, and water vapor (moist helium),

(2) Hot cell studies that dried full N Reactor fuel elements, where reaction rates in water vapor (moist argon) can be inferred from the data recorded during the study of fuel drying characteristics, and

(3) Fuel element shipping observations where gas generation rates were measured from full $\mathrm{N}$ Reactor fuel elements reacting with liquid water in the basin prior to shipment to laboratories for study. 
Reaction rates have also been inferred by monitoring the rate of ${ }^{137} \mathrm{Cs}$ accumulation in $\mathrm{K}$ East Basin water treatment ion exchange columns (Johnson and Burke 1995). While these data provide an indication of the total fuel reacted in the $\mathrm{K}$ East Basin, uncertainty as to whether the oxygenated or de-oxygenated water uranium oxidation reaction dominates the overall basin observations preclude use of these plant observations to confirm reaction rate correlations.

Dry air reaction rate studies at relatively high temperature $\left(200^{\circ} \mathrm{C}\right.$ to $\left.275^{\circ} \mathrm{C}\right)$ were the initial focus of $\mathrm{N}$ Fuel tests, followed by moist air reaction rates in a similar temperature range (Abrefah, et al. 1998a and 1998b). These high temperature data were developed to support evaluation of accident scenarios in a hot conditioning process system. The hot conditioning process step was subsequently eliminated from the overall project, reducing the maximum temperature of interest part way through the experimental program. Water vapor reaction rate test data were developed recognizing the modified project processes. However, equipment sensitivity limited the minimum test temperature that could be investigated to approximately $100^{\circ} \mathrm{C}$ (Trimble 2000).

Single element drying test procedures also reflect the concept of performing hot conditioning steps, including a final heating of elements to $400^{\circ} \mathrm{C}$ (Lawrence 1998). However, reaction rate data for the water vapor oxidation reaction can be inferred from isothermal periods in the drying experiment procedure, which occur at temperatures of $50^{\circ} \mathrm{C}$ and $75^{\circ} \mathrm{C}$. Fuel element shipping observations allow estimate of liquid water oxidation reaction rates at approximately $20^{\circ} \mathrm{C}$ under real plant conditions (Briggs and Roe 1997).

\subsection{Generalized Rate Equation Description}

Uranium corrosion rates are dependent on the surface area of uranium exposed to reactants and temperature. This is typical of solid-fluid reactions. The uranium corrosion reactions of interest are also characterized by the development of an oxide layer. As the oxide layer thickness increases, corrosion reaction rates are reduced. Therefore, fresh uranium metal surfaces exhibit corrosion rates that are reduced as the oxide surface layer increases.

Formation of oxide results in a twofold volume expansion, as compared to uranium metal. The oxide layer mechanical strength and adherence properties are limited. These limitations result in the oxide layer spalling from the metal surface as it approaches a thickness on the order of 2 to 10 microns. The spalling results in effectively reaching an equilibrium oxide layer thickness and the reaction rate becomes constant with respect to time at a specific set of conditions. For application in the SNF processes, the oxide layer is assumed to be established by corrosion during storage in the $\mathrm{K}$ Basins such that only linear reaction rate data are applicable in design calculations.

The uranium oxidation reaction kinetic equations used to support project design were defined based on the following general form.

$$
\text { Rate }=A g \xi K(T) f(C)
$$


where:

Rate $=$ mass reaction rate, mass $/ \mathrm{hr}$. Mass is expressed in terms of weight gain throughout this report. Weight gain is converted to other parameters based on an assumed reaction stoichiometry.

$\mathrm{A}_{\mathrm{g}}=$ geometric surface area reacting.

$\xi=\quad$ an enhancement factor accounting for factors that increase the reaction rate observed during tests with $\mathrm{N}$ Reactor fuel as compared to literature data. These differences could be the result of increased surface roughness, alloy composition differences, hydride inclusions, etc. The enhancement factor is also used to add conservatism to reaction rates addressing uncertainty in the literature observations.

$K(T)=$ temperature dependence function.

$f(C)=$ function describing the reaction rate dependence on reactant concentration.

Since solid-fluid reactions depend on the area of solid exposed to reactants, rate data are reported on a specific surface area basis such that Equation (1-1) takes the following form $(\xi=1$ for a literature data correlation).

$$
\frac{\text { Rate }}{A_{\mathrm{g}}}=\xi \mathrm{K}(\mathrm{T}) \mathrm{f}(\mathrm{C})
$$

A geometric surface area (i.e., projection of the reacting area to a smooth surface defined by the metal geometry, neglecting surface roughness) has been consistently used throughout the consideration of experimental data and application to design. It is important to recognize the basis for reacting area since a comparable area basis must be used in the analysis of a MultiCanister Overpack (MCO). The temperature dependence (based on an Arrhenius' Law form) and reactant concentration dependence for oxidation reactions are taken from the literature.

The term "rate constant" is used imprecisely throughout this report. Typically, this term would be reserved for the pre-exponential factor of the Arrhenius expression describing the reaction rate temperature dependence, $\mathrm{K}(\mathrm{T})$. However, prior project reports have used the term "rate constant" to describe $\mathrm{K}(\mathrm{T})$, which is also the reaction rate for reactions that are independent of reactant concentration. The terminology of prior reports was maintained to minimize potential confusion among project reports.

The enhancement factor was defined as a temperature and reactant concentration independent relationship to define the difference between correlations of literature data and observed reaction rates for $\mathrm{N}$ Reactor fuel. It is used as a composite factor for accumulating uncertainties in the reaction rate from a number of potential differences between $N$ Fuel and uranium used in literature studies. Potential metal differences include the surface roughness developed during oxidation, alloy composition, presence of hydride inclusions, and other factors unique to $\mathrm{N}$ Reactor fuel. The enhancement factor is also used as a simplified method for addressing the uncertainty of reaction rates reported in the literature. 


\subsection{SUMMARY}

The oxidation conditions of concern to the SNF Project process design are described in Section 3.0. The system temperatures and pressures of interest are bounded for all SNF Project process steps by $132^{\circ} \mathrm{C}$ and 150 psig.

Uranium oxidation reactions in water, moist air, and dry air are discussed in Sections 4.0, 5.0, and 6.0, respectively. Stoichiometry simplifications produce conservative estimates of heat generation, hydrogen generation, radionuclide content of particulate and depletion rates of oxygen. Therefore, it is concluded that the following reaction stoichiometry simplifications are appropriate for use in SNF Project design.

$$
\mathrm{U}+2 \mathrm{H}_{2} \mathrm{O} \rightarrow \mathrm{UO}_{2}+2 \mathrm{H}_{2} \text {, for }
$$

- oxygen free liquid water,

- water vapor oxidation, and

- moist air at saturation (condensation).

$$
\mathrm{U}+\mathrm{O}_{2} \rightarrow \mathrm{UO}_{2}, \text { for }
$$

- dry air,

- subsaturated moist air (no condensation), and

- oxygenated liquid water.

Figure 2-1 presents a comparison of the reaction rate correlations in Reilly (1998). At the process conditions of interest, the oxidation rate in oxygen free water vapor is approximately an order of magnitude greater than $100 \%$ Relative Humidity $(\mathrm{RH})$ air, which is approximately an order of magnitude greater than dry air. The oxidation rate in oxygen-free liquid water is the same as the rate observed in an inert gas saturated with water vapor. Data also indicate that the oxidation rate in air saturated water, at temperatures less than $70^{\circ} \mathrm{C}$, are similar to the oxidation rate observed in air saturated with water vapor. These observations would be anticipated because liquid water forms with no increase in free energy when it is in equilibrium with water vapor, as is the case for a gas at saturation. The reaction rate correlations in Reilly (1998) conservatively bound literature data, for all oxidation reactions considered, when increased by an enhancement factor.

In addition to literature data, rate observations from actual irradiated $\mathrm{N}$ Reactor fuel are available for comparison with rate correlations. These rate observations originate from:

- Laboratory scale data, measuring reaction rates using $1 \mathrm{~g}$ to $8 \mathrm{~g}$ samples cut from two different elements. Data were developed for dry air, moist air, and moist helium (oxygen free water vapor) oxidation reactions. 
Figure 2-1. Comparison of Uranium Oxidation Reaction Rate Correlations $($ Enhancement Factor $=1)$

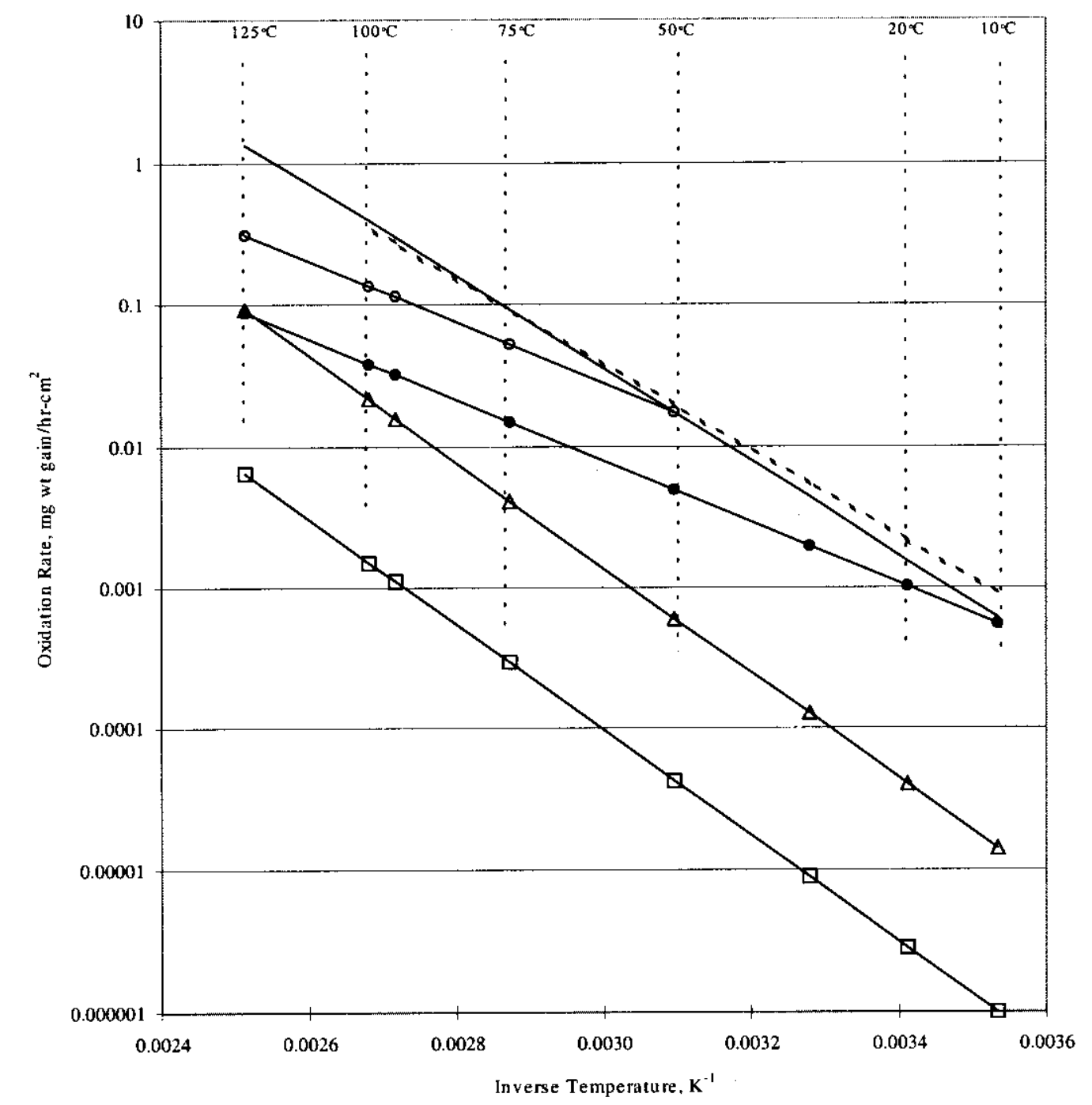

\begin{tabular}{|c|c|}
\hline $\begin{array}{l}\square-\text { Dry Air } \\
-- \text { Liquid Water } \\
-O x y g e n \text { Free W ater Vapor }(12.3 \mathrm{kPa})\end{array}$ & $\begin{array}{l}\longrightarrow \text { Moist Air (100\% RH, Water Vapor at Suturation Pressure) } \\
- \text { Maximum Oxygen Free Water Vapor (at Saruration Pressure) } \\
\longrightarrow \text { Oxygen Free Water Vapor (1 kPa) }\end{array}$ \\
\hline
\end{tabular}


- Single element drying data, where reaction rates are estimated from hydrogen generated during drying of complete elements. Element conditions ranged from intact to bad, with a majority of drying tests performed using elements in bad condition. Oxidation rate data were derived from $50^{\circ} \mathrm{C}$ and $75^{\circ} \mathrm{C}$ isothermal phases of the drying procedure in moist argon and represent oxidation in an oxygen free water vapor system.

- Single element shipping data, where reaction rates were estimated from hydrogen measurements obtained as part of shipping procedures during the transfer of characterization samples from the basin to the laboratory. Oxidation rate data were obtained when basin water temperatures reached $20^{\circ} \mathrm{C}$ and represent oxidation in an oxygen free liquid water system.

The qualification status of the data referenced and used in this document is "existing" as defined in DOE/RW-0333P (DOE 1998).

Table 2-1 provides a summary of the basis for recommended oxidation rate enhancement factors derived from the alternative rate observations. The literature data based correlations, combined with an enhancement factor of 10 , bound:

- rates measured in the laboratory on cut $\mathrm{N}$ Reactor fuel samples in moist helium

- $50^{\circ} \mathrm{C}$ reaction rates inferred from single element drying in moist argon, and

- $20^{\circ} \mathrm{C}$ reaction rates inferred from single element shipping observations.

Single element reaction rates inferred from drying at $75^{\circ} \mathrm{C}$ were not bounded by the correlation prediction until the enhancement factor was increased to 22 . However, comparison of single element observations at $20^{\circ} \mathrm{C}, 50^{\circ} \mathrm{C}$, and $75^{\circ} \mathrm{C}$ indicates that the conservatism of reaction rate predictions appears to be larger at conditions similar to planned operating conditions. Figure 2-2 provides an example of the conservatism produced by the selected enhancement factors when compared to literature data.

Two dry air rate measurements obtained from thermo-gravimetric analysis (TGA) reaction tests produced reaction rates outside the bounds predicted from literature data. These data, by themselves, were considered insufficient to conclude $\mathrm{N}$ Reactor fuel reacts faster than uranium metal in dry air. However, the test results produce uncertainty in the validity of applying the literature-based dry air correlation to $\mathrm{N}$ Reactor fuel. A sensitivity analysis was performed to address this uncertainty, using the higher dry air reaction rates in dry air indicated by laboratory tests to investigate project specific configurations. The sensitivity analysis indicates that an MCO will be thermally stable, even if the projected higher dry reaction rates are applicable. Therefore, the dry air experiment uncertainty does not impact SNF Project design.

An updated method of predicting reaction rates for reactant concentrations in ranges that represent a transition region between oxidation rate correlations is described in Section 7.0. The transition method is based on linear interpolation between data correlations. An alternate method of describing the transitions, used in Reilly (1998), is shown in Section 10.3. The transition method in Reilly (1998) is shown to provide similar results to the transition method of Section 7.0 such that either method can be used to predict oxidation rates. 
The implication of oxidation reaction observations unique to $\mathrm{N}$ Reactor fuel is discussed in Section 8.0. The potential impact of localized rapid reaction rates, attributed to fuel hydride inclusions, is bounded by oxidation rate correlations when the enhancement factor is 22 . The implications of fuel sample crumbling are also discussed. Potential fuel crumbling effects are also considered to be bounded by use of a reaction rate enhancement factor of 22 .

Figure 2-2. Example of Conservatism Produced by Enhancement Factors (Water Vapor Oxidation)

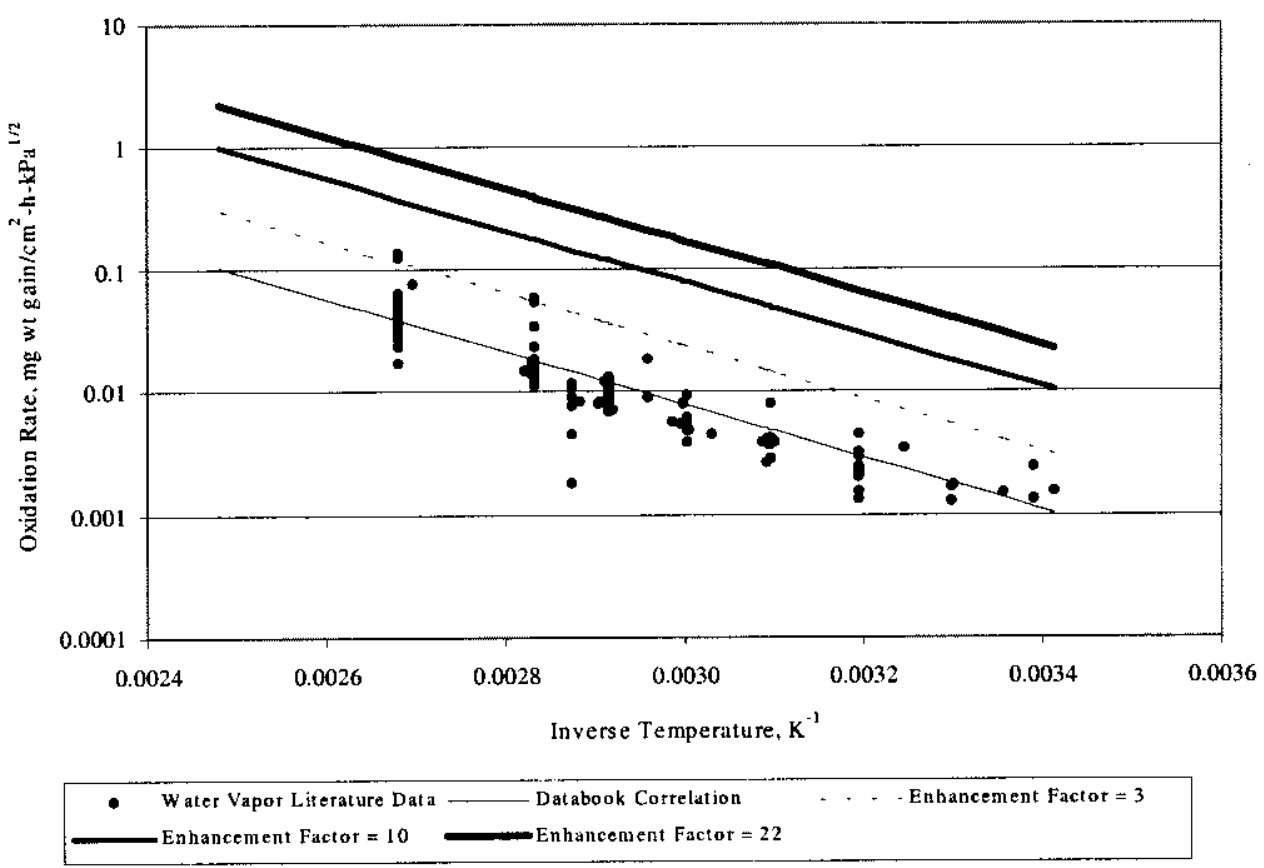


HNF-4165, Rev 1

Table 2-1. Uranium Oxidation Rate Enhancement Factor Recommendations

\begin{tabular}{|c|c|c|c|c|c|}
\hline \multirow[b]{2}{*}{ Oxidant } & \multicolumn{3}{|c|}{ Enhancement Factor Basis } & \multicolumn{2}{|c|}{$\begin{array}{l}\text { Recommended Rate } \\
\text { Enhancement Factors }\end{array}$} \\
\hline & $\begin{array}{c}\text { Bounds Variation of } \\
\text { Literature Data }^{(1)}\end{array}$ & $\begin{array}{c}\text { Bounds Laboratory } \\
\text { Scale N Fuel } \\
\text { Observations }\end{array}$ & $\begin{array}{l}\text { Bounds Observations } \\
\text { Derived from Large } \\
\text { Scale Configurations }\end{array}$ & $\begin{array}{l}\text { Safety } \\
\text { Basis }\end{array}$ & $\begin{array}{l}\text { Design } \\
\text { Basis }\end{array}$ \\
\hline Water Vapor & 3 & 10 & 22 & 22 & 3 \\
\hline Liquid Water ${ }^{(2)}$ & 3 & $\mathrm{NA}$ & 10 & $22^{(3)}$ & 3 \\
\hline Moist Air & $3^{(4)}$ & $\mathrm{NA}^{(5)}$ & NA & $22^{(6)}$ & 3 \\
\hline Dry Air & $10^{(9)}$ & $10^{(7)}$ & $22^{(8)}$ & $22^{(9)}$ & $3^{(10)}$ \\
\hline
\end{tabular}

Notes:

NA $=$ Not Available

(1) Approximates $95 \%$ prediction limit from literature data $95 \%$ confidence that an individual oxidation rate observation from the fiterature is bounded).

(2) Based on de-oxygenated water. No adjustment for lower reaction rates due to the presence of oxygenated water has been used in the project design basis.

(3) Available data indicate a safety basis reaction rate enhaneement factor of 10 is sufficient to bound all liquid water oxidation rate observations. The enhancement factor recommendation of 22 for this system is based on a simplification such that all reacting systems use the same enhancement factor. However, reduction of this enhancement factor could be considered for specific situations.

(4) The $95 \%$ prediction limit for moist air literature data was not developed due to complexity of the correlation. However. an enhancement factor of 3 bounds all literature data at $100 \% \mathrm{RH}$.

(5) Laboratory scale moist air data were not obtained in the current temperature range of interest.

(6) Recommended to maintain constant factor for dry air, moist air. and oxygen-free water vapor oxidation rates.

(7) Two low temperature dry air oxidation rate measurements were observed outside this bound. These observations provided insufficient data to conclude $N$ Fuel reaction rates are faster than other tests reported in the literature. However, sensitivity analyses indicate an MCO is thermally stable for SNF Project systems, even if the higher dry air oxidation rates were conservatively applied to the project analysis.

(8) Based on analysis of rapid reacting inclusions extrapolated to large surfice areas.

(9) An enhancement factor of 0.1 provides a conservative lower bound to literature data. Analyses where minimum oxidation rates are important (e.g., oxygen gettering) should consider evaluations using a reduced enhancement factor.

(10) Dry air literature datla are more numerous and widely scattered than data for other systerns. A design basis enhancement factor of 3 provides a practical bound of most literature data. 


\subsection{PRIMARY CONDITIONS OF INTEREST TO PROJECT PROCESSES}

The normal range of operating conditions for fuel removal processes defines the primary temperature (and pressure) range of interest for oxidation reactions. Table 3-1 provides a summary of process conditions and identifies the reaction that dominates uranium oxidation during a particular activity.

Table 3-1. Reactions and Conditions of Interest to Spent Nuclear Fuel Project Processes

\begin{tabular}{|c|c|c|c|c|c|c|}
\hline \multirow[b]{2}{*}{ Reaction } & \multicolumn{5}{|c|}{ Process Activity } & \multirow{2}{*}{$\begin{array}{l}\text { Parameters } \\
\text { Influenced by } \\
\text { Reaction }^{(1)}\end{array}$} \\
\hline & $\begin{array}{l}\text { Basin } \\
\text { Processes }\end{array}$ & $\begin{array}{l}\text { Transfer to } \\
\text { CVD }\end{array}$ & $\begin{array}{l}\text { CVD } \\
\text { Processing }\end{array}$ & $\begin{array}{l}\text { Transport } \\
\text { to CSB }\end{array}$ & $\begin{array}{l}\text { CSB Handling } \\
\text { and Storage }\end{array}$ & \\
\hline $\mathrm{U}+\mathrm{H}_{2} \mathrm{O}(\mathrm{l})$ & $\mathrm{X}$ & $\mathrm{X}$ & $\mathrm{X}$ & & & (a) (b) (c) \\
\hline $\mathrm{U}+\mathrm{H}_{2} \mathrm{O}(\mathrm{v})$ & & & $\mathrm{X}$ & $\mathrm{X}$ & $\mathrm{X}$ & (a) (b) (c) \\
\hline $\mathrm{U}+$ Moist Air & & & & & $\mathrm{X}^{(2)}$ & (a) (d) \\
\hline U + Dry Air & & & & & $\mathrm{X}^{(2)}$ & (a) (d) \\
\hline $\begin{array}{l}\text { Peak Fuel Temperature } \\
\text { During Processing }\end{array}$ & $10-25^{\circ} \mathrm{C}$ & $10-60^{\circ} \mathrm{C}$ & $15-100^{\circ} \mathrm{C}$ & $<130^{\circ} \mathrm{C}$ & $<150^{\circ} \mathrm{C}$ & \\
\hline Total Pressure & $<10 \mathrm{psig}$ & $<150$ psig & $<30$ psig & $<30$ psig & $<50$ psig & \\
\hline
\end{tabular}

$\mathrm{X}=$ Primary reaction of interest.

$\mathrm{CVD}=$ Cold Vacuum Drying

CSB $=$ Canister Storage Building

(1) Parameters Influenced by Reactions - (a) Heat Generation, (b) Hydrogen Generation, (c) Particulate Generation, (d) Oxygen Gettering

(2) The actual reaction of interest is $U+$ oxygen. Air oxidation reaction rates are used to define these rates assuming the nitrogen in air is essentially inert at the conditions of interest.

Fuel is maintained flooded with water for the basin processes (fuel retrieval, basket loading, and cask loadout), transfer to the Cold Vacuum Drying (CVD) Facility, and initial phase of CVD processing. Therefore, the uranium-liquid water reaction dominates the oxidation during these process activities. Basin process temperatures are controlled by the basin water treatment system. The maximum temperature during transfer to the CVD Facility is based on the equilibrium temperature of fuel assuming an indefinite hot day transfer, while CVD processing temperatures are based on the tempered water system control temperature limit (fuel temperatures within the $\mathrm{MCO}$ can be higher or lower than the tempered water external to the $\mathrm{MCO}$, depending on the operation being performed). Total pressure does not influence the uranium-liquid water reaction rate.

While the uranium-liquid water reaction generates heat that adds to decay heat, the MCO was found to be capable of rejecting sufficient heat from fuel when flooded with water (Smith 2000 and Piepho 2000). Therefore, the hydrogen and particulate generation rates are the primary design parameters defined by the oxidation reaction during activities where the fuel is flooded.

The uranium-water vapor reaction is the dominant oxidation reaction during drying operations at the CVD Facility and transport of an MCO to the Canister Storage Building (CSB). This reaction is the main heat generation source that must be controlled by CVD Facility systems during fuel drying in order to preclude a thermal excursion. The reaction rate also defines hydrogen generation rates that must be controlled in offgas systems and is the basis for estimating the growth in the particulate inventory of an MCO. 
Once dried, the oxidation reaction can continue to act as a heat generation source during the transport and storage in the CSB. However, the total water inventory of an MCO (from hydration water) limits the maximum fuel and MCO temperature that can be achieved after drying. The water inventory also limits the total particulate and hydrogen that can be generated in an MCO after drying. Therefore, the primary reaction of interest during storage at the CSB is the reaction with oxygen (or air), which controls the potential for generating combustible gas mixtures in an MCO during storage.

\subsection{URANIUM - WATER REACTION}

\subsection{Water Vapor Oxidation}

\subsubsection{Stoichiometry}

The oxidation of uranium by water or water vapor produces hydrogen according to the following stoichiometry,

$$
\mathrm{U}+(2+\mathrm{x}) \mathrm{H}_{2} \mathrm{O} \rightarrow \mathrm{UO}_{(2+\mathrm{x})}+(2+\mathrm{x}) \mathrm{H}_{2}
$$

with $0 \leq \mathrm{x} \leq 0.25$ at temperatures up to about $250^{\circ} \mathrm{C}$. The release of non-stoichiometric hydrogen has been observed in laboratory tests indicating the formation of uranium hydride as an intermediate product (Trimble 1998b). Laboratory experiments indicate that 2 to $9 \mathrm{wt} \%$ of the uranium corrosion products formed in oxygen free liquid water is uranium hydride. This results in an interstitial mixture of $\mathrm{UO}_{2+\mathrm{x}}$ and $\mathrm{UH}_{3}$. Fixation of some hydrogen as uranium hydride creates a hydrogen gas deficiency from that predicted by Equation (4-1). This deficiency was found to vary from $1 \%$ to $13 \%$ (Baker, et al. 1966).

The observations by Baker, et al. (1966) can be described by the following water oxidation stoichiometry.

$$
\begin{aligned}
& (1+y) U+(2+x) \mathrm{H}_{2} \mathrm{O} \rightarrow \mathrm{UO}_{2+\mathrm{x}}+\mathrm{y} \mathrm{UH}_{3}+\left(2+\mathrm{x}-\frac{3}{2} \mathrm{y}\right) \mathrm{H}_{2} \\
& \text { where } \mathrm{y}=0 \text { to } 0.09 \text { and } \mathrm{x}=0 \text { to } 0.25
\end{aligned}
$$

Experiments reported in Baker, et al. (1966) were performed in a constant volume system with continuously increasing hydrogen pressure. Uranium hydride formation has not been observed in water vapor oxidation experiments carried out in a flow system where a carrier gas continuously sweeps away hydrogen produced by the reaction (Colmenares 1984).

Conservative estimates of heat generation, hydrogen generation, and particulate generation are produced by assuming a simplified reaction stoichiometry.

$$
\mathrm{U}+2 \mathrm{H}_{2} \mathrm{O} \rightarrow \mathrm{UO}_{2}+2 \mathrm{H}_{2} \quad-\Delta \mathrm{H}_{\mathrm{r}}^{0}=143.7 \mathrm{kcal} / \mathrm{gmol} \mathrm{U}
$$


Reaction rate data are reported in terms of weight gained per unit time per unit area of uranium. Figure 4-1 indicates the variation of reaction heat and uranium content in oxides produced by the water vapor corrosion reaction. These estimates are based on the heat of reaction from Thurgood (1997) and partial molar enthalpy of oxygen in $\mathrm{UO}_{2+x}$ from Olander (1976). The simplified stoichiometry maximizes the heat produced per unit weight gained and maximizes the mass of uranium in particulate (maximizes predicted radionuclides in particulate). Equation 4-3 predicts conservative hydrogen generation rates by neglecting the potential formation of uranium hydride and assuming all the water reactant produces hydrogen.

Figure 4-1. Water Vapor Oxidation Reaction Characteristics Variation with Stoichiometry

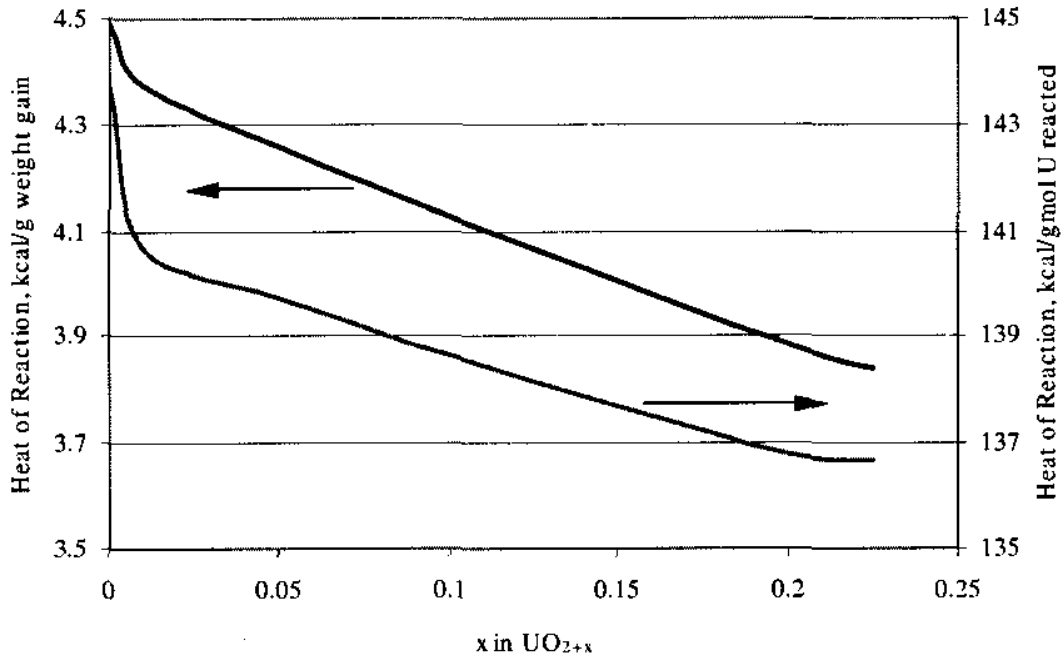

(a) Heat of reaction variation with water vapor oxidation stoichiometry

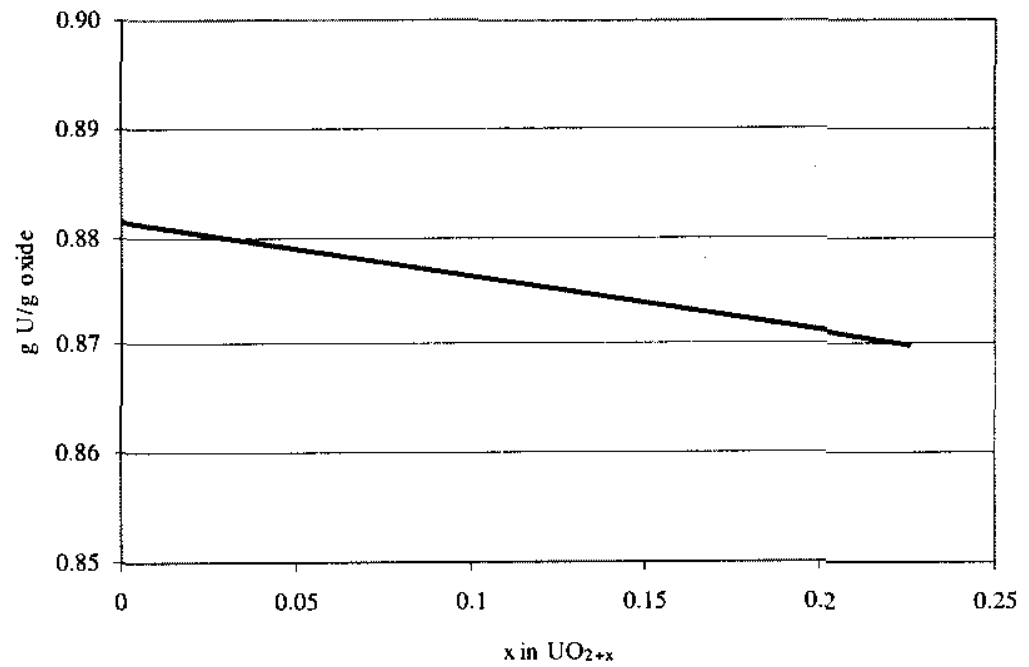

(b) Variation of uranium content in oxides with stoichiometry 
Baker, et al. (1966) studied the effects of adding nitrogen, hydrogen, carbon dioxide and oxygen on the uranium-water vapor reacting system. Nitrogen and hydrogen additions had no effect on either the reaction products or oxidation rate. Addition of carbon dioxide, at partial pressures ranging from $0.07 \mathrm{~atm}$ to $2 \mathrm{~atm}$, halved the observed uranium corrosion and hydrogen evolution rates. No change was observed in the quantity of carbon dioxide during the oxidation by water vapor and no carbon monoxide was found as a reaction product, indicating that the above stoichiometry is applicable in the presence of carbon dioxide. The effect of oxygen addition to this system is equivalent to moist air corrosion, which is discussed in Section 5.0.

\subsubsection{Literature Rate Data}

Reilly (1998) uses the following kinetic expression for the mean oxidation rate of uranium in oxygen free water vapor at the conditions of interest for process design.

$$
\log K=4.33-2144 / T+0.5 \log P
$$

where: $\mathrm{K}=$ rate constant, $\mathrm{mg}$ wt gain $/ \mathrm{hr}-\mathrm{cm}^{2}$

$\mathrm{T}=$ temperature, $\mathrm{K}(\mathrm{T} \leq 523 \mathrm{~K})$

$\mathrm{P}=$ partial pressure water vapor, $\mathrm{kPa}$

Equation (4-4) is based on a correlation of literature data and indicates that the reaction rate is observed to depend on the partial pressure (concentration) of water vapor. Literature data at different temperatures are compared by rearranging the kinetic expression as shown in Equation (4-5). Figure 4-2 compares the rate correlation in the form shown by Equation (4-5) with literature data in the temperature range of interest from Trimble (1998b).

$$
\frac{\text { Oxidation Rate }}{A_{g} \sqrt{\mathrm{P}}}=10^{4.33} 10^{-2144 / \mathrm{r}} \approx\left(2.14 \times 10^{4}\right) 10^{-2144 / \mathrm{T}} \frac{\mathrm{mg} \mathrm{wt} \text { gain }}{\mathrm{hr}-\mathrm{cm}^{2}-\mathrm{kPa}^{1 / 2}}
$$

Trimble (1998b) also presents an equation describing the mean of literature rate observations. The constants of this correlation are slightly different from those indicated in Equation (4-4), but the predicted reaction rate is not significantly different (the correlation by Trimble (1998b) predicts reaction rates $1 \%$ to $30 \%$ lower in the temperature range of interest). Trimble (1998b) concludes that the modified correlation for oxygen free water vapor agrees with Equation (4-4) at temperatures below $200^{\circ} \mathrm{C}$. Therefore, Equation (4-4) is considered an appropriate estimate of the uranium oxidation rate in water vapor.

Figure 4-2 compares the literature data observations to oxidation rate predictions assuming enhancement factors of 3 and 10 . The enhancement factor estimates originate with a predicted difference in surface roughening between $\mathrm{N}$ Reactor fuel and uranium metal tested in the literature. An enhancement factor of 3 approximates the $95 \%$ prediction limit developed in Trimble (2000) for the literature data (that is, there is a $95 \%$ confidence that the next oxidation rate observation from literature tests is bounded by the prediction interval). An enhancement factor of 3 appears to adequately bound water vapor literature data. 
Figure 4-2. Water Vapor Oxidation of Uranium Metal $\left(<210^{\circ} \mathrm{C}\right)$

[Data from Trimble (1998b) and Trimble (2000)]

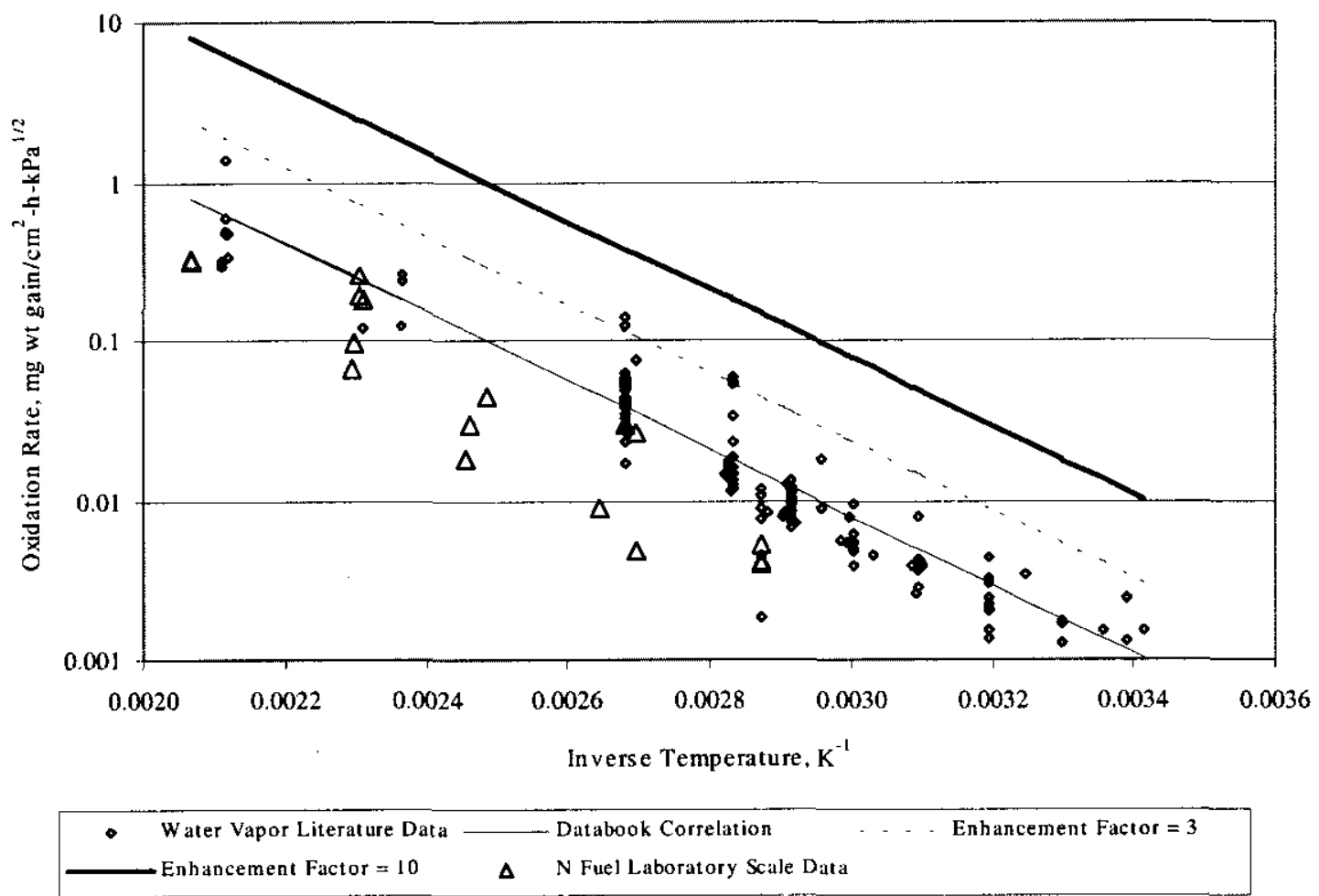

Equation (4-5) results in a temperature and water vapor dependent oxidation rate that cannot be directly compared with the other reactions. Rearrangement of the rate correlation and evaluation at the water vapor saturation pressure, as indicated by Equation (4-6), estimates the maximum oxidation rate for this system that is also comparable to the other oxidation reaction rates.

$$
\frac{\text { Maximum Water Vapor Oxidation Rate }}{\mathrm{A}_{\mathrm{g}}}=\left(2.14 \times 10^{4}\right) 10^{-2144 / \mathrm{T}} \sqrt{\mathrm{P}_{\text {sat }}} \frac{\mathrm{mg} \text { wt gain }}{\mathrm{hr}-\mathrm{cm}^{2}}
$$

where: $P_{\text {sat }}=$ saturation pressure of water vapor at temperature $T$ (from Equation 5-3), $\mathrm{kPa}$

Figure 4-3 compares this maximum oxidation rate prediction with the literature data from Trimble (1998b). Test conditions that are at, or below, the saturation pressure have been used in literature tests. Therefore, the databook correlation at saturation is expected to be above the mean of literature data, as indicated in Figure 4-3. Application of an enhancement factor of 3 to oxidation rate predictions using Equation (4-4) at the saturation pressure conservatively bounds all literature observations. 


\section{Figure 4-3. Water Vapor Oxidation of Uranium Metal Compared with Saturated Water Vapor Reaction Rate Predictions $\left(<130^{\circ} \mathrm{C}\right)$}

[Data from Trimble (1998b) and Trimble (2000)]

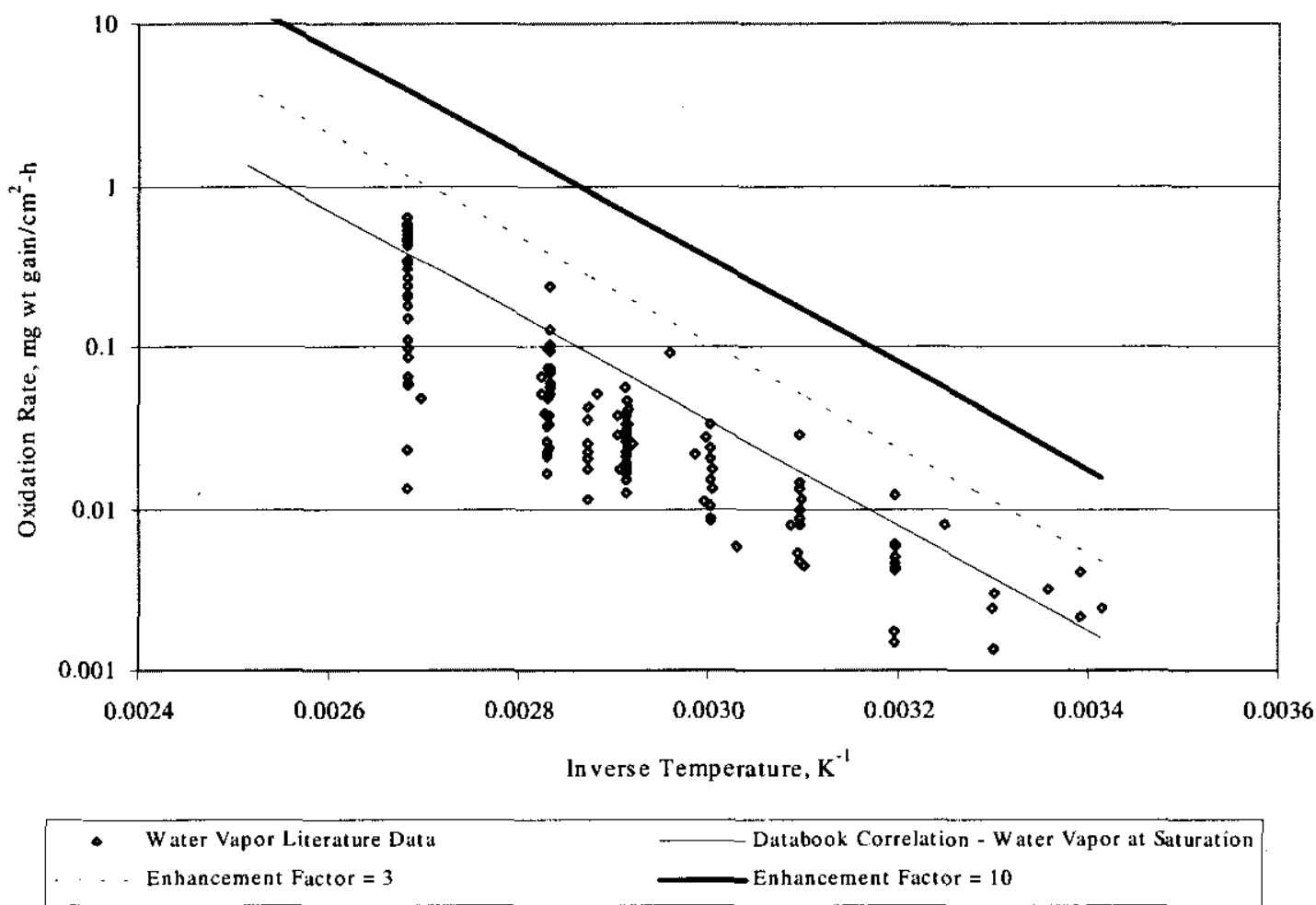

\subsubsection{N Reactor Fuel Reaction Rate Observations}

\subsubsection{Laboratory Scale TGA Tests}

Oxidation rates in moist helium were measured using selected samples from an $\mathrm{N}$ Reactor fuel element that was stored in the K West Basin (Trimble 2000). The laboratory scale rate measurements are based on sample weight gain measured by a TGA system and exposed geometric surface area measured from the sample cut surfaces. Sample masses ranged from $1.5 \mathrm{~g}$ to $3.5 \mathrm{~g}$, with surfaces visually free of cracks and surface voids. The measured rate data are based on linear portions of sample weight versus time plots at a given sample temperature.

Seventeen irradiated $\mathrm{N}$ Reactor fuel samples were tested in moist helium, with a water vapor partial pressure of $6 \mathrm{kPa}$ to $7 \mathrm{kPa}$, at temperatures ranging from $76^{\circ} \mathrm{C}$ to $211^{\circ} \mathrm{C}$. The test results are shown on Figure 4-2, indicating that the $\mathrm{N}$ Reactor fuel sample reaction rates are bounded by literature observations. Post experiment measurements of the test equipment indicated that the presence of up to $80 \mathrm{ppm}$ oxygen in the reactant gas could not be discounted. Based on data in Colmenares (1984), an oxygen concentration of $80 \mathrm{ppm}$ could reduce the reaction rate by approximately a factor of 10 . The oxidation rate indicated on Figure 4-2, assuming an enhancement factor of 10 , continues to bound the $\mathrm{N}$ Reactor fuel laboratory scale observations, 
even if they are increased by a factor of 10 , to address the uncertainty of oxygen in the reactant gas. In addition, the plant helium delivery system is likely to supply helium to an MCO containing at least as much oxygen as found in the laboratory experiments. Therefore, while not used as a basis for design, actual plant operation is expected to experience reduced reaction rates compared to oxygen-free conditions.

\subsubsection{Single Element Drying Tests}

Laboratory scale reaction rate measurements are obtained from small samples $(1 \mathrm{~g}$ to $5 \mathrm{~g})$ cut from a single element. Fuel sample preparation introduces an uncertainty as to whether the laboratory data are representative of actual plant scale reacting surfaces. Therefore, reaction rate data from complete elements have been accumulated from tests and observations that were not originally intended to evaluate reaction rates.

Single element drying tests were performed to investigate the drying characteristics of fuel elements. Reaction rate estimates from complete elements (generally outer elements were tested) can be derived from hydrogen generation measurements by assuming the reaction stoichiometry shown by Equation (4-3). Hydrogen generation rates from entire elements in a water vapor system were observed during single element drying tests in the laboratory hot cell. The individual drying test reports are summarized and compared in Lawrence, 1998.

Single element drying tests produced hydrogen generation rate measurements during constant temperature operation at $50^{\circ} \mathrm{C}$ and a partial pressure of water vapor of approximately $1 \mathrm{kPa}$ $(\sim 10$ torr) from two elements (Runs 7 and 8 ). Hydrogen generation rate measurements are also available from five elements (Runs 4 through 8 ) at a constant temperature of $75^{\circ} \mathrm{C}$ and partial pressures of water vapor ranging from $0.001 \mathrm{kPa}$ to $0.027 \mathrm{kPa}(\sim 0.008$ torr to 0.2 torr). The hydrogen generation rate was observed to decrease with the partial pressure of water vapor during the constant temperature operating region of each run. Therefore, two data points were taken from each run for comparison with literature correlations reflecting the highest and lowest partial pressure of water vapor observed. Table 4-1 presents the development of oxidation rates from the single element drying tests. 
HNF-4165, Rev 1

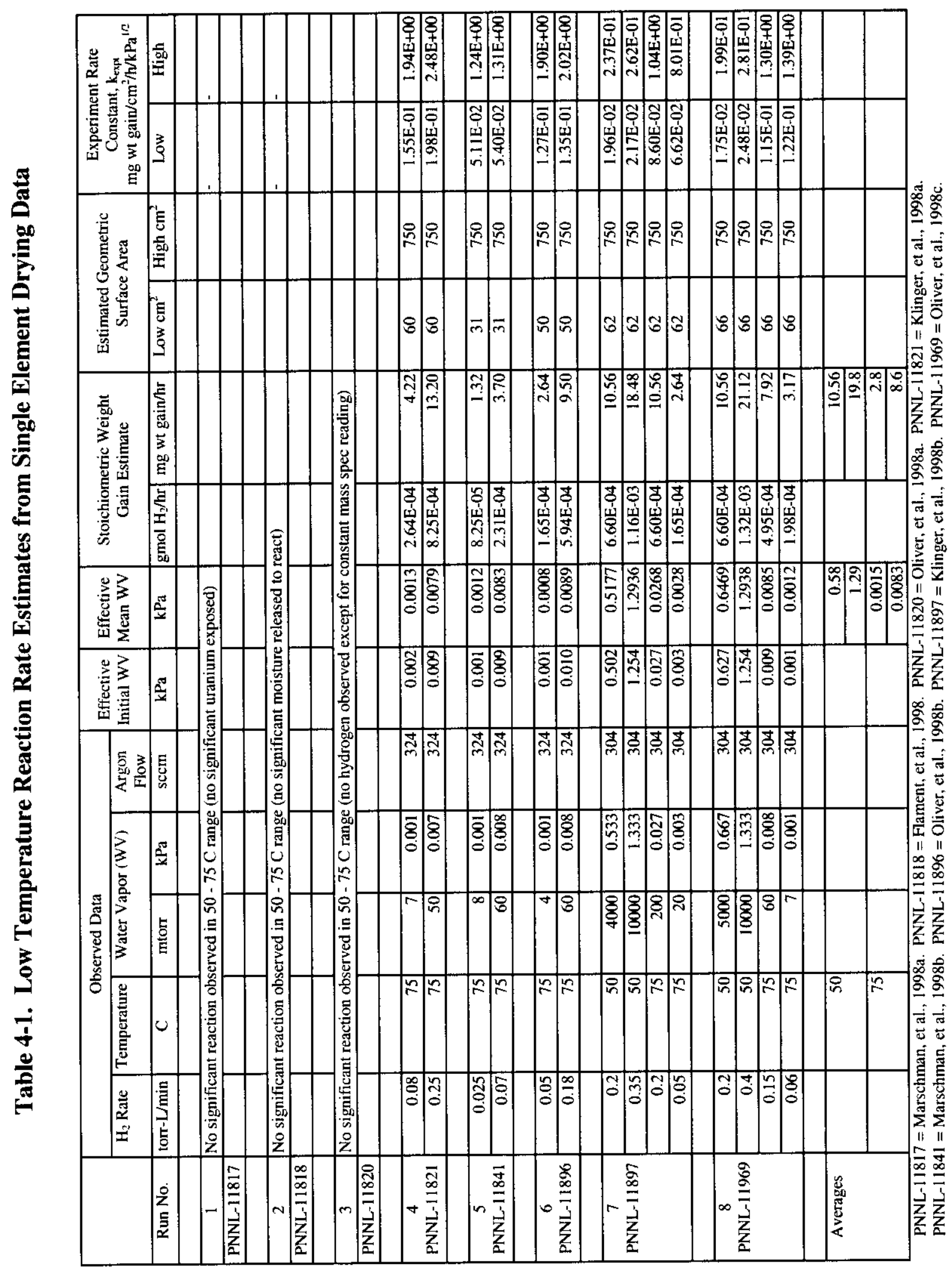


The surface area uncertainty of each element interferes with a direct comparison of oxidation rate predictions from the drying tests with literature data. Table 4-1 presents reaction rates based on the single element drying data in a form that is comparable to Equation (4-5). Estimates of the enhancement factor, comparing drying test reaction observations to Equation (4-5) are developed in Appendix 10.4 and range from 3 to 170. An uncertainty analysis in Appendix 10.4 is based on error propagation of the rate measurements, area estimate, and water vapor uncertainties. The uncertainty analysis expands the enhancement factor estimate from single element drying data to between $<1$ and 1200. Therefore, no conclusive comparison between whole element observations and the literature could be derived from drying tests on a specific surface area basis. The whole element surface area uncertainty dominates the overall uncertainty in this estimate.

\subsubsection{Bounding Rate Comparisons}

An alternate approach for comparing single element reaction rate observations with bounds from literature correlations was developed based on the number of elements in an MCO. The alternate comparison approach assumes an MCO is loaded with elements in comparable condition to the elements used in each test. This assumes that primarily outer elements are damaged, reflecting visual observations of fuel condition. The reaction rate derived from whole element drying test observations is compared with the reaction rate calculated for a bounding MCO based on Equation (4-4) and enhancement factors of 3, 10, and 22 (the enhancement factors selected for comparisons are based on literature data and laboratory data bounds described in Sections 4, 5, 6, and 8). This results in a comparison of MCO reaction rates, based on application of literature correlations to conservative estimates of surface area, with rate estimates that rely only on a count of the number elements in the MCO (knowledge of the surface area not required).

Table 4-2 describes loading configurations used to compare reaction rates from drying tests with the rate correlation. 
HNF-4165, Rev. 1

Table 4-2. MCO Configurations for Comparing Single Element Rate Data

\begin{tabular}{|l|l|l|l|}
\hline Configuration & $\begin{array}{l}\text { Number of Equivalent } \\
\text { Elements }\end{array}$ & $\begin{array}{l}\text { Assumed Number of "Bad" } \\
\text { Elements }\end{array}$ & $\begin{array}{l}\text { Comparable Bounding Surface } \\
\text { Area from Reilly (1998) } \\
\mathrm{cm}^{2}\end{array}$ \\
\hline $\begin{array}{l}\text { MCO with 2 Scrap Baskets } \\
\text { and 3 Fuel Baskets }\end{array}$ & 240 & $138^{(2)}$ & 120,000 \\
\hline Scrap Basket & 39 & $39^{(1)}$ & 45,000 \\
\hline Fuel Basket & 54 & $20^{(1)}$ & 7,900 \\
\hline
\end{tabular}

Notes:

(1) consistent with bounding surface area assumptions, assuming the elements dried in test runs $4,5,6,7$, and 8 would be classified as "bad" elements.

(2) two scrap baskets and 3 fuel baskets.

Sample calculation of oxidation rates for comparison

Rate based on Drying Tests:

For Run 8 at $50^{\circ} \mathrm{C}$ and $\mathrm{P}=0.6469 \mathrm{kPa}$, rate from one element $=10.56 \mathrm{mg}$ wt gain $/ \mathrm{hr}$ (from Table $4-1$ )

Rate from MCO containing 138 elements at same conditions $=10.56 \mathrm{mg} \mathrm{wt}$ gain $/ \mathrm{hr} \times 138$ elements $/ \mathrm{MCO}=1457 \mathrm{mg} \mathrm{wt}$ gain $/ \mathrm{hr}-$ $\mathrm{MCO}$

Rate based on bounding MCO:

Rate $=\mathrm{A}_{\mathrm{g}} \xi\left(2.14 \times 10^{4}\right)\left(10^{-2144 / \mathrm{T}}\right) \sqrt{\mathrm{P}} \quad$ (from Equation 4-6)

Rate $=(120,000)(22)\left(2.14 \times 10^{4}\right)\left(10^{-2144 / 323}\right) \sqrt{0.6469}$

Rate $=10,463 \mathrm{mg} w \mathrm{wain} / \mathrm{hr}-\mathrm{MCO}$

Figures 4-4, 4-5, and 4-6 compare the reaction rates at $50^{\circ} \mathrm{C}$ and $75^{\circ} \mathrm{C}$ from the MCO loading configurations. The results at $50^{\circ} \mathrm{C}$ indicate significant margin between rates derived from drying tests and the bounding $\mathrm{MCO}$ description with water vapor partial pressures of approximately $1 \mathrm{kPa}$ (about 10 torr), which represents conditions expected during plant operation. The margin appears to be reduced when comparing the bounding MCO with observations at low partial pressures of water vapor available from $75^{\circ} \mathrm{C}$ data $(0.004$ torr to 0.06 torr). 
Figure 4-4. Comparison of Bounding MCO Reaction Rates with Single Element Drying Observations

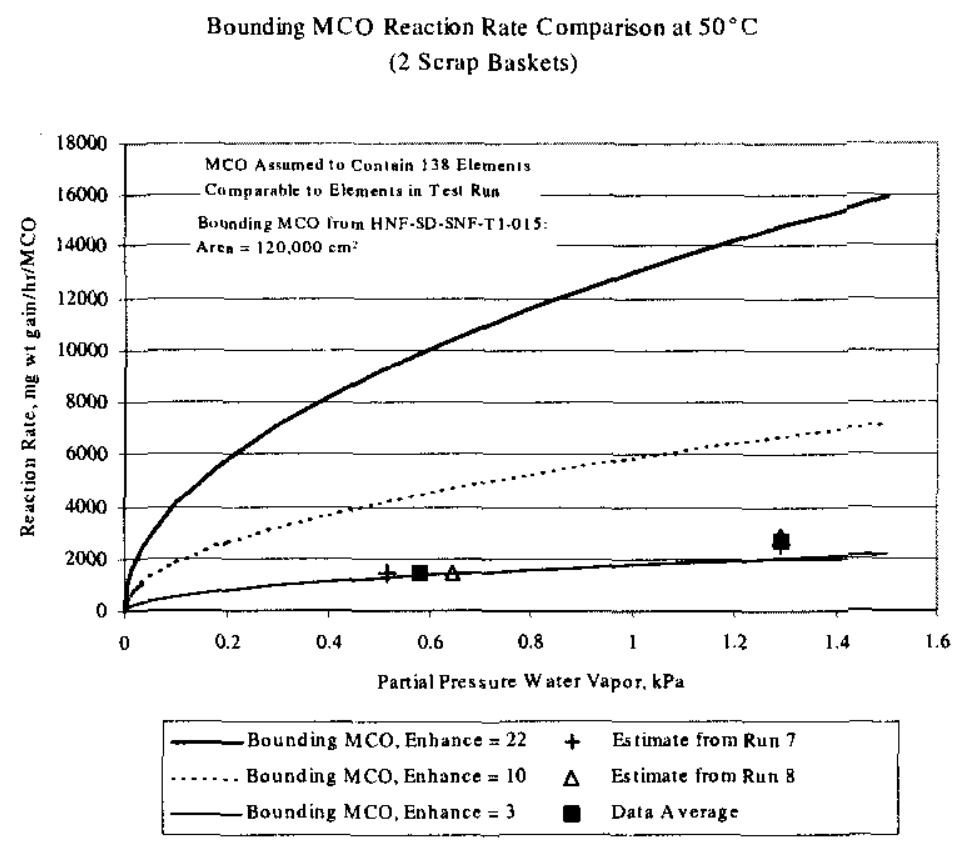

Bounding MCO Reaction Rate Comparison at $75^{\circ} \mathrm{C}$

(2 Scrap Baskets)

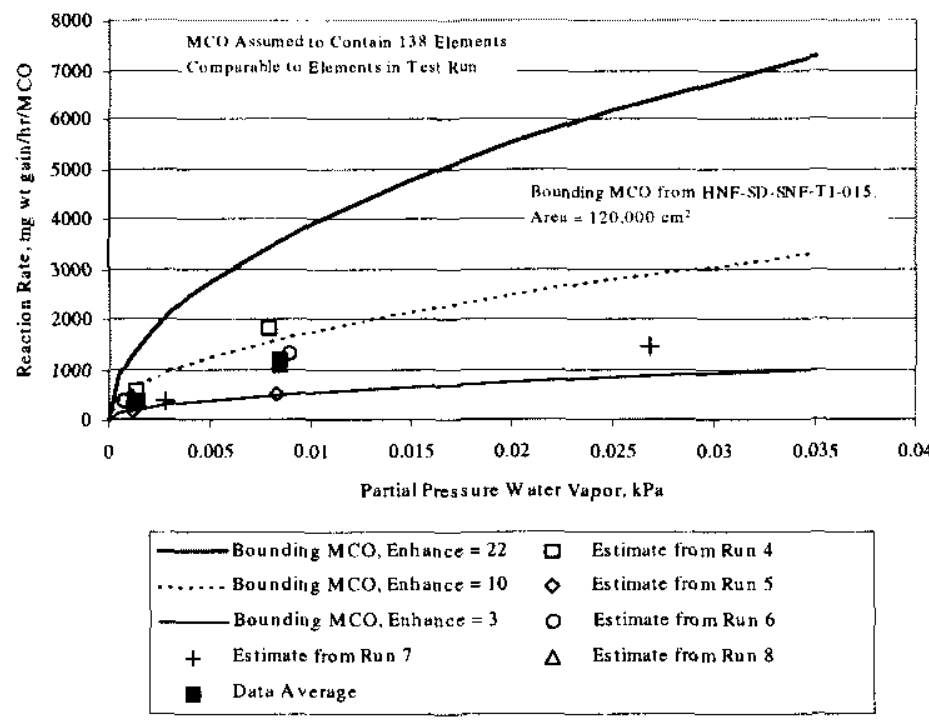




\section{Figure 4-5. Comparison of Bounding MCO Scrap Basket Reaction Rate with Single Element Drying Observations}

Bounding MCO Scrap Basket Reaction Rate Comparison at $50^{\circ} \mathrm{C}$

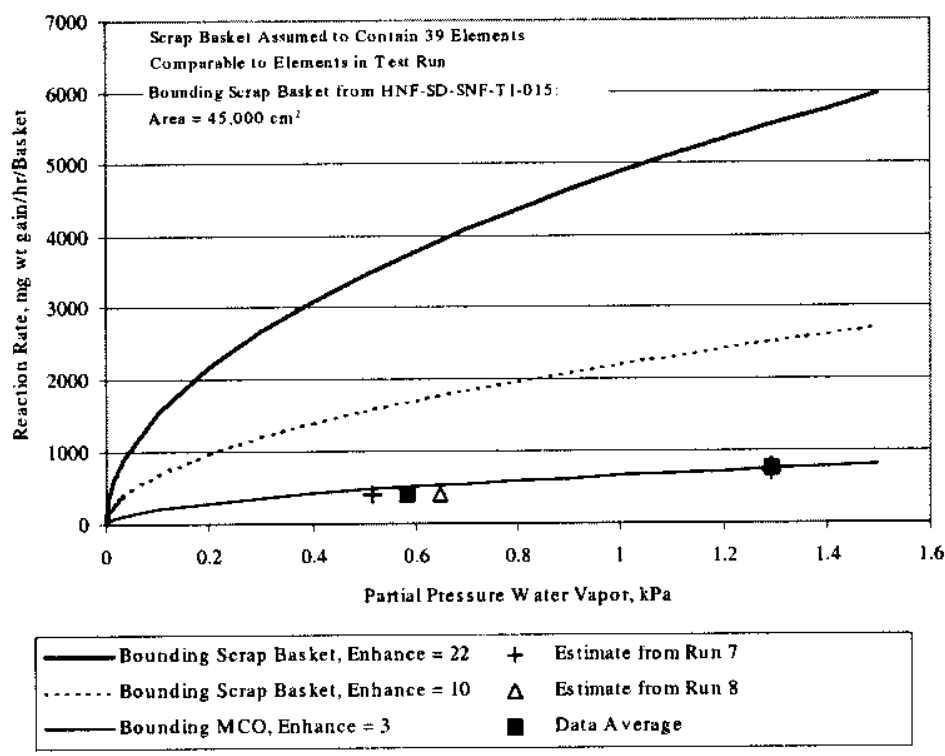

Bounding MCO Scrap Basket Reaction Rate Comparison at $75^{\circ} \mathrm{C}$

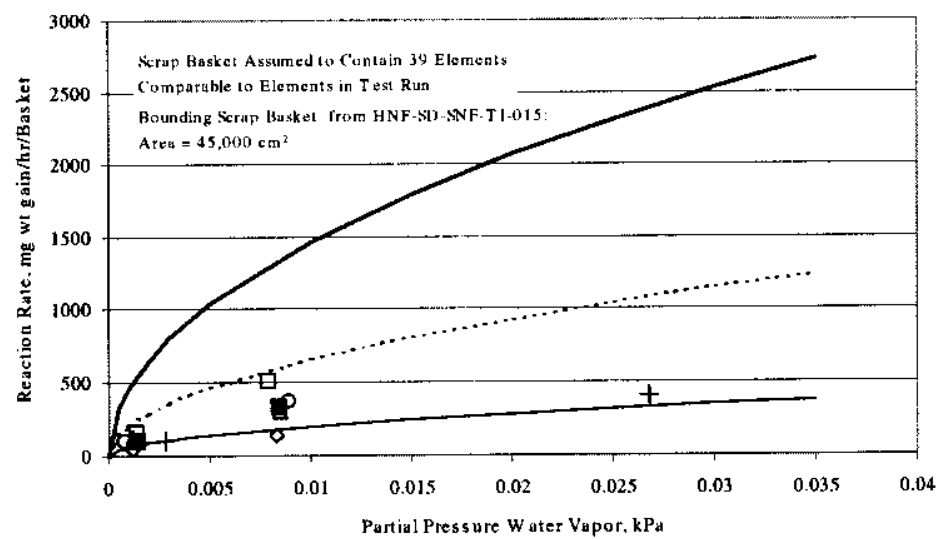

\begin{tabular}{|c|c|c|}
\hline Bounding Scrap Basket, Enhatice $=22$ & D & Estimute from Run 4 \\
\hline ...... Bounding Scrup Basket, Enhance $=10$ & $\diamond$ & Estimute trom Ru n 5 \\
\hline — Bounding MCO, Enhance $=3$ & 0 & Estimate from Run 6 \\
\hline Estimute from Run 7 & $\Delta$ & Estimate from Run 8 \\
\hline - Data Average & & \\
\hline
\end{tabular}


Figure 4-6. Comparison of MCO Fuel Basket Reaction Rate with Single Element Drying Observations

Bounding MCO Fuel Basket Reaction Rate Comparison at $50^{\circ} \mathrm{C}$

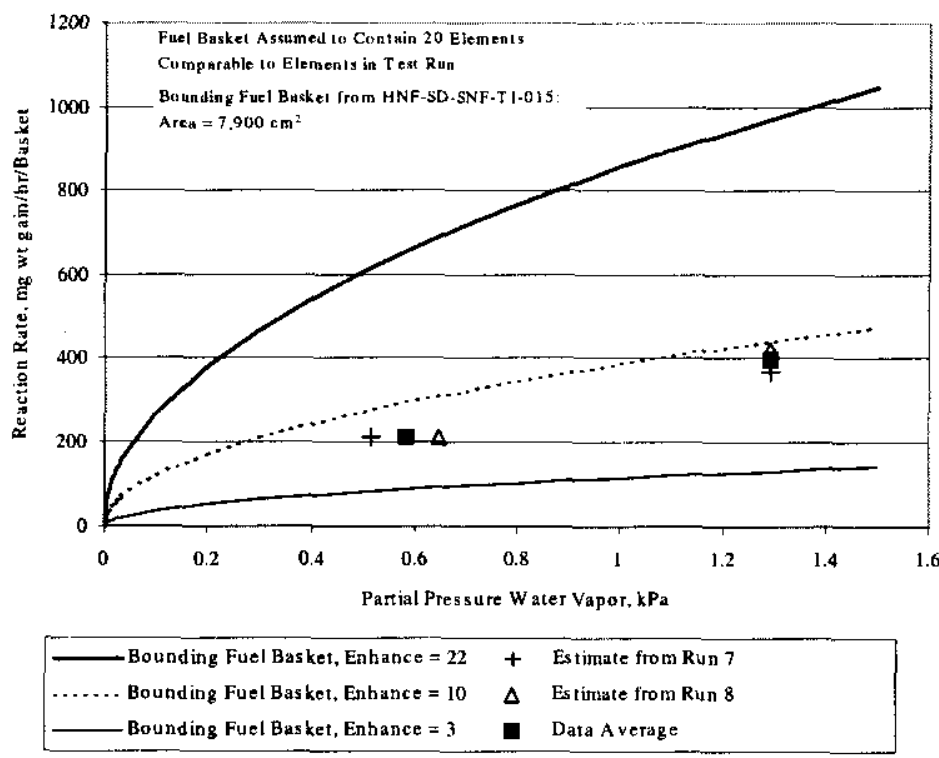

Bounding MCO Fuel Basket Reaction Rate Comparison at $75^{\circ} \mathrm{C}$

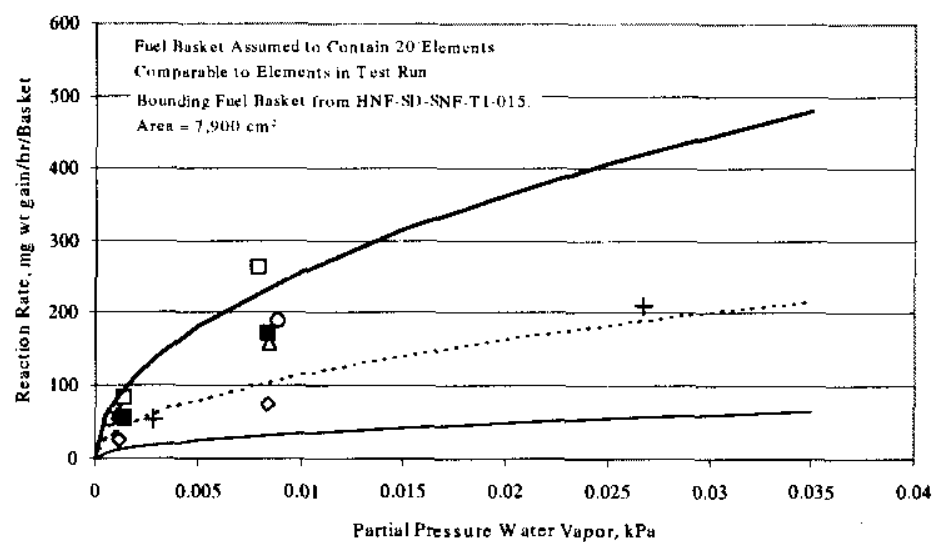

\begin{tabular}{|lll|}
\hline Bounding Fuel Basket, Enhunce $=22$ & $\square$ & Estimate from Run 4 \\
…... Bounding Fuel Busket. Enhance $=10$ & $\diamond$ & Estimate from Run 5 \\
\hline Bounding Fuel Basket, Enhance $=3$ & 0 & Estimate from Run 6 \\
$+\quad$ Estirnate from Run 7 & $\Delta$ & Estimate from Run 8 \\
Data Average & &
\end{tabular}


Reaction rate estimates are important to predictions of bounding hydrogen generation rates and thermal stability in an MCO. Hydrogen generation rates are applicable to design considerations only on an MCO basis. The current bounding hydrogen generation rate for CVD design is $2.4 \times 10^{-3} \mathrm{~g} / \mathrm{sec}$ (Pajunen 1998). This is equivalent, assuming a stoichiometric corrosion reaction, to a weight gain of $69,000 \mathrm{mg}$ wt gain $/ \mathrm{hr}$, or in excess of a factor of 10 greater than rates derived from drying tests shown on Figure 4-4.

Since the reaction rate is important to the thermal stability of an $\mathrm{MCO}$, and models indicate most heat transfer occurs radially, bounding scrap and fuel basket reaction rates were evaluated individually. A scrap basket is assumed to contain 39 equivalent assemblies and a fuel basket assumed to contain 20 "bad" elements out of a total of 54 assemblies for comparison with bounding scrap and fuel baskets containing reactive surface areas of $45,000 \mathrm{~cm}^{2}$ and $7,900 \mathrm{~cm}^{2}$, respectively. Figure 4-5 shows the results of the scrap basket comparison, indicating a larger margin between the bounding estimate and rates derived from observations on an MCO basis. However, Figure 4-6 indicates that fuel basket reaction rate predictions from drying data observations at $75^{\circ} \mathrm{C}$ and low water vapor pressure approach the bounding fuel basket.

The single element drying observations indicate that the oxidation rate dependence on water vapor determined from the literature is applicable to $\mathrm{N}$ Reactor fuel oxidation. Comparison of the line slopes on Figure 4-7 shows that the $75^{\circ} \mathrm{C}$ reaction rate from each single element test varies with the square root of water vapor partial pressure. Similar results were observed for the $50^{\circ} \mathrm{C}$ drying test results.

\subsubsection{Conclusion}

The following conclusions concerning the water vapor oxidation reaction are derived from the discussion above.

- The simplified stoichiometry described by Equation (4-3) provides a conservative description of the water vapor oxidation reaction for use in SNF Project design.

- The correlation of rate data in Reilly (1998) is an appropriate description of the literature data. Application of an enhancement factor of 3 to the rate correlation for process design yields an oxidation rate estimate that bounds most literature data for conditions of interest to SNF processes. An enhancement factor of 10 provides a conservative bound of the literature data at the conditions of interest.

- Laboratory-scale oxidation rate measurements using cut $\mathrm{N}$ Reactor fuel samples produced results below the literature data, but the potential for oxygen in the reactant gas could have depressed oxidation rate observations by up to a factor of 10 . However, an enhancement factor of 10 bounds the $\mathrm{N}$ Reactor fuel rate observations when increased by a factor of 10 to address potential oxygen contamination during testing. These data indicate that designs based on oxidation rates bounding the literature data will bound $\mathrm{N}$ Reactor fuel oxidation in water vapor. 
- Reaction rates from single element drying test data at $50^{\circ} \mathrm{C}$ and water vapor pressures of about 10 torr are a factor of 2 to 5 less than rates predicted for a bounding MCO at comparable conditions using the project data in Reilly (1998) and an assumed enhancement factor of 22.

- Reaction rates from single element drying test data at $75^{\circ} \mathrm{C}$ and water vapor pressures of about 0.01 torr to 0.1 torr are bounded by rates predicted for a bounding $\mathrm{MCO}$ at comparable conditions using the project data in Reilly (1998) and an assumed enhancement factor of 22 . Some rates estimated from observations approach the bounding MCO prediction.

- Since the rate predictions based on Reilly (1998) bound the single element observations, it is concluded that the correlations will bound reaction rates from actual fuel surfaces encountered during processing.

- The rate dependence on the square root of water vapor pressure, derived in the literature, is applicable to $\mathrm{N}$ Reactor fuel oxidation.

Figure 4-7. Reaction Rate Dependence on Water Vapor Indicated by Single Element Drying Tests (data at $75^{\circ} \mathrm{C}$ )

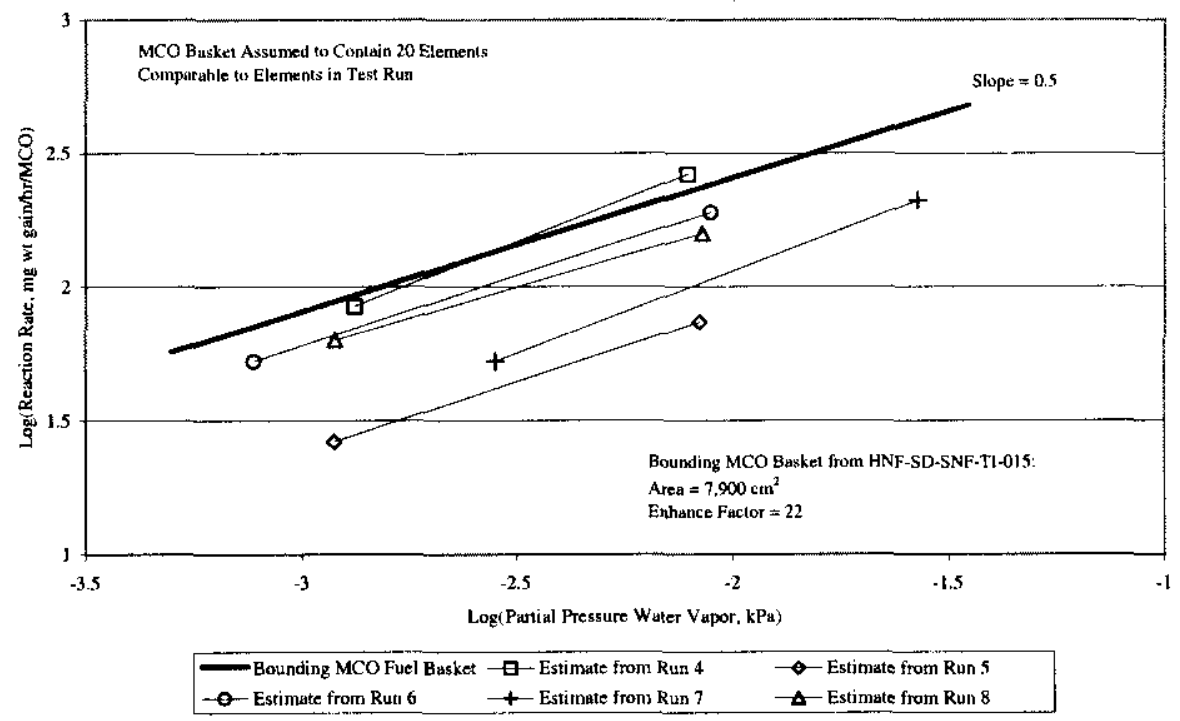




\subsection{Liquid Water Oxidation}

\subsubsection{Stoichiometry}

The reaction stoichiometry of uranium oxidation in liquid water is also described by Equation (4-1) or (4-2). As with the water vapor oxidation reaction, stoichiometry simplification to Equation (4-3) provides conservative estimates of design parameters for heat generation, hydrogen generation, and uranium in particulate, derived from reaction rates. Additional conservatism in the heat of reaction estimated by Equation (4-3) is provided by neglecting the enthalpy difference between liquid water and water vapor. This enthalpy change would reduce the actual liquid water heat of reaction estimate by approximately $20 \mathrm{kcal} / \mathrm{gmol} U$ reacted. Therefore, the oxygen free liquid water oxidation stoichiometry is based on Equation (4-3).

\subsubsection{Literature Rate Data}

Reilly (1998) uses the following kinetics expression for the mean oxidation rate of uranium in oxygen free liquid water at the conditions of interest for process design.

$$
\log K=7.634-3016 / T
$$

where: $\mathrm{K}=$ rate constant, $\mathrm{mg}$ wt gain $/ \mathrm{hr}-\mathrm{cm}^{2}$

$\mathrm{T}=$ temperature, $\mathrm{K}(\mathrm{T} \leq 373 \mathrm{~K})$

Equation (4-7) is based on a correlation of literature data identified by Cooper (1998).

Equation (4-7) indicates that the oxidation rate is dependent only on temperature. Equation (4-7) can be rearranged to the form shown as Equation (4-8), which simplifies comparison with other reaction rate correlations. Figure 4-8 compares the rate correlation shown by Equation (4-8) with literature data in the temperature range of interest from Trimble (1998b).

$$
\frac{\text { Oxidation rate }}{\mathrm{A}_{\mathrm{g}}}=10^{7.634} 10^{-3016 / \mathrm{T}} \approx\left(4.31 \times 10^{7}\right) 10^{-3016 / \mathrm{T}} \frac{\mathrm{mg} \mathrm{wt} \mathrm{gain}}{\mathrm{hr}-\mathrm{cm}^{2}}
$$

Trimble (1998b) also presents an equation describing the mean of literature observations. The constants of this correlation are slightly different from those indicated by Equation (4-7), but the predicted reaction rate is not significantly different (the correlation by Trimble (1998b) predicts reaction rates $4 \%$ to $60 \%$ lower in the temperature range of interest). Trimble (1998b) concludes that the modified correlation of oxygen free liquid water oxidation agrees with Equation (4-7) below $200^{\circ} \mathrm{C}$. Therefore, Equation (4-7) is considered an appropriate estimate of the uranium oxidation rate in oxygen free liquid water. 
HNF-4165, Rev. 1

Figure 4-8. Liquid Water Oxidation of Uranium Metal $\left(<100^{\circ} \mathrm{C}\right)$

[From Trimble (1998b)]

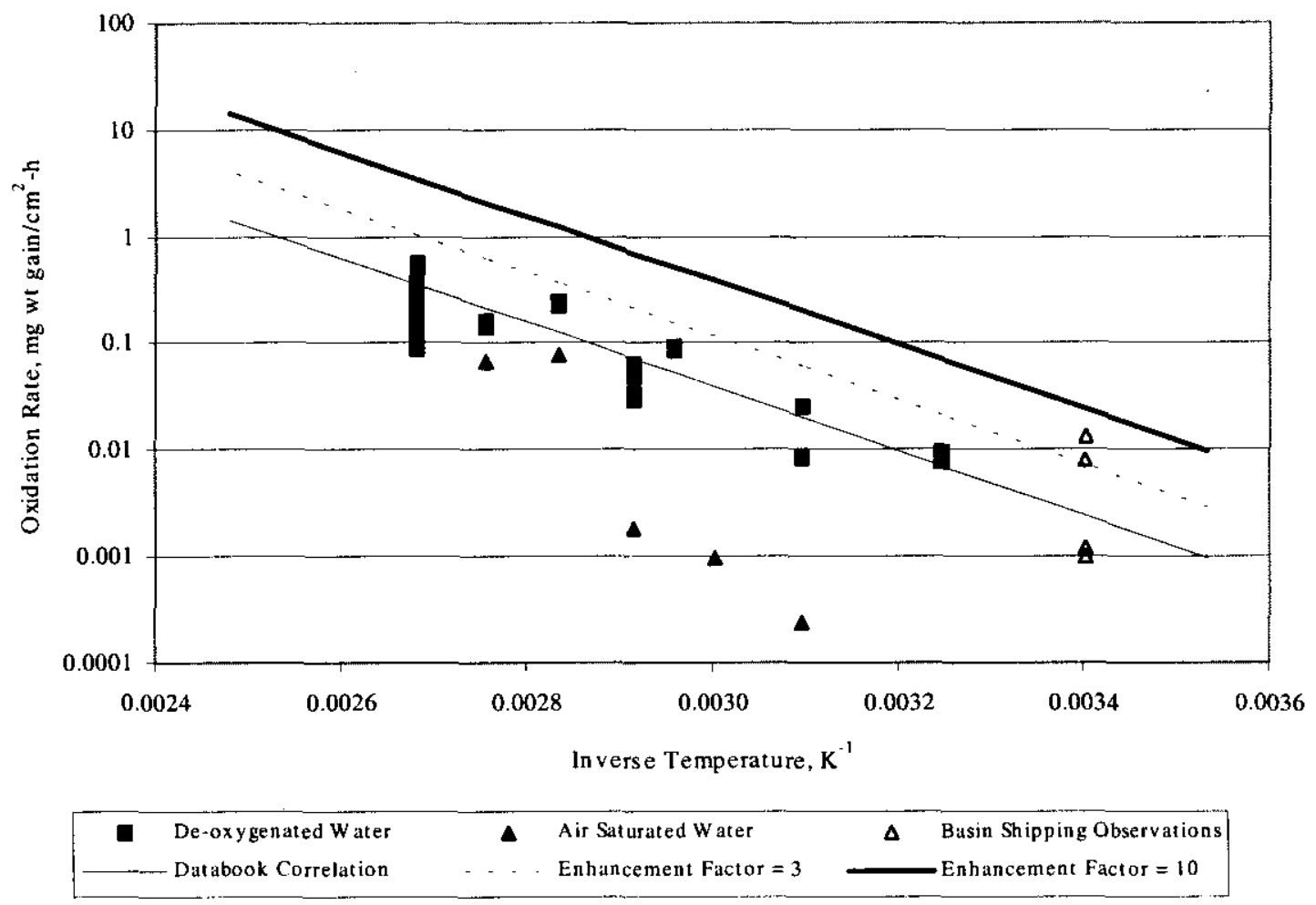

Note: Basin shipping observations shown on Figure 4-8 contain uncertainty associated with estimating fuel clement exposed surface area and hydrogen generation rate measurements under plant conditions. Figure 4-9 shows an alternate comparison indicating basin shipping observations of reaction rate are significantly lower than projections using an enhancement factor of 3 .

Figure 4-8 compares the literature data observations to oxidation rate predictions using Equation (4-8) and enhancement factors of 3 and 10. An enhancement factor of 3 results in oxidation rate predictions that bound all literature reaction rate observations.

A correlation predicting uranium oxidation rates in oxygenated water has not been specifically developed for use in the SNF process design. Figure 4-8 indicates that air saturated uranium corrosion rates are significantly lower than oxidation rates in oxygen free water. The oxidation rate reduction in oxygenated water can be estimated from literature data listed in Table 4-3, which are reported by the same investigator. 
Table 4-3. Uranium Oxidation in Oxygenated Water

[circa. 1945 data from listing in Trimble (1998b)]

\begin{tabular}{|c|c|c|c|}
\hline \multirow{2}{*}{$\begin{array}{c}\text { Temperature, } \\
{ }^{\circ} \mathrm{C}\end{array}$} & \multicolumn{2}{|c|}{ Oxidation Rate, mg wt gain $/ \mathrm{hr}^{-\mathrm{cm}^{2}}$} & oxygen free \\
\cline { 2 - 4 } & Air Saturated Water & Hydrogen Saturated Water & oxygenated \\
\hline 50 & $2.42 \times 10^{-4}$ & $8.9 \times 10^{-3}$ & 37 \\
\hline 60 & $9.55 \times 10^{-4}$ & - & - \\
\hline 70 & $1.83 \times 10^{-3}$ & $6.23 \times 10^{-2}$ & 34 \\
\hline 80 & $7.73 \times 10^{-2}$ & - & - \\
\hline 90 & $6.74 \times 10^{-2}$ & $1.36 \times 10^{-1}$ & 2 \\
\hline
\end{tabular}

Table 4-3 indicates that uranium oxidation rates in oxygenated water are approximately a factor of 10 lower than the oxidation rate in oxygen free water at temperatures up to $70^{\circ} \mathrm{C}$.

\subsubsection{N Reactor Fuel Reaction Rate Observations}

Hydrogen generation rate measurements from single elements were performed as part of shipping procedures during the transfer of characterization samples to the laboratory. These measurements provide estimates of the reaction rate of an element flooded with water at approximately $20^{\circ} \mathrm{C}$. The hydrogen rate measurements from shipping containers were performed underwater in the basins, which is not equivalent to the controlled environment of a laboratory experiment. Measurable hydrogen generation rates were only observed from 7 of 15 shipping containers. Elements indicating measurable hydrogen generation rates were all stored for an extended time period (e.g., 8 days) at higher than routine temperatures $\left(20^{\circ} \mathrm{C}\right.$ vs. routine temperature of $10^{\circ} \mathrm{C}$ ). The observation of measurable hydrogen in some, but not other, containers is attributed to an increase in corrosion rate from deoxygenating of the shipping container water prior to shipment.

The reaction rate observations are reported in Appendix 10.1. Rate estimates from the basin shipping observations, based on an approximation of exposed uranium surface area, are compared with literature data on Figure 4-8. While these estimates are comparable to the literature, the observed rate contains considerable uncertainty due to the uncertainty in the area estimate. Therefore, a reaction rate comparison was performed based on the alternative MCO loadings in Table 4-2.

Figure 4-9 compares bounding MCO configuration reaction rates with rates predicted from single element shipping observations at approximately $20^{\circ} \mathrm{C}$. This comparison indicates a margin in excess of a factor of 10 between bounding and predicted rates under flooded conditions. 
HNF-4165, Rev. 1

Figure 4-9. Comparison of Bounding Reaction Rates in Liquid Water with Single Element Shipping Observations

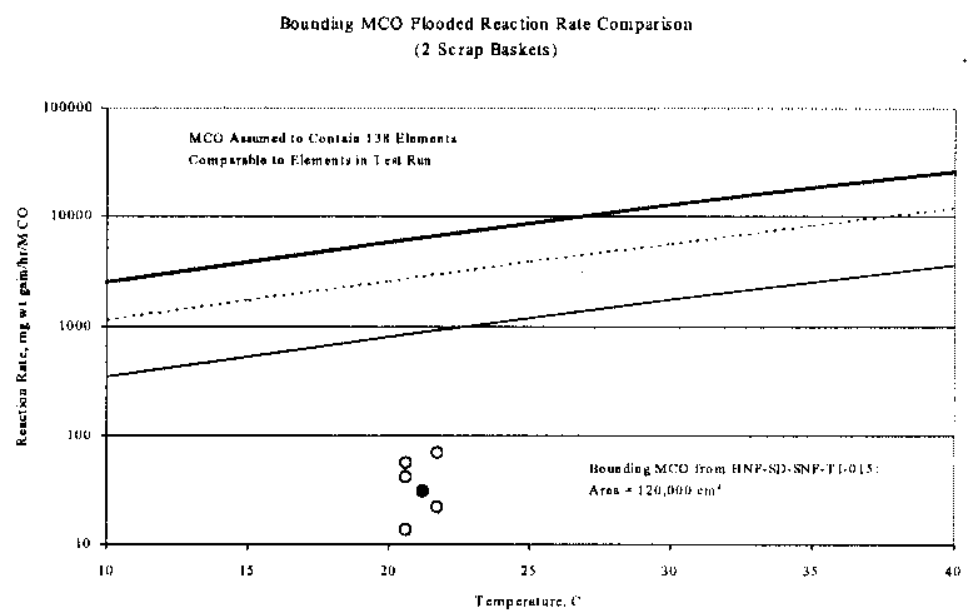

Bounding MCO Scrap Basket Flooded Reaction Rate Compurison

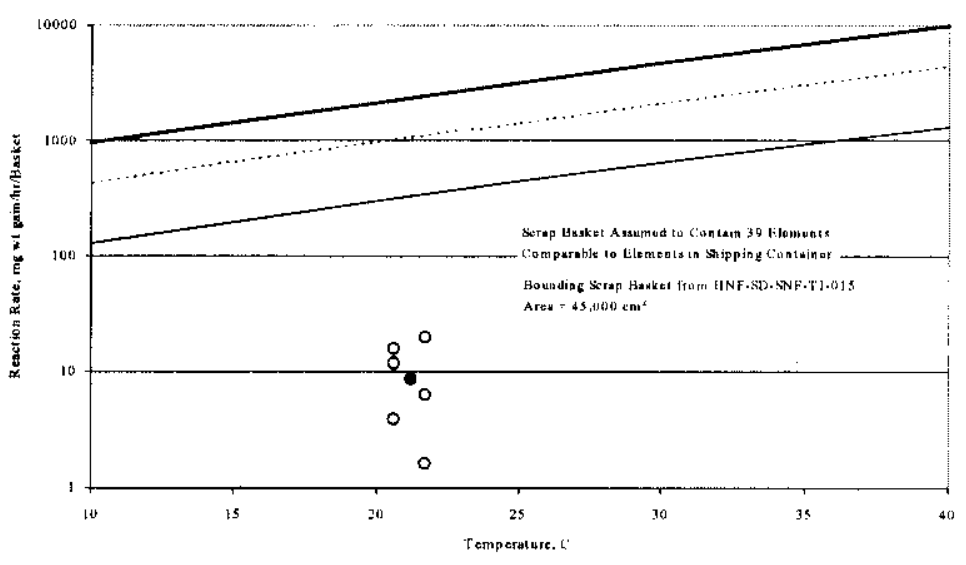

Bounding MCO Fuel Basket Flooded Reaction Rate Comparison

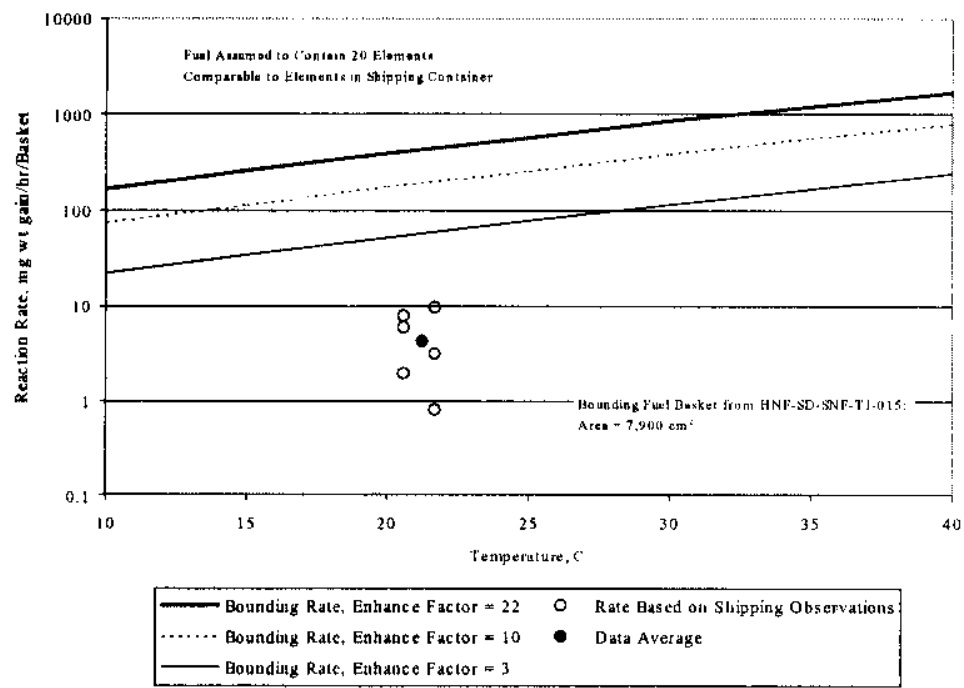




\subsubsection{Conclusions}

The following conclusions concerning the liquid water oxidation reaction are derived from the discussion above.

- The simplified stoichiometry described by Equation (4-3) provides a conservative description of the oxygen free liquid water reaction for use in SNF project design.

- The correlation of rate data in Reilly (1998) is an appropriate description of the literature data. Application of an enhancement factor of 3 to the rate correlation for process design yields an oxidation rate estimate that bounds most literature data for conditions of interest to SNF processes. An enhancement factor of 10 provides a conservative bound of the literature data the conditions of interest.

- Whole element reaction rate observations, from shipping data, flooded with water at $20^{\circ} \mathrm{C}$ indicate the bounding MCO description in Reilly (1998) predicts reaction rates that are conservative by more than a factor of 10 .

- Observations from shipping data support laboratory observations that the oxidation rate in oxygenated water is significantly reduced as compared to the oxygen free oxidation rate, and/or the reaction stoichiometry does not produce hydrogen gas.

\subsection{URANIUM-MOIST AIR REACTION}

\subsection{Stoichiometry}

In the presence of oxygen ( $>1000 \mathrm{ppm}$ ), with water vapor in the range of 0 to $90 \%$ relative humidity, Baker, et al. (1966) indicates the following reaction stoichiometry is observed.

$$
\mathrm{U}+(1.1-1.2) \mathrm{O}_{2}+\mathrm{H}_{2} \mathrm{O} \rightarrow \mathrm{UO}_{2.2-2.4}+\mathrm{H}_{2} \mathrm{O}
$$

Isotopic studies show that the oxygen combining with uranium originates in the water molecule, and the hydrogen from water is transferred to the oxygen gas molecules to reform water. No significant quantities of uranium hydride, or hydrogen gas, are produced in the presence of oxygen when the partial pressure of water is less than a RH of $90 \%$. Note that the partial pressure of water associated with a specific $\mathrm{RH}$ varies with temperature as the saturation pressure changes according to the following equation.

$$
\% \mathrm{RH}=100 \frac{\mathrm{P}}{\mathrm{P}_{\text {sat }}}
$$

where: $\% \mathrm{RH}=$ percent relative humidity

$\mathrm{P}=$ partial pressure of water vapor, $\mathrm{kPa}$

$P_{\text {sat }}=$ Saturation pressure of water vapor, $\mathrm{kPa}$ 
Appendix 10.3 shows that the saturation pressure of water vapor can be approximated over the temperature range of $10^{\circ} \mathrm{C}$ to $180^{\circ} \mathrm{C}$ by the following.

$$
\log P_{\text {sat }}=7.6726-2126.5 / T
$$

where: $\mathrm{T}=$ Absolute temperature, $\mathrm{K}$

As the oxygen concentration is reduced below $100 \mathrm{ppm}$, or the water vapor partial pressure is increased above $90 \% \mathrm{RH}$, the reaction rate increases and hydrogen is evolved.

Figure 5-1 indicates the heat of reaction for oxidation of uranium by oxygen to form hyperstoichiometric oxides. These estimates are based on the heat of formation for $\mathrm{UO}_{2}$ from Dean (1979) and the partial molar enthalpy of oxygen in $\mathrm{UO}_{2+\mathrm{x}}$ from Olander (1976). The heat of formation of hyperstoichiometric oxides increases as oxygen is dissolved in stoichiometric $\mathrm{UO}_{2}$. This results in an increase in the heat of oxidation reaction when evaluated per mole of uranium oxidized. However, heat generation rate estimates are the product of reaction rate and heat of reaction. Figure 5-1 shows that the heat of reaction on a weight gain basis decreases as oxygen is added to stoichiometric $\mathrm{UO}_{2}$. Therefore, heat generation rate estimates from weight gain rates are maximized by assuming the following simplified reaction stoichiometry.

$$
\mathrm{U}+\mathrm{O}_{2} \rightarrow \mathrm{UO}_{2}-\Delta \mathrm{H}_{\mathrm{r}}^{0}=270 \mathrm{kcal} / \mathrm{gmol} \mathrm{U}
$$

The simplified stoichiometry also maximizes the mass of uranium in particulate (maximizes predicted radionuclides in particulate) and minimizes the oxygen depletion rate by a specified weight gain (minimizes oxygen gettered by weight gain). Each of these attributes result in conservative estimates for SNF process design parameters.

Figure 5-1. Heat of Reaction Variation for Uranium Oxidation by Oxygen with Stoichiometry

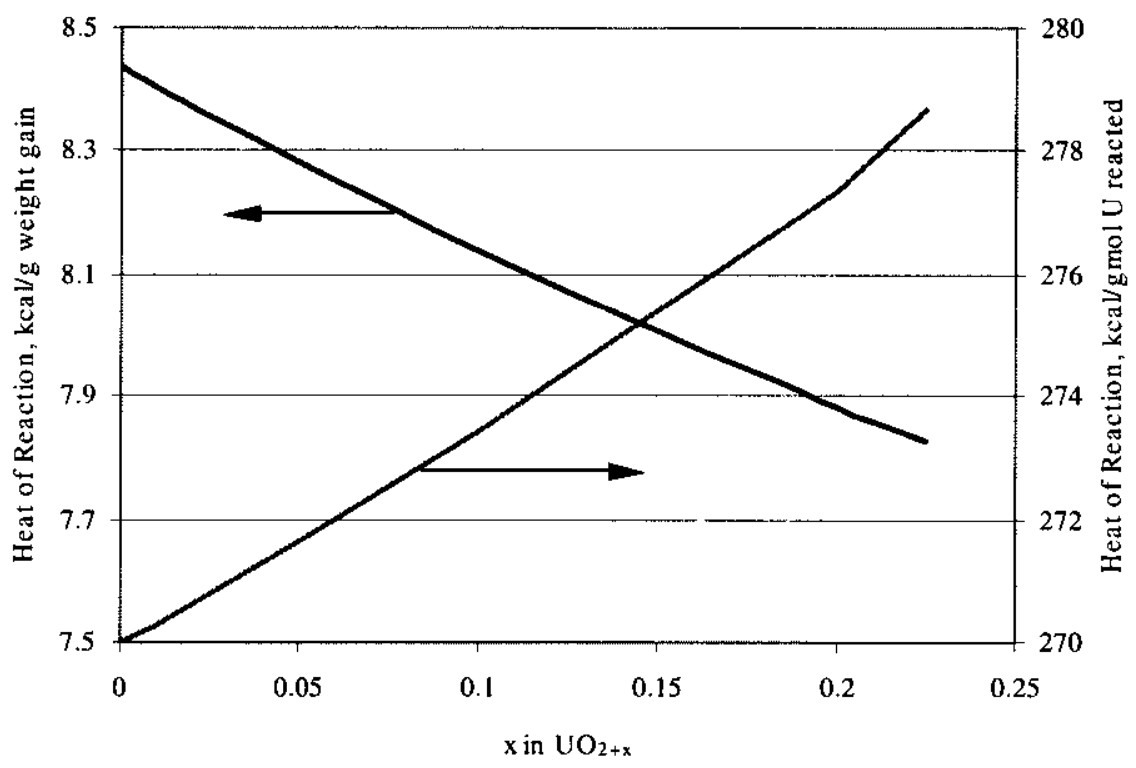




\subsection{Literature Rate Data}

Reilly (1998) used the following kinetic expression for the mean oxidation rate of uranium in moist air at the conditions of interest for process design.

For $100 \% \mathrm{RH}$ :

$$
\log K=8.333-3730 / T
$$

For $10 \%$ to $75 \% \mathrm{RH}$ :

$$
\log K=13.8808-5769.9 / \mathrm{T}
$$

where: $\mathrm{K}=$ rate constant, $\mathrm{mg}$ wt gain $/ \mathrm{hr}-\mathrm{cm}^{2}$

$\mathrm{T}=$ temperature, $\mathrm{K}(\mathrm{T} \leq 373 \mathrm{~K})$

Equations (5-5) and (5-6) are based on correlations of literature data identified by Cooper (1998). Both correlations are dependent on temperature. The rate observations at $10 \%$ to $75 \% \mathrm{RH}$ vary from equivalent to dry air at $30^{\circ} \mathrm{C}$ to equivalent to $100 \% \mathrm{RH}$ air at approximately $100^{\circ} \mathrm{C}$.

Equations (5-5) and (5-6) can be rearranged, as follows, to simplify comparison with other reaction rate correlations.

For $100 \%$ RH:

$$
\frac{\text { Oxidation Rate }}{\mathrm{A}_{\mathrm{g}}}=10^{8.333} 10^{-3730 \mathrm{r}} \approx\left(2.15 \times 10^{8}\right) 10^{-3730 / \mathrm{r}} \frac{\mathrm{mg} \mathrm{wt} \text { gain }}{\mathrm{hr}-\mathrm{cm}^{2}}
$$

For $10 \%$ to $75 \% \mathrm{RH}$ :

$$
\frac{\text { Oxidation Rate }}{\mathrm{A}_{\mathrm{g}}}=10^{13.8808} 10^{-5769.9 / \mathrm{T}} \approx\left(7.6 \times 10^{13}\right) 10^{-5769.9 \mathrm{r}} \frac{\mathrm{mg} \mathrm{wt} \text { gain }}{\mathrm{hr}-\mathrm{cm}^{2}}
$$

Figure 5-2 compares the rate correlation shown by Equation (5-7) with literature data in the temperature range of interest from Ritchie (1981). Figure 5-3 provides a similar comparison for Equation (5-8) and data from Ritchie (1986). 
Figure 5-2. Moist Air Oxidation of Uranium Metal at $100 \%$ Relative Humidity $\left(<\mathbf{1 0 0}{ }^{\circ} \mathrm{C}\right)$ [Data from Ritchie (1981)]

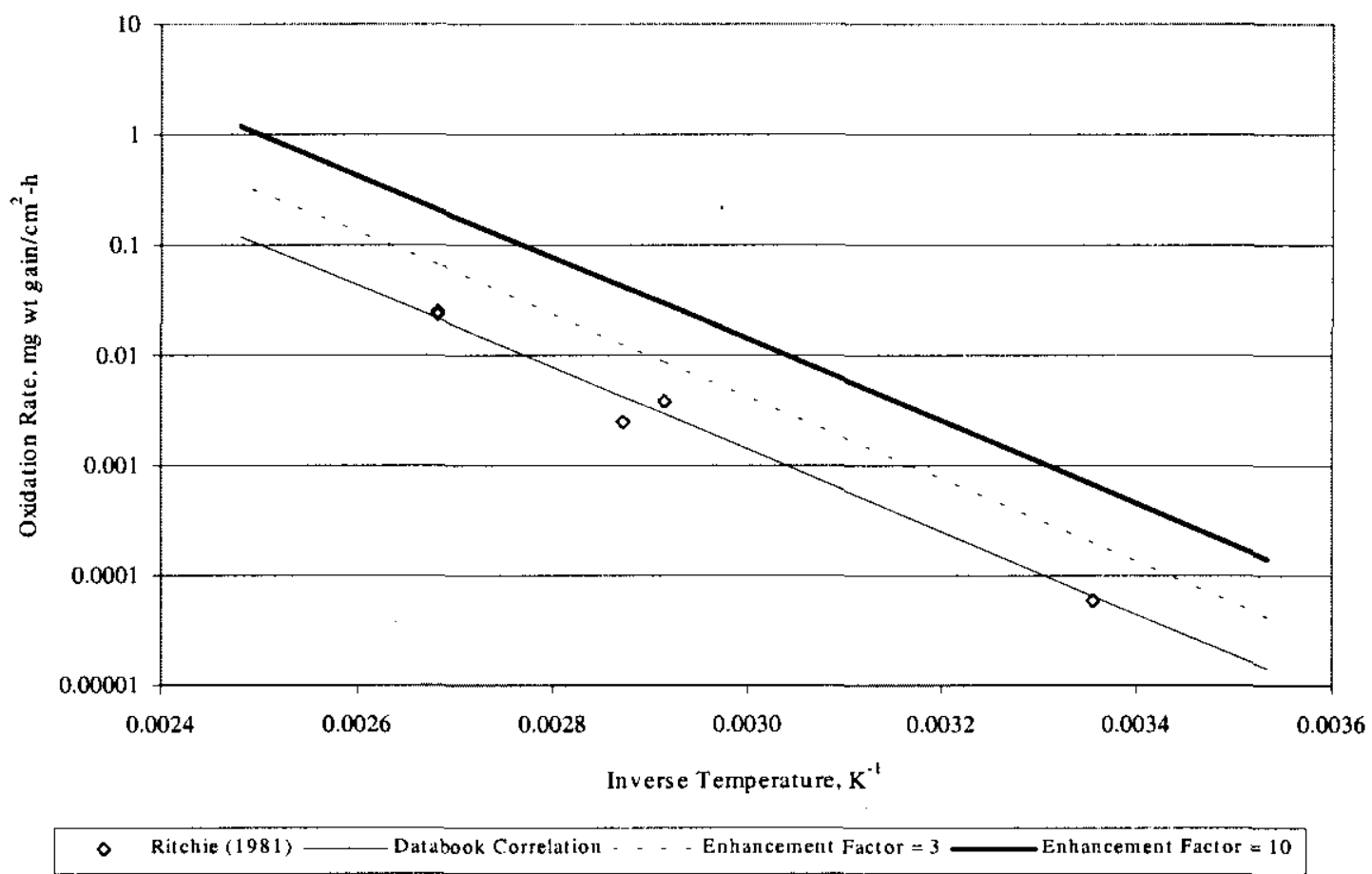

Figure 5-3. Moist Air Oxidation of Uranium Metal at $11 \%$ to $75 \%$ Relative Humidity $\left(<100^{\circ} \mathrm{C}\right)$

[Data from Ritchie (1986)]

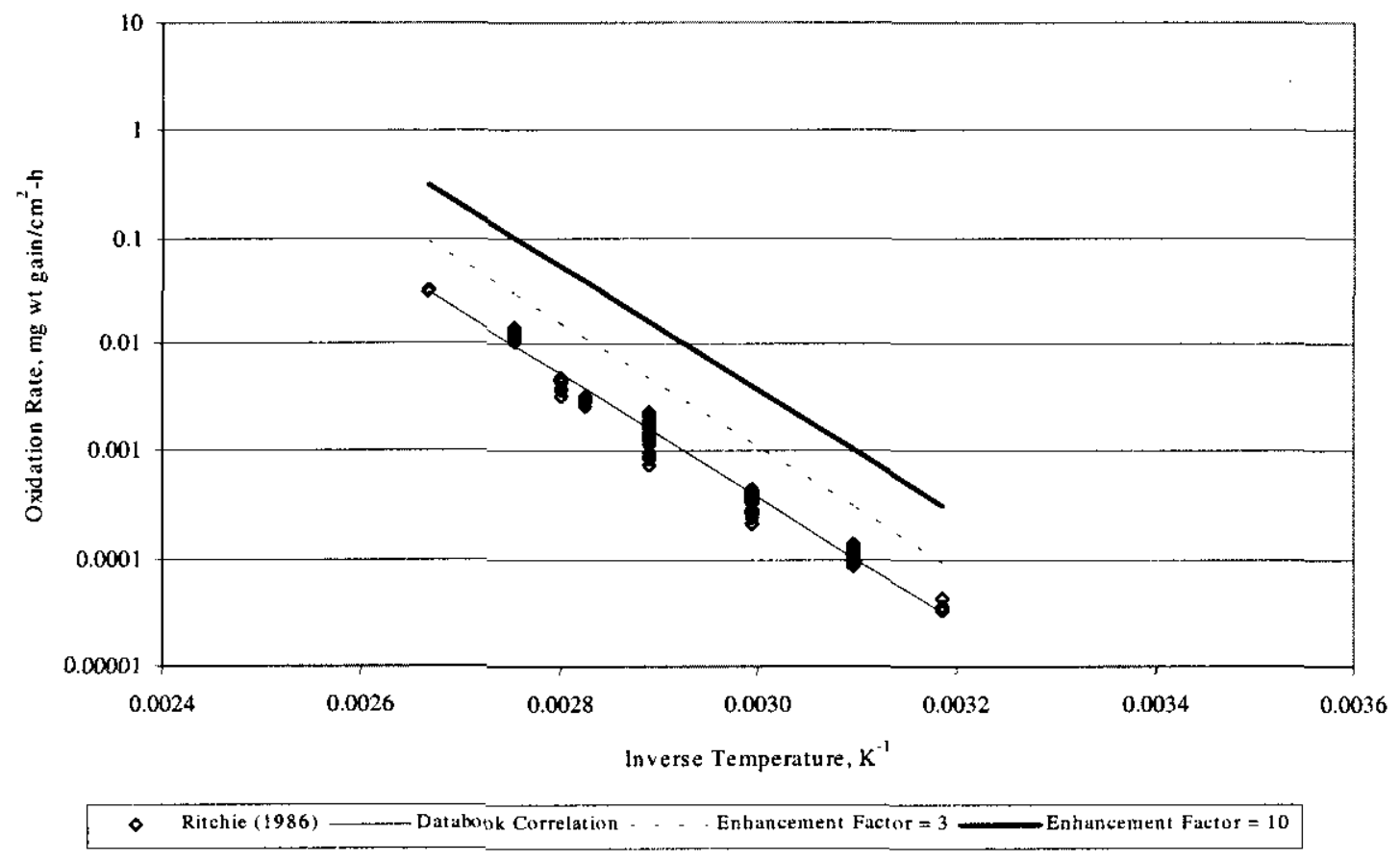


Figures 5-2 and 5-3 also compare literature data observations to oxidation rates assuming enhancement factors of 3 and 10. An enhancement factor of 3 results in oxidation rate predictions that bound all literature reaction rate observations.

McGillivray (1994) provides an analysis of the moist air reaction kinetics and develops a model for predicting reaction rates over a temperature range of $0^{\circ} \mathrm{C}$ to $350^{\circ} \mathrm{C}$ and water vapor pressure range of $0 \mathrm{kPa}$ to $101.3 \mathrm{kPa}$. The model is based on the assumption that the surface concentration of water determines the rate of reaction and that the adsorption of water onto the oxide follows a Langmuir type isotherm. The model proposed by McGillivray (1994) is considered applicable over RHs ranging from $0 \%$ to $90 \%$. As the $\mathrm{RH}$ increases above $90 \%$, it is believed that a change in reaction mechanism occurs. Therefore, the basic modeling assumption relating rate to water surface concentration is no longer applicable as saturation is approached.

The rate equation proposed by McGillivray (1994) is as follows [note that time basis for Equations (5-9), (5-10), (5-11), and (5-12) is minutes instead of hours].

For $0 \%$ to $90 \% \mathrm{RH}$ :

$$
\frac{\text { McGillivray Moist Air Rate }}{\mathrm{A}_{\mathrm{g}}}=\frac{\mathrm{k}_{1} \mathrm{P}}{1+\mathrm{k}_{2} \mathrm{P}}+\mathrm{D} \frac{\mathrm{mg} \text { wt gain }}{\mathrm{min}-\mathrm{cm}^{2}}
$$

where: $\mathrm{P}=$ water vapor pressure, $\mathrm{kPa}$

$\mathrm{k}_{1}=$ temperature dependent rate constant, $\mathrm{mg}$ wt gain $/ \mathrm{cm}^{2}-\mathrm{min}-\mathrm{kPa}$

$\mathrm{k}_{2}=$ temperature dependent rate constant, $\mathrm{kPa}^{-1}$

$\mathrm{D}=$ dry air reaction rate, $\mathrm{mg} w \mathrm{tgain} / \mathrm{cm}^{2}-\mathrm{min}$

The rate constant relationships derived from McGillivray (1994) are shown as follows.

$$
\begin{gathered}
\operatorname{Lnk}_{1}=7.831-(6432 / \mathrm{T}) \\
\mathrm{Lnk}_{2}=-15.208+(5327 / \mathrm{T}) \\
\mathrm{LnD}=11.093-(8077 / \mathrm{T})
\end{gathered}
$$

The McGillivray (1994) prediction is based on a correlation of dry air reaction rates. The McGillivray dry air rate prediction yields results that are nearly identical to the correlation prediction developed for the SNF Project [Equation (6-3)]. Therefore, the McGillivray moist air rate was modified for use by the SNF Project, as follows, to provide consistent dry air reaction rate predictions when the water vapor pressure is zero.

$$
\frac{\text { Oxidation Rate }}{\mathrm{A}_{\mathrm{g}}}=60\left\{\frac{\mathrm{k}_{1} \mathrm{P}}{1+\mathrm{k}_{2} \mathrm{P}}\right\}+\mathrm{K}_{\mathrm{DA}} \frac{\mathrm{mgwt} \text { gain }}{\mathrm{hr}-\mathrm{cm}^{2}}
$$

where: $\mathrm{k}_{1}$ is from Equation (5-10)

$\mathrm{k}_{2}$ is from Equation $(5-11)$

$\mathrm{K}_{\mathrm{DA}}$ is from Equation (6-3) 
The resulting correlation is compared in Figure 5-4 to data from Ritchie (1986) and McGillivray (1994) at temperatures less than $200^{\circ} \mathrm{C}$ and water vapor pressures up to $50 \mathrm{kPa}$. The data in Ritchie (1986) are reported in terms of $\mu \mathrm{g}$ weight gain $/ \mathrm{cm}^{2}$-hr versus temperature and RH. The RHs reported in Ritchie (1986) are converted to water vapor pressure using Equations (5-2) and (5-3) to facilitate the comparisons shown in Figure 5-4. The modified data plotted on Figure 5-4 are shown in Table 5-1.

Figure 5-4 compares the McGillivray moist air reaction rate predictions based on Equation (5-13) with experimental results. Experimental data were divided into three ranges of water vapor pressures for comparison: $0.4 \mathrm{kPa}$ to $3 \mathrm{kPa}, 3 \mathrm{kPa}$ to $20 \mathrm{kPa}$, and $20 \mathrm{kPa}$ to $50 \mathrm{kPa}$. These groupings represent convenient pressure ranges that describe the available data. In each case, reaction rate predictions based on Equation (5-13) approximate the experimental observations. Figure 5-5 compares the moist air oxidation rate predicted by Equation (5-8) for a RH range of $11 \%$ to $75 \%$ with oxidation rates predicted by Equation (5-13) for a $\mathrm{RH}$ range of $11 \%$ to $90 \%$. Note that the McGillivray model does not predict significant oxidation rate variations with RH between $11 \%$ and $90 \%$. The difference between the alternative oxidation rate predictions appears to be within the uncertainty of the experimental observations at the conditions of interest to the SNF Project. 
Figure 5-4. Comparison of McGillivray Correlation to Moist Air Oxidation Rate Data

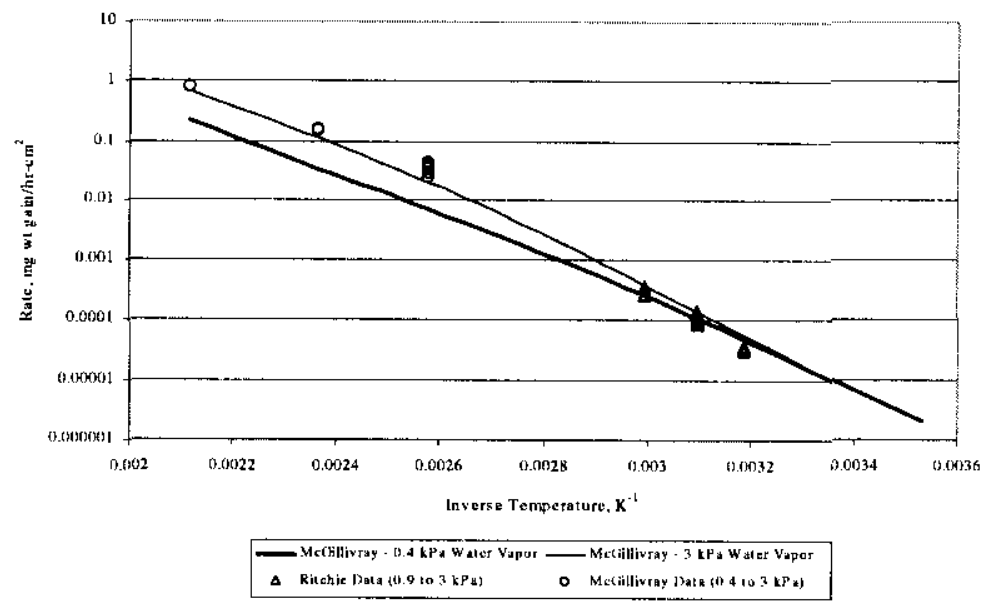

(a) Comparison to observations with water vapor pressure ranging from $0.4 \mathrm{kPa}$ to $3 \mathrm{kPa}$

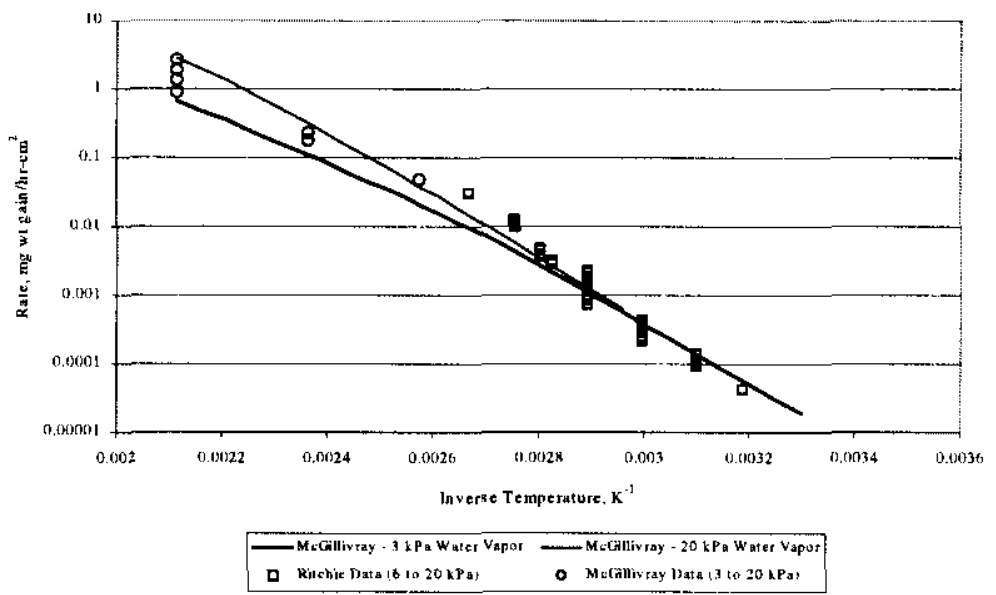

(b) Comparison to observations with water vapor pressure ranging from $3 \mathrm{kPa}$ to $20 \mathrm{kPa}$

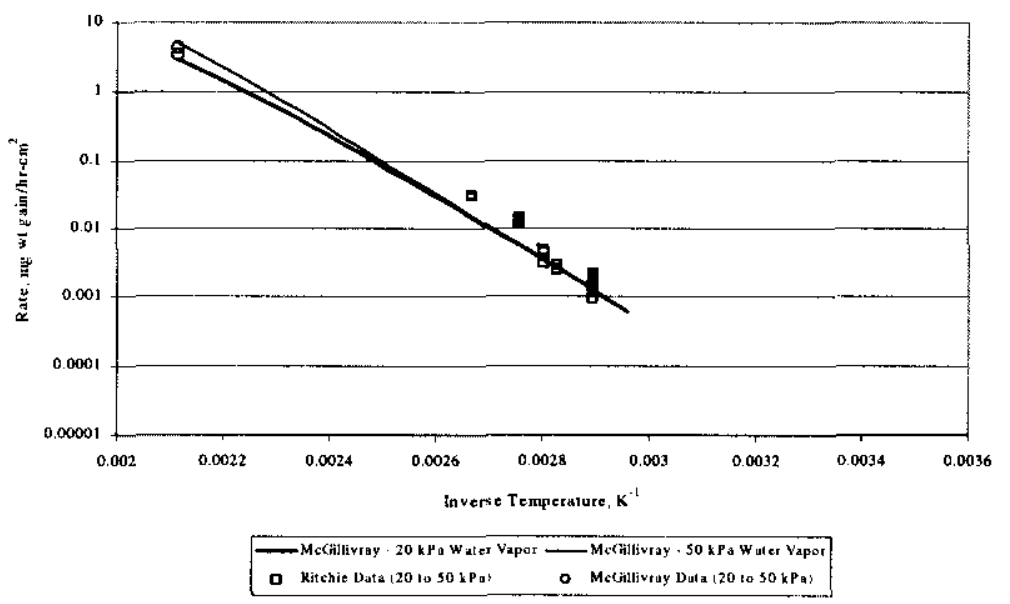

(c) Comparison to observations with water vapor pressure ranging from $20 \mathrm{kPa}$ to $50 \mathrm{kPa}$ 
HNF-4165, Rev. 1

Table 5-1. Moist Air Uranium Metal Oxidation Rate Data [from Ritchie (1986)]

\begin{tabular}{|c|c|c|c|c|c|c|c|c|}
\hline Temp, ${ }^{\circ} \mathrm{C}$ & $\begin{array}{l}\text { Water Vapor } \\
\text { Pressure. kPa }\end{array}$ & $\begin{array}{c}\text { Rate. } \\
\text { mg wt gain } / \mathrm{hr} / \mathrm{cm}^{2}\end{array}$ & Temp, ${ }^{\circ} \mathrm{C}$ & $\begin{array}{c}\text { Water Vapor } \\
\text { Pressure, kPa }\end{array}$ & $\begin{array}{l}\text { Rate, } \\
\text { mg wt gain } / \mathrm{hr} / \mathrm{cm}^{2}\end{array}$ & Temp, ${ }^{\circ} \mathrm{C}$ & $\begin{array}{l}\text { Water Vapor } \\
\text { Pressure, kPa }\end{array}$ & $\begin{array}{l}\text { Rate. } \\
\mathrm{mg} \text { wt gain } / \mathrm{hr} / \mathrm{cm}^{2}\end{array}$ \\
\hline 41 & 0.9 & 0.000031 & 61 & 6.1 & 0.000439 & 90 & 17.0 & 0.0106 \\
\hline $4 !$ & 0.9 & 0.000033 & 61 & 6.1 & 0.00034 & 90 & 17.0 & 0.0104 \\
\hline 50 & 2.1 & 0.000129 & 61 & 6.1 & 0.000334 & 90 & 17.0 & 0.0113 \\
\hline 50 & 2.1 & 0.000128 & 81 & 8.3 & 0.00294 & 90 & 17.0 & 0.0123 \\
\hline 50 & 2.1 & 0.000137 & 81 & 8.3 & 0.00309 & 90 & 17.0 & 0.0118 \\
\hline 50 & 2.1 & 0.000097 & 81 & 8.3 & 0.00322 & 90 & 17.0 & 0.0122 \\
\hline 50 & 2.1 & 0.000108 & 81 & 8.3 & 0.00285 & 90 & 17.0 & 0.0124 \\
\hline 50 & 2.1 & 0.000111 & 50 & 9.2 & 0.000103 & 90 & 17.0 & 0.0123 \\
\hline 50 & 2.1 & $0.00009 \mathrm{l}$ & 50 & 9.2 & 0.000107 & 102 & 19.1 & 0.0299 \\
\hline 50 & 2.1 & 0.000089 & 50 & 9.2 & 0.000108 & 102 & 19.1 & 0.0305 \\
\hline 41 & 2.5 & 0.000033 & 50 & 9.2 & 0.000137 & 102 & 19.1 & 0.0316 \\
\hline 41 & 2.5 & 0.000037 & 50 & 9.2 & 0.000093 & 102 & 19.1 & 0.0305 \\
\hline 61 & 3.4 & 0.000357 & 84 & 9.4 & 0.00385 & 102 & 19.1 & 0.0311 \\
\hline 61 & 3.4 & 0.000369 & 84 & 9.4 & 0.00383 & 102 & 19.1 & 0.0317 \\
\hline 61 & 3.4 & 0.000359 & 84 & 9.4 & 0.00363 & 102 & 19.1 & 0.0306 \\
\hline 61 & 3.4 & 0.000371 & 84 & 9.4 & 0.00367 & 102 & 19.1 & 0.0312 \\
\hline 61 & 3.4 & 0.000377 & 73 & 9.8 & 0.00074 & 102 & 23.1 & 0.0319 \\
\hline 61 & 3.4 & 0.000376 & 73 & 9.8 & 0.00084 & 102 & 23.1 & 0.0317 \\
\hline 61 & 3.4 & 0.000267 & 73 & 9.8 & 0.00097 & 102 & 23.1 & 0.0308 \\
\hline 61 & 3.4 & 0.000282 & 73 & 9.8 & 0.00124 & 102 & 23.1 & 0.0322 \\
\hline 50 & 3.9 & 0.000139 & 73 & 9.8 & $0.0(0149$ & 102 & 23.1 & 0.0314 \\
\hline 50 & 3.9 & 0.000107 & 73 & 9.8 & 0.00145 & 102 & 23.1 & 0.0314 \\
\hline 50 & 3.9 & 0.000138 & 73 & 9.8 & 0.00086 & 102 & 23.1 & 0.0303 \\
\hline 50 & 3.9 & 0.000141 & 73 & 9.8 & 0.00088 & 102 & 23.1 & 0.0 .312 \\
\hline 50 & 3.9 & 0.000119 & 90 & 12.4 & 0.0097 & 73 & 24.9 & 0.00139 \\
\hline 50 & 3.9 & 0.0001 .34 & 90 & 12.4 & 0.0098 & 73 & 24.9 & 0.00116 \\
\hline 50 & 3.9 & 0.000086 & 90 & 12.4 & 0.0108 & 73 & 24.9 & 0.00175 \\
\hline 50 & 3.9 & 0.000097 & 90 & 12.4 & 0.0109 & 73 & 24.9 & 0.00222 \\
\hline 41 & 6.0 & 0.000043 & 90 & 12.4 & 0.0108 & 73 & 24.9 & 0.00193 \\
\hline 41 & 6.0 & 0.000044 & 90 & 12.4 & 0.0107 & 73 & 24.9 & 0.00096 \\
\hline 73 & 6.1 & 0.00189 & 90 & 12.4 & 0.0106 & 73 & 24.9 & 0.00211 \\
\hline 73 & 6.1 & 0.00169 & 90 & 12.4 & 0.0103 & 81 & 34.3 & 0.00299 \\
\hline 73 & 6.1 & 0.00182 & 84 & 14.0 & 0.00444 & 81 & 34.3 & 0.00259 \\
\hline 73 & 6.1 & 0.00161 & 84 & 14.0 & 0.00439 & 84 & 38.5 & 0.00485 \\
\hline 73 & 6.1 & 0.00215 & 84 & 14.0 & 0.00459 & 84 & 38.5 & 0.00322 \\
\hline 73 & 6.1 & 0.00228 & 84 & 14.0 & 0.0044 & 84 & 38.5 & $0.00+4$ \\
\hline 73 & 6.1 & 0.00174 & 61 & 15.2 & 0.000374 & 90 & 48.3 & 0.0119 \\
\hline 73 & 6.1 & 0.00133 & 61 & 15.2 & 0.000296 & 90 & 48.3 & 0.0118 \\
\hline 61 & 6.1 & $0.000+11$ & 61 & 15.2 & 0.000246 & 90 & 48.3 & 0.0123 \\
\hline 61 & 6.1 & 0.000404 & 61 & 15.2 & 0.000423 & 90 & 48.3 & 0.0144 \\
\hline 61 & 6.1 & 0.000387 & 61 & 15.2 & 0.000331 & 90 & 48.3 & 0.0127 \\
\hline 61 & 6.1 & 0.000433 & 61 & 15.2 & 0.000219 & 90 & 48.3 & 0.0131 \\
\hline 61 & 6.1 & 0.000436 & 61 & 15.2 & 0.000239 & 90 & 48.3 & 0.0132 \\
\hline
\end{tabular}

Note: Original data in Ritchie provided in $\mathrm{RH}$ and $\mu \mathrm{g}$ wt gain $/ \mathrm{hr} / \mathrm{cm}^{2}$. 
HNF-4165, Rev. 1

Figure 5-5. Comparison of Uranium Metal Moist Air Oxidation Correlations $\left(<100^{\circ} \mathrm{C}\right)$ [data from Ritchie (1986)]

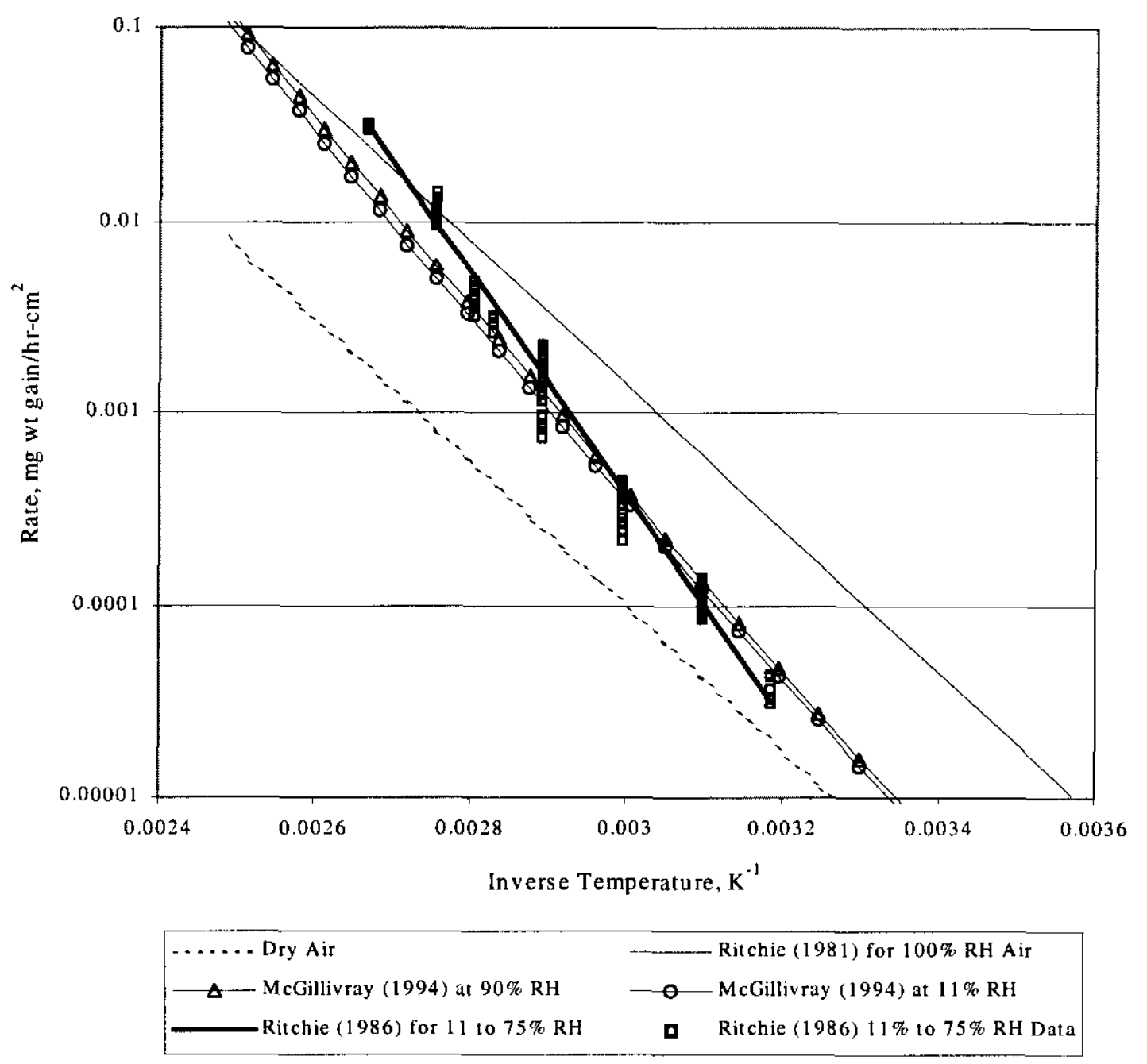

\subsection{N Fuel Reaction Rate Observations}

Oxidation rates in moist air were measured using selected samples from a damaged portion of an $\mathrm{N}$ Reactor fuel element that was stored in the K West Basin (Abrefah, et al., 1998b). The laboratory scale rate measurements are based on sample weight gain measured by a TGA system and exposed geometric surface area measured from the samples' cut surfaces. Sample masses ranged from $4 \mathrm{~g}$ to $8 \mathrm{~g}$ with surfaces visually free of cracks and surface voids. The measured rate data are based on linear portions of sample weight versus time plots at a given sample temperature. 
Five N Reactor fuel samples were tested in moist air, with a water vapor partial pressure of $12.3 \mathrm{kPa}$ (93 torr), at temperatures ranging from $198^{\circ} \mathrm{C}$ to $350^{\circ} \mathrm{C}$. These moist air conditions are no longer within the range of projected operating conditions for the SNF Project process. However, the $\mathrm{N}$ Reactor fuel moist air reaction rate measurements were bounded by predictions based on literature data at similar conditions.

\subsection{Conclusions}

The following conclusions concerning the moist air oxidation reaction are derived from the discussion above.

- The simplified stoichiometry described by Equation (5-4) provides a conservative description of the moist air (or moist oxygen) oxidation reaction for use in SNF Project design.

- The correlation of rate data in Reilly (1998) can be used to describe the literature data. Application of an enhancement factor of 3 to the rate correlation for process design yields an oxidation rate estimate that bounds most literature data for conditions of interest to SNF processes. An enhancement factor of 10 provides a conservative bound of the literature data the conditions of interest.

- The model presented in McGillivray (1994) also describes the moist air oxidation rate data and would be preferred for future applications to simplify prediction of oxidation rates when conditions transition between data correlations (See Section 7.0).

- Moist air data, specific to $\mathrm{N}$ Reactor fuel oxidation, at current proposed operating conditions are not available. However, the available higher temperature $\mathrm{N}$ Reactor fuel rate data are bounded by rate correlations derived from literature data.

\subsection{URANIUM-DRY AIR REACTION}

\subsection{Stoichiometry}

The oxidation of uranium by dry air is described by the following overall reaction stoichiometry,

$$
\mathrm{U}+\left(\frac{2+\mathrm{x}}{2}\right) \mathrm{O}_{2} \rightarrow \mathrm{UO}_{2+\mathrm{x}}
$$

where $\mathrm{x} \leq 0.25$ for temperatures up to $200^{\circ} \mathrm{C}$ in dry air. Dry air is defined to contain less than $15 \mathrm{ppm}$ water vapor. At temperatures greater than $275^{\circ} \mathrm{C}$, formation of $\mathrm{U}_{3} \mathrm{O}_{8}$ (or $\mathrm{UO}_{2.67}$ ) is observed (Trimble 1998a). As with the moist air reaction, conservative estimates of heat generation, generated particulate radionuclide composition, and oxygen depletion are produced by the simplified reaction stoichiometry shown by Equation (6-2) for use in SNF process design.

$$
\mathrm{U}+\mathrm{O}_{2} \rightarrow \mathrm{UO}_{2}-\Delta \mathrm{H}_{\mathrm{r}}^{0}=270 \mathrm{kcal} / \mathrm{gmol} \mathrm{U}
$$




\subsection{Literature Rate Data}

Dry air oxidation of clean uranium metal surfaces is initially non-linear with respect to time. The oxidation rate decreases as an oxide layer develops on the metal surface. The reaction rate becomes constant with respect to time (linear) when the oxide layer reaches an equilibrium thickness (spalling rate equals formation rate). This effect has been modeled by investigators using parabolic and paralinear kinetic expressions. Under the SNF process conditions, fuel has been oxidized by water prior to any events which could lead to oxidation by dry air. Therefore, only linear dry air oxidation rate data are used in the SNF process design (Trimble 1998a).

Reilly (1998) used the following kinetic expression for the mean oxidation rate of uranium in dry air at the conditions of interest for process design.

$$
\log \mathrm{K}=7.19-3732 / \mathrm{T}
$$

where: $\mathrm{K}=$ rate constant, $\mathrm{mg}$ wt gain $/ \mathrm{hr}-\mathrm{cm}^{2}$

$\mathrm{T}=$ temperature, $\mathrm{K}(\mathrm{T} \leq 692 \mathrm{~K})$

Equation (6-3) is based on a regression analysis of literature data initially developed by Trimble and Welsh (1998) and confirmed in Trimble (1998a). Duncan and Plys (1998) report that this correlation is also similar to a correlation of dry air data developed by McGillivray (1994). Experimental data indicate that the reaction rate is insensitive to the partial pressure of oxygen. Johnson and Clemmer (1996) observed that the rate is independent of oxygen concentration when the oxygen partial pressure is greater than $1 \mathrm{kPa}(7$ torr) and the temperature is less than $200^{\circ} \mathrm{C}$. 
Figure 6-1. Dry Air Oxidation of Uranium Metal $\left(<275^{\circ} \mathrm{C}\right)$

[Data from Trimble (1998a) and Trimble (2000)]

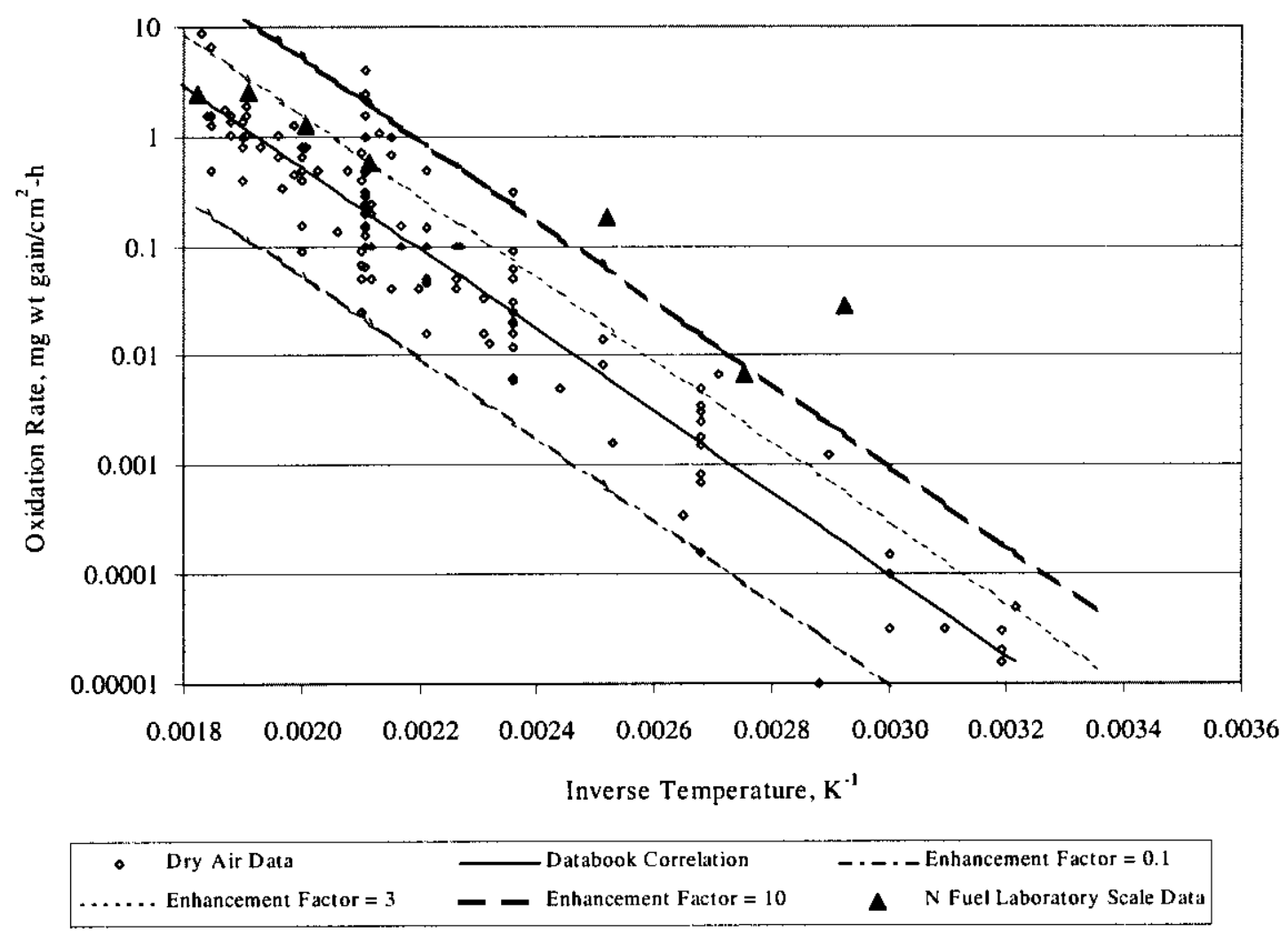

Equation (6-3) can be rearranged to the form shown as Equation (6-4), which simplifies comparison with other reaction rate correlations. Figure 6-1 compares the rate correlation shown by Equation (6-4) with literature data in the temperature range of interest from Trimble (1998a).

$$
\frac{\text { Oxidation rate }}{\mathrm{A}_{\mathrm{g}}}=10^{7.19} 10^{.3732 / \mathrm{T}} \approx\left(1.55 \times 10^{7}\right) 10^{-3732 / \mathrm{T}} \frac{\mathrm{mg} \mathrm{wt} \text { gain }}{\mathrm{hr}-\mathrm{cm}^{2}}
$$

Figure 6-1 compares the literature data observations to oxidation rates assuming enhancement factors of $0.1,3$ and 10. An enhancement factor of 10 approximates the upper limit of the $95 \%$ prediction interval for literature data calculated in Trimble (1998a). This prediction limit represents an estimate that provides $95 \%$ confidence that the next oxidation rate observation from a literature test will be below reaction rates predicted by Equation (6-4) using an enhancement factor of 10. An enhancement factor of 3 bounds most of the literature rate observations. Selected project design calculations also evaluate systems where the minimum reaction rate with oxygen is of interest (primarily for oxygen gettering by uranium metal during storage at the CSB). The enhancement factor of 0.1 indicated on Figure 6-1 approximates the lower limit of the $95 \%$ prediction interval for literature data calculated in Trimble (1998a). 


\subsection{N Reactor Fuel Reaction Rate Observations}

Oxidation rates in dry air were measured using selected samples from damaged portions of two $\mathrm{N}$ Reactor fuel elements that were stored in the K West Basin (Abrefah, et al. 1998a). The laboratory scale rate measurements are based on sample weight gain measured by a TGA system and exposed geometric surface area measured from the samples' cut surfaces. Sample masses ranged from $3 \mathrm{~g}$ to $8 \mathrm{~g}$ with surfaces visually free of cracks and surface voids. The measured rate data are an average of approximate linear portions of sample weight versus time plots at a given sample temperature (Trimble 1998a).

Seventeen N Reactor fuel samples were tested in dry air at temperatures ranging from $69^{\circ} \mathrm{C}$ to $400^{\circ} \mathrm{C}$. Seven of these tests, at temperatures ranging from $69^{\circ} \mathrm{C}$ to $275^{\circ} \mathrm{C}$, exhibited normal oxidation behavior, producing typical weight gain curves. The results from eight tests were atypical, potentially affected by experimental equipment problems. Two additional tests were performed using anomalous samples (Trimble 1998a). Reaction rate observations from the seven tests exhibiting typical weight gain curves are shown on Figure 6-1.

Single data points at $69^{\circ} \mathrm{C}$ and $124^{\circ} \mathrm{C}$ indicate increased dry air oxidation rates for $\mathrm{N}$ Reactor fuel in comparison to literature data. These limited data do not provide a sufficient basis to conclude $\mathrm{N}$ Reactor fuel oxidation rates are faster than the uranium metal used in tests by other investigators. However, the data do provide an uncertainty that some mechanism exists (for example, hydride inclusions or small pockets of high surface area uranium) that increase the effective $\mathrm{N}$ Reactor fuel reaction rate in dry air when evaluated on the basis of geometric reacting surface area. Project designs, defining safety systems, were developed using the literature data correlations to describe dry air reaction rates. A sensitivity analysis, specific to the SNF Project systems, was then developed to address the uncertainty identified by the $\mathrm{N}$ Reactor fuel dry air measurements.

Table 3-1 indicates that the dry air oxidation reaction influences the process design of CVD and CSB Handling and Storage. The uranium oxidation rate is used as a basis for evaluating oxygen gettering by fuel during storage at the CSB, precluding development of a combustible gas mixture in an MCO. Increased oxidation rates add conservatism to the oxygen gettering analysis. Therefore, an air ingress event during CVD processing represents the SNF Project analysis that could be impacted by increased dry air reaction rates.

Air ingress scenarios during CVD processing result from the potential for pipe breaks during different phases of the process cycle. The safety class system isolates the MCO, purges the gas space with helium, and produces a stagnant helium atmosphere in the MCO. For most operating phases, the moist air reaction rates are applicable to the air ingress event. The dry air reaction rate can be applicable to analysis of pipe break scenarios when the $\mathrm{MCO}$ is at vacuum near the end of the drying cycle.

Appendix 10.2 presents an analysis of the MCO thermal stability assuming the dry air reaction rate is based on the correlation of $\mathrm{N}$ Reactor fuel observations in Abrefah, et al. (1998a). This rate correlation is shown by Equation (6-5). 


$$
\frac{\text { Sensitivity oxidation rate }}{\mathrm{A}_{\mathrm{g}}}=\left(60 \frac{\mathrm{min}}{\mathrm{hr}}\right)(475) \mathrm{e}^{-\frac{10000}{\mathrm{RT}}} \frac{\mathrm{mg} \mathrm{wt} \text { gain }}{\mathrm{hr}-\mathrm{cm}^{2}}
$$

An enhancement factor of 12 is included in the dry air reaction rate sensitivity to address the potential for rapidly reacting inclusions (see Section 8.1 for summary discussion on inclusions).

Appendix 10.2.1 evaluates the potential adiabatic fuel temperature increase from a sudden ingress of dry air. The results indicate that, assuming no heat losses, a $6,000 \mathrm{~kg}$ batch of fuel would increase in temperature between $2^{\circ} \mathrm{C}$ and $15^{\circ} \mathrm{C}$ from the dry air reaction heat. The calculated adiabatic temperature rise can be higher if smaller uranium masses are assumed heated by the air reaction. However, complete reaction of the oxygen entering during a sudden air ingress is estimated to require at least $2.4 \mathrm{hr}$ based on the reaction rate predicted by Equation (6-5) and a conservative fuel temperature of $100^{\circ} \mathrm{C}$. Since significant heat losses would occur over this time period, it is concluded that the adiabatic temperature rise from a sudden air ingress can be based on the total fuel mass and, by itself, will not result in MCO thermal instability at the CVD.

Since the adiabatic fuel temperature rise is modest during an air ingress event, the MCO can only become thermally unstable if a continuing supply of reactant is available. Conceptually, the worst case configuration could be described by some type of double pipe break scenario sufficient to supply oxygen such that the air reaction rate limits heat generation in an MCO. Appendix 10.2.2 evaluates the thermal stability for this situation by comparing the change in reaction heat generation and system thermal conductance of the air and water vapor systems. As long as the ratio of the reaction heat to conductance for the air system is bounded by a similar ratio for the water vapor system, then the water vapor system thermal analysis bounds the air system thermal analysis.

Appendix 10.2.2 compares an air system, assuming the reaction rate is described by Equation (6-5), to a stable water vapor system thermal analysis presented in Duncan and Plys (1998). Peak fuel temperatures of $107^{\circ} \mathrm{C}$ are predicted in the water vapor analysis. The air ingress configuration is predicted to be bounded by the water vapor analysis for temperatures up to $407^{\circ} \mathrm{C}$. Therefore, it is concluded that an MCO would remain thermally stable during a flowing air scenario in an MCO even if the higher dry air reaction rate data from $\mathrm{N}$ Fuel TGA experiments were used to characterize $\mathrm{N}$ Fuel oxidation.

\subsection{Conclusions}

The following conclusions concerning the dry air oxidation reaction are derived from the discussion above.

- The simplified stoichiometry described by Equation (6-2) provides a conservative description of the dry air oxidation reaction for use in SNF Project design. 
- The correlation of rate data in Reilly (1998) is an appropriate description of the literature data. Application of an enhancement factor of 3 to the rate correlation for process design yields an oxidation rate estimate that bounds most literature data for conditions of interest to SNF processes. An enhancement factor of 10 provides a conservative bound of the literature data at the conditions of interest. An enhancement factor of 0.1 provides a conservative lower bound for literature data.

- $\mathrm{N}$ Reactor fuel oxidation measurements in dry air at two temperatures $\left(69^{\circ} \mathrm{C}\right.$ and $\left.124^{\circ} \mathrm{C}\right)$ indicate increased reaction rates, in comparison to literature data, are possible. Insufficient data are available to conclude $\mathrm{N}$ Fuel reaction rates are faster than the uranium metal used in tests by other investigators. However, a comparative analysis indicates that the MCO is thermally stable for conditions encountered by the SNF process systems, even if the dry air oxidation rates were conservatively applied in project analyses.

\subsection{BASIS FOR TRANSITIONS BETWEEN REACTIONS}

Figure 7-1 compares the uranium oxidation correlations described in Sections 4.0, 5.0, and 6.0. At comparable temperatures, the water oxidation rate (liquid water or vapor at the saturation pressure) is approximately a factor of 10 greater that the moist air oxidation rate at $100 \% \mathrm{RH}$, which is a factor of 10 greater that the dry air oxidation rate. Interpolations between correlations are used to define continuous estimates of oxidation rates.

Figure 7-1. Comparison of Uranium Oxidation Reaction Rate Correlations

(Enhancement Factor $=1)$

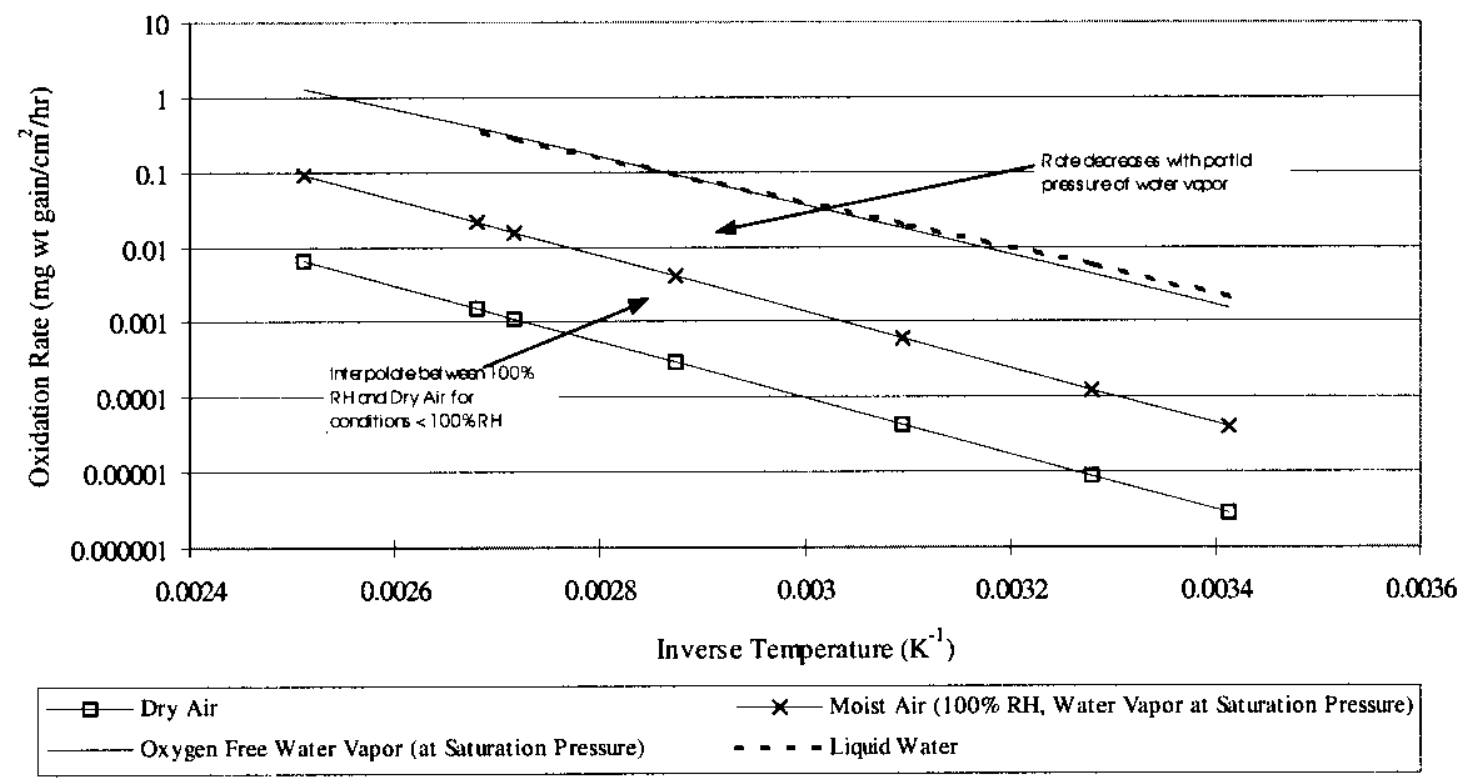


The definition of transitions between correlations are summarized in Figure 7-2. Figure 7-2 indicates the composition of gas mixtures containing three components: water vapor, oxygen, and an inert gas (inert with respect to the uranium oxidation reaction). The partial pressure of inert gas corresponding to a point within the regions labeled $\mathrm{A}$ through $\mathrm{E}$ is found by difference between the total pressure and sum of oxygen and water vapor partial pressure. Vertical lines represent gas mixtures of constant water vapor partial pressure, which is equivalent to constant RH. The composition plot presented is based on water vapor mixed with air at $50^{\circ} \mathrm{C}$, and a total system pressure of $1 \mathrm{~atm}$, for illustrative purposes. Expanded scales are included on Figure 7-2 to emphasize regions of transition between correlations.

Lines drawn within regions A through $\mathrm{E}$ of Figure 7-2 parallel to the sloped upper bound of regions $D$ and $E$ represent gas mixtures with inert gas added to the nitrogen in air. An example of this situation occurs when helium is added to an air/water vapor mixture. The absolute value of oxygen and water vapor pressure defining the sloped regions of Figure 7-2 varies with total system pressure. However, the basic shape of the composition relationships remains constant for all combinations of water vapor, oxygen, and inert gas. Variation of temperature changes the partial pressure of water representing $90 \% \mathrm{RH}$ and $100 \% \mathrm{RH}$.

The transition between oxygen free water vapor and air reactions rates shown on Figure 7-2 is based on data in Colmenares (1984), indicating the more rapid oxygen free reaction rate is observed when the oxygen partial pressure in water vapor is less than $0.001 \mathrm{kPa}(10 \mathrm{ppm}$ for systems at $1 \mathrm{~atm})$. A transition to the slower moist air reaction rate is observed as the oxygen partial pressure increases from $0.001 \mathrm{kPa}$ to $0.01 \mathrm{kPa}(10 \mathrm{ppm}$ to $100 \mathrm{ppm}$ for systems at $1 \mathrm{~atm})$. Increasing the oxygen partial pressure above $0.01 \mathrm{kPa}$ had no further impact on the observed reaction rates. McGillivray (1994) suggests that an oxygen concentration in excess of approximately $0.1 \%(1000 \mathrm{ppm})$ is required to achieve a full degree of reaction rate inhibition, but presents no supporting data.

Varying the partial pressure of water had no apparent effect on the oxygen partial pressure range for transition between oxygen free and moist air reaction rates. Based on the Colmenares (1984) data, uranium oxidation rates in systems containing an oxygen partial pressure less than $0.001 \mathrm{kPa}$ are estimated based on the oxygen free water vapor correlation indicated by Equation (4-5). This corresponds to the gas mixtures in region A of Figure 7-2. A linear interpolation between oxygen free water vapor and moist air oxidation rates at the same temperature and water vapor pressure is assumed when estimating the oxidation rate of systems containing between $0.001 \mathrm{kPa}$ and $0.01 \mathrm{kPa}$ oxygen. This corresponds to regions $\mathrm{B}$ and $\mathrm{C}$ of Figure 7-2.

The McGillivray prediction of reaction rates in moist air [Equation (5-13)] describes the transition between dry air and moist air. However, the model is not applicable for RHs greater than $90 \%$ (limited to region D of Figure 7-2). Therefore, a linear interpolation based on the difference in RHs is used to predict oxidation rates when the system $\mathrm{RH}$ is between $90 \%$ and $100 \%$. This interpolation allows prediction of oxidation rates for system compositions of region $\mathrm{E}$ on Figure 7-2. The oxidation rate calculations for conditions in each region defined on Figure 7-2 are summarized in Table 7-1. 
Figure 7-2. Uranium Oxidation Reaction Transitions

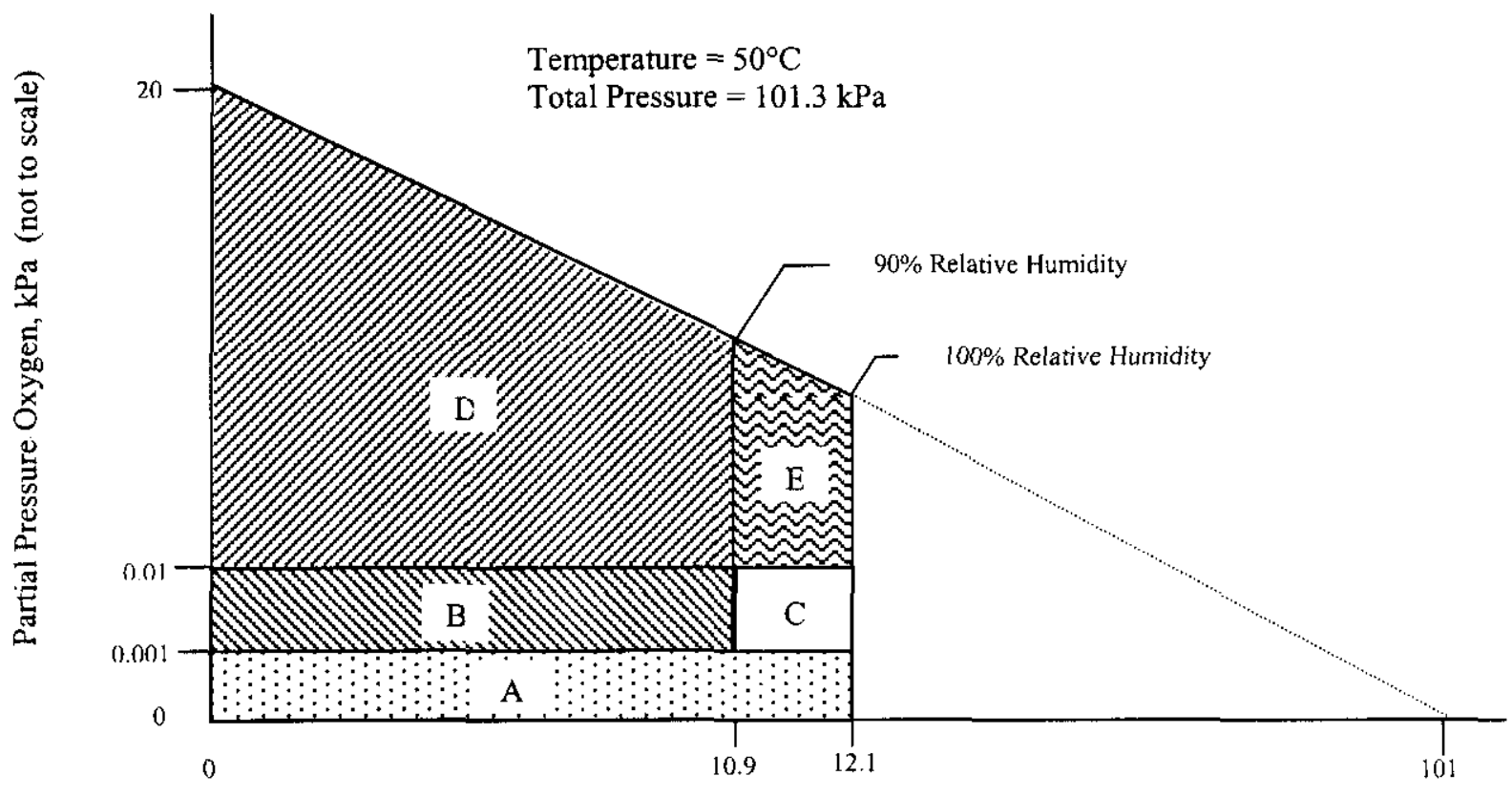

Partial Pressure Water Vapor, $\mathrm{kPa}$ (not to scale)

Interpolation Methods:

A - Use Moist Inert Correlation \{Equation (4-5)\}

$\mathrm{B}$ - Linear Interpolation between Moist Inert \{Equation (4-5)\} and Moist Air \{Equation (5-13)\} at constant water vapor partial pressure

C - Linear Interpolation between Moist Inert \{Equation (4-5)\} and Result from Region E at constant water vapor partial pressure

D - Use Moist Air Correlation \{Equation (5-13)\}

E - Linear Interpolation between Moist Air \{Equation (5-13)\} and 100\% RH Moist Air \{Equation (5-5)\} based on change in relative humidity

Examples of oxidation rate variation with conditions are shown on Figures 7-3, 7-4, and 7-5 using the correlations in Table 7-1. Figure 7-3 shows the variation of oxidation rate with an emphasis on changing water vapor partial pressure. Figure 7-4 shows the oxidation rate variation with an emphasis on changing oxygen partial pressure, and is similar to the oxidation rate variation presented in Colmenares (1984). Figure 7-3 and 7-4 are both based on a constant temperature of $50^{\circ} \mathrm{C}$. Figure 7-5 indicates the temperature variation of reaction rates in the moist air regime (partial pressure oxygen greater than $0.01 \mathrm{kPa}$ ). 
HNF-4165, Rev. 1

Table 7-1. Summary of Oxidation Rate Interpolation Calculations ${ }^{(1)}$

\begin{tabular}{|c|c|c|c|}
\hline $\begin{array}{c}\text { Figure 7-2 } \\
\text { Region }\end{array}$ & $\begin{array}{c}\text { Partial Pressure } \\
\text { Oxygen, } \mathrm{kPa}\end{array}$ & $\begin{array}{c}\text { Partial Pressure } \\
\text { Water Vapor, } \\
\mathrm{kPa}\end{array}$ & Oxidation Rate Calculation \\
\hline $\mathrm{A}$ & $\mathrm{P}_{\mathrm{O} 2} \leq 0.001$ & $0 \leq \mathrm{P}_{\mathrm{w}} \leq \mathrm{P}_{\mathrm{sat}}$ & Rate $=\mathrm{R}_{\mathrm{w}}$ \\
\hline $\mathrm{B}$ & $0.001<\mathrm{P}_{\mathrm{O} 2} \leq 0.01$ & $0 \leq \mathrm{P}_{\mathrm{w}} \leq \mathrm{P}_{90 \%}$ & Rate $=\mathrm{R}_{\mathrm{w}}-\frac{\left(\mathrm{P}_{\mathrm{O} 2}-0.001\right)}{(0.01-0.001)}\left(\mathrm{R}_{\mathrm{w}}-\mathrm{R}_{\mathrm{ma}}\right)$ \\
\hline $\mathrm{C}$ & $0.001<\mathrm{P}_{\mathrm{O} 2} \leq 0.01$ & $\mathrm{P}_{90 \%}<\mathrm{P}_{\mathrm{w}} \leq \mathrm{P}_{\mathrm{sat}}$ & Rate $=\mathrm{R}_{\mathrm{w}}-\frac{\left(\mathrm{P}_{\mathrm{O} 2}-0.001\right)}{(0.01-0.001)}\left(\mathrm{R}_{\mathrm{w}}-\mathrm{R}_{\mathrm{E}}\right)$ \\
\hline $\mathrm{D}$ & $\mathrm{P}_{\mathrm{O} 2}>0.01$ & $0 \leq \mathrm{P}_{\mathrm{w}} \leq \mathrm{P}_{90 \%}$ & $\mathrm{Rate}=\mathrm{R}_{\mathrm{ma}}$ \\
\hline $\mathrm{E}$ & $\mathrm{P}_{\mathrm{O} 2}>0.01$ & $\mathrm{P}_{90 \%}<\mathrm{P}_{\mathrm{w}} \leq \mathrm{P}_{\mathrm{sat}}$ & Rate $=\mathrm{R}_{\mathrm{E}}=\mathrm{R}_{\mathrm{ma}}+\frac{\left(\mathrm{P}_{\mathrm{w}} / \mathrm{P}_{\mathrm{sat}}-0.9\right)}{(1-0.9)}\left(\mathrm{R}_{\mathrm{sa}}-\mathrm{R}_{\mathrm{ma}}\right)$ \\
\hline
\end{tabular}

(1) Definition of Terms:

$\mathrm{P}_{\mathrm{O}_{2}}=$ Partial pressure of oxygen in system, $\mathrm{kPa}$

$P_{w}=$ Partial pressure of water vapor in system, $k \mathrm{~Pa}$

$\mathrm{P}_{\mathrm{sit}}=$ Saturation pressure of water vapor at system temperature, $\mathrm{kPa}$

$\mathrm{R}_{w}=$ Oxygen free water vapor oxidation rate from Equation (4-5)

$\mathrm{R}_{\mathrm{ma}}=$ Moist air oxidation rate for $0 \% \mathrm{RH}$ to $90 \% \mathrm{RH}$ from Equation $(5-13)$, which is equivalent to Equation (6-3) for dry air when $\mathrm{P}_{\mathrm{w}}=0$

$\mathrm{R}_{\mathrm{Sa}}=$ Moist air oxidation rate at saturation (100\% RH) from Equation (5-7)

$\mathrm{R}_{\mathrm{E}}=$ Reaction rate calculated for Region $\mathrm{E}$ 
HNF-4165, Rev. 1

Figure 7-3. Variation of Moist Air Oxidation Rate with Partial Pressure Water Vapor at $50^{\circ} \mathrm{C}$

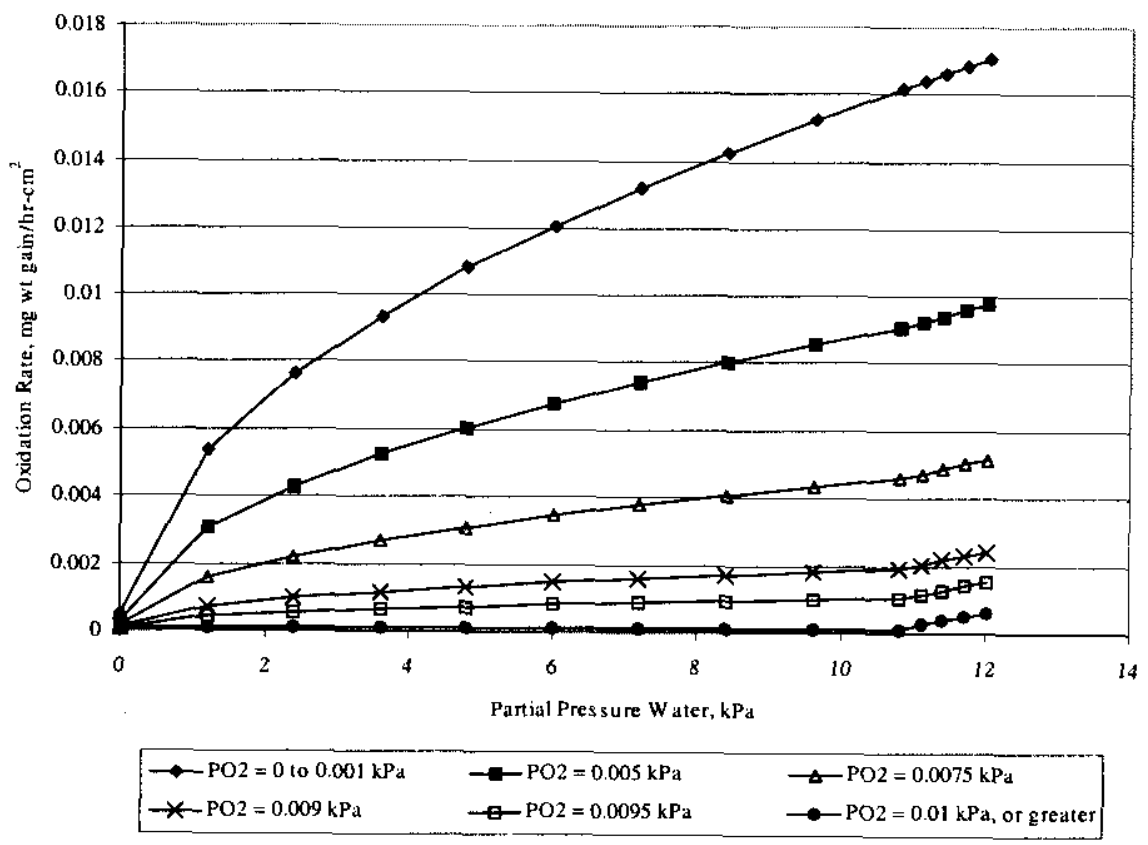

(a) Linear Scale

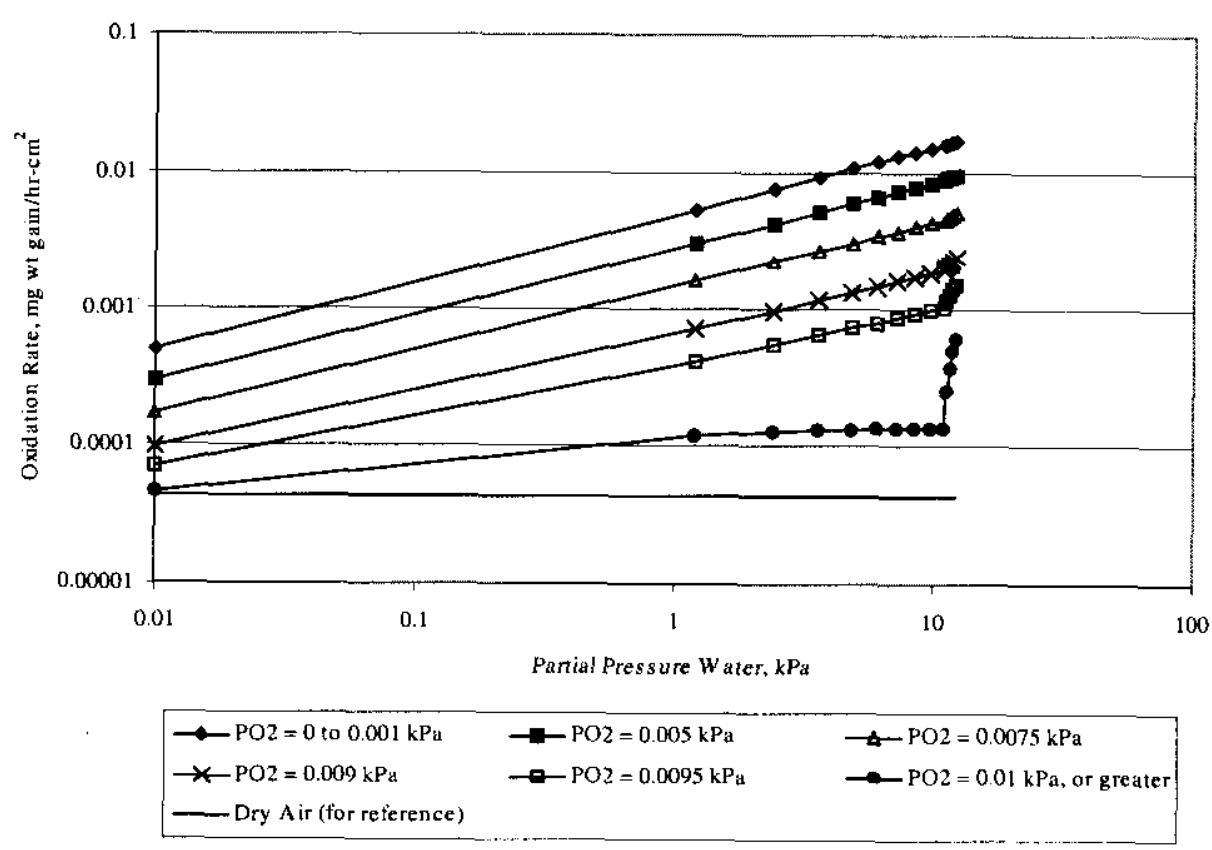

(b) Logarithmic Scale 
Figure 7-4. Variation of Moist Air Oxidation Rate with Partial Pressure Oxygen at 50 ${ }^{\circ} \mathrm{C}$

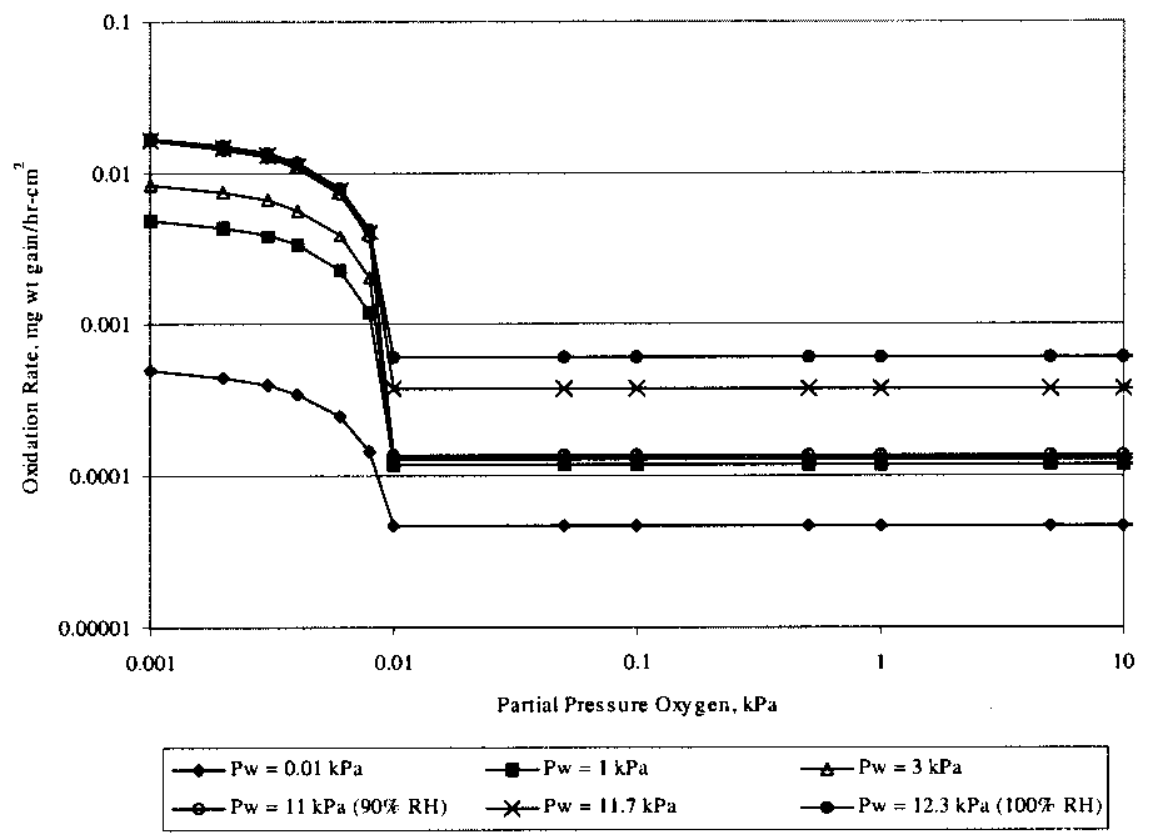

Figure 7-5. Variation of Moist Air Oxidation Rate with Temperature and Water Vapor Partial Pressure

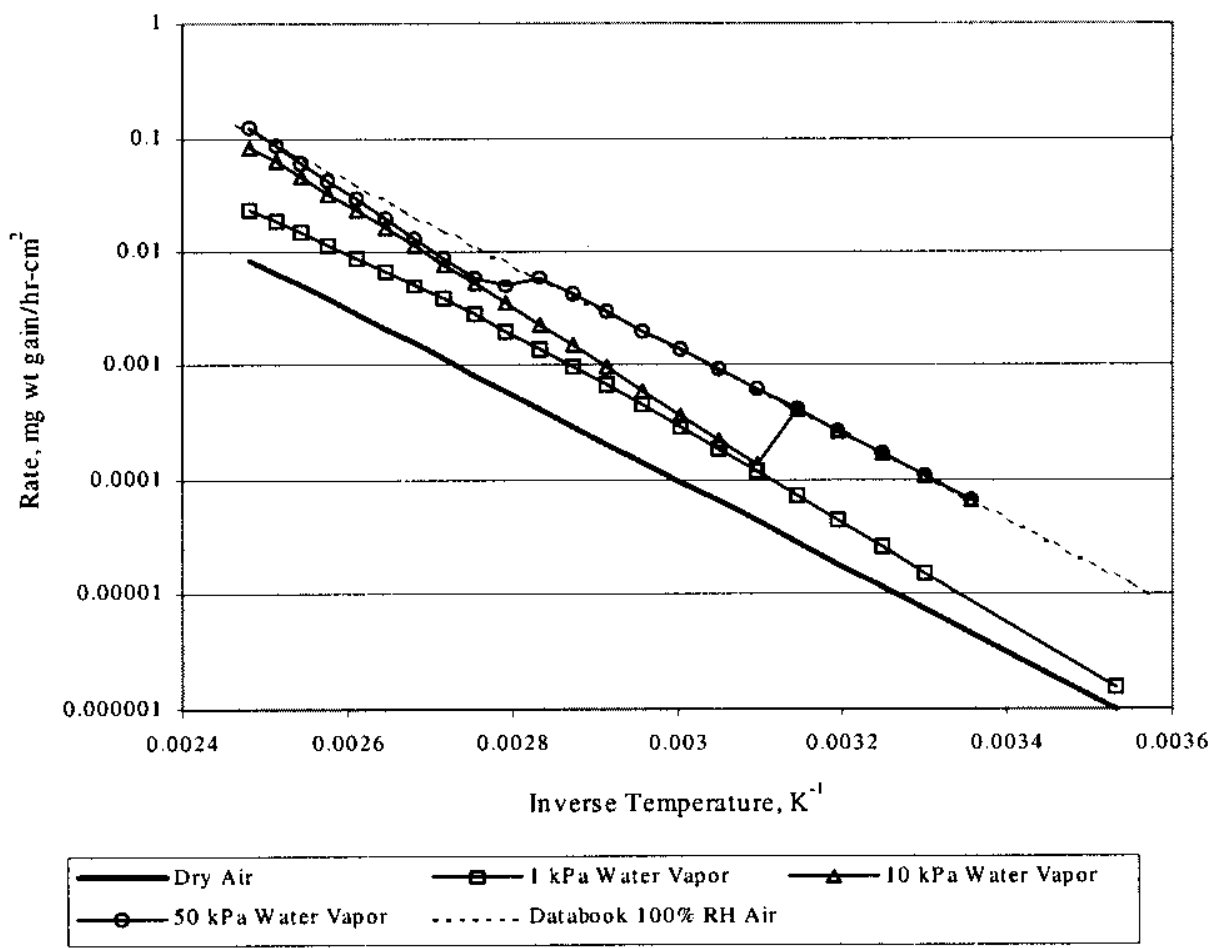




\subsection{OTHER REACTION RATE CONSIDERATIONS}

\subsection{Rapid Reacting Inclusions}

Figures 4-2, 4-8, 5-2, 5-3, and 6-1 indicate that applying an enhancement factor of 10 to reaction rates predicted by literature data correlations conservatively bound reported oxidation rates for uranium metal in the environments of interest to SNF Project designs. The enhancement factor of 10 also results in oxidation rate predictions that bound laboratory test observations on cut $\mathrm{N}$ Reactor fuel samples in water vapor, complete single elements reacting with water vapor at $50^{\circ} \mathrm{C}$, and complete single elements reacting in liquid water at $20^{\circ} \mathrm{C}$.

The reaction rate predictions from correlations are derived from measurements using materials of a relatively uniform uranium. Sporadic weight gain data were obtained during the dry air oxidation of cut $\mathrm{N}$ Reactor fuel samples. These inconsistent weight gains and losses during the oxidation tests were generally attributed to equipment problems. However, two test runs produced data containing rapid weight gains that could not be clearly attributed to the test equipment. The observed rapid weight gains have been hypothesized to be the result of rapidly oxidizing inclusions of uranium hydride, but no mechanism explaining the rapid reaction rates has been clearly demonstrated.

Rapid weight gains were not observed during oxidation of all $\mathrm{N}$ Reactor cut fuel samples. However, the cut samples originate from a non-homogeneous element where part of the fuel is near a corroded region. Therefore, the rapid weight gain observations in dry air create an uncertainty as to the conservatism of enhancement factors strictly based on literature data due to the potential for $\mathrm{N}$ Reactor fuel to generate hot spots from some type of rapidly reacting inclusion.

Duncan and Plys (1998) evaluate the rapid weight gain observations, describing the basis for estimating an enhancement factor of 300 for the rapidly reacting inclusions, as compared to uranium metal, in dry air. The dry air rate data evaluation concludes that the rapid inclusion reactions occur at the equivalent to an overall average of $4 \%$ of the geometric surface area. Duncan and Plys (1998) also present an analysis of hot spots that could occur if multiple inclusions were near one another. A probabilistic analysis is also presented in Duncan and Plys (1998) estimating the likelihood that more concentrated regions of uranium hydride could be observed on a reacting surface. Duncan and Plys (1998) increase the overall average composite enhancement factor from 10 to 22 to address the uncertainty caused by rapid reactions observed during dry air $\mathrm{N}$ Reactor fuel reaction tests.

The enhancement factor of 22 is directly applicable to evaluations in dry air. Similar effects were not observed in the water vapor tests. However, implementation of the higher enhancement factor results in reaction rate predictions that bound reaction rate observations derived from full element drying in water vapor at $75^{\circ} \mathrm{C}$. This results in process design basis oxidation rate predictions that bound all identified reaction rate data that can be inferred from laboratory and plant scale observations (two dry air reaction rate observations are an exception to this statement, but are treated in Section 6.3). 
HNF-4165, Rev. 1

\subsection{Fuel Crumbling}

Some cut $\mathrm{N}$ Reactor fuel samples used in laboratory scale reaction rate tests were observed to fragment at some point during the test run. This effect could create a potential for increasing reaction rates in an MCO. Trimble (2000) summarizes the fragmentation observations from dry air, moist air, and water vapor TGA testing. The observations indicate that the potential for fuel fragmentation is dependent on oxidation temperature. No sample fragmentation is observed in oxidation tests performed below $140^{\circ} \mathrm{C}$. Plys and Duncan (2000) evaluates the $\mathrm{N}$ Reactor reaction rate data in moist helium (water vapor) from TGA tests and concludes that the enhancement factor increase attributed to inclusions in Section 8.1 conservatively bounds the potential effects of fuel crumbling.

This conclusion is further supported by observations from single element drying tests. Fuel element photographs are available to support before and after condition descriptions of fuel elements dried in the furnace system. Most drying test runs were performed using elements in poor to severely damaged condition and would be regarded as scrap during plant operations. Drying was performed at temperatures up to $400^{\circ} \mathrm{C}$. While axial cracks in elements were reported to open further during the drying process, no significant fuel fragmentation is reported or indicated by the post-drying photographs (Lawrence 1998).

\subsection{REFERENCES}

Abrefah, J., H. C. Buchanan, W. M. Gerry, W. J. Gray, and S. C. Marschman, 1998a, Dry Air Oxidation Kinetics of $K$-Basin Spent Nuclear Fuel, PNNL-11786, Pacific Northwest National Laboratory, Richland, Washington.

Abrefah, J., H. C. Buchanan, and S. C. Marschman, 1998b, Oxidation Rate of K-Basin Spent Nuclear Fuel in Moist Air, PNNL-11844, Pacific Northwest National Laboratory, Richland, Washington.

Baker, M. McD., L. N. Ness, and S. Orman, 1966, Uranium + Water Reaction, Transactions of the Faraday Society, Vol. 62, No. 525, Part 9, pp. 2513 - 2530.

Briggs, W. A., and N. R. Roe, 1997, Transmittal of the Monitoring Gas in 105-K West Basin Report, Internal Memo to R. P. Omberg, dated May 2, 1997, Duke Engineering and Serivces Hanford, Richland, Washington (Attached in Appendix 10.1).

Colmenares, C. A., 1984, Oxidation Mechanisms and Catalytic Properties of the Actinides, Prog. Solid St. Chem., Vol. 15, pp 257-364.

Cooper, T. D., 1998, Spent Nuclear Fuel Project Recommended Reaction Rate Constants for Corrosion of N-Reactor Fuel, HNF-SD-SNF-TI-020, Rev. 2, Duke Engineering and Services Hanford, Richland, Washington.

Dean, J. A., 1979, Lange's Handbook of Chemistry, $12^{\text {th }}$ Edition, McGraw-Hill Book Company, New York, New York. 
DOE, 1998, Quality Assurance Requirements and Description, DOE/RW-0333P, Rev. 8, Office of Civilian Radioactive Waste Management, U.S. Department of Energy, Washington, D.C.

Duncan, D. R., and M. G. Plys, 1998, Simulation of Normal and Off-Normal Multi-Canister Overpack Behavior, HNF-2256, Rev. 2, Duke Engineering and Services Hanford, Richland, Washington.

Flament, T. A., J. Abrefah, G. S. Klinger, B. M. Oliver, S. C. Marschman, P. J. MacFarlan, and G. A. Ritter, 1998, Drying Results of K-Basin Fuel Element 3128W (Run 2), PNNL-11818, Pacific Northwest National Laboratory, Richland, Washington.

Johnson, A. B., Jr., and S. P. Burke, 1995, K Basin Corrosion Program Report, WHC-EP-0877, Westinghouse Hanford Company, Richland, Washington.

Klinger, G. S., B. M. Oliver, J. Abrefah, S. C. Marschman, P. J. MacFarlan, and G. A. Ritter, 1998a, Drying Results of K-Basin Fuel Element 5744U (Run 4), PNNL-11821, Pacific Northwest National Laboratory, Richland, Washington.

Klinger, G. S., B. M. Oliver, J. Abrefah, S. C. Marschman, P. J. MacFarlan, and G. A. Ritter, 1998b, Drying Results of K-Basin Fuel Element 2660M (Run 7), PNNL-11897, Pacific Northwest National Laboratory, Richland, Washington.

Lawrence, L. A., 1998, Drying Damaged K West Fuel Elements (Summary of Whole Element Furnace Runs 1 through 8), HNF-3377, Rev. 0, Duke Engineering and Services Hanford, Richland, Washington.

Marschman, S. C., J. Abrefah, G. S. Klinger, B. M. Oliver, P. J. MacFarlan, and G. A. Ritter, 1998a, Drying Results of K-Basin Fuel Element 1990 (Run 1), PNNL-11817, Pacific Northwest National Laboratory, Richland, Washington.

Marschman, S. C., J. Abrefah, G. S. Klinger, B. M. Oliver, P. J. MacFarlan, and G. A. Ritter, 1998b, Drying Results of K-Basin Fuel Element 6603M (Run 5), PNNL-11841, Pacific Northwest National Laboratory, Richland, Washington.

McGillivray, G. W., D. A. Geeson, and R. C. Greenwood, 1994, Studies of the Kinetics and Mechanism of the Oxidation of Uranium by Dry and Moist Air - A Model for Determining the Oxidation Rate over a Wide Range of Temperatures and Water Vapour Pressures, Journal of Nuclear Materials, No. 208, pp. $81-97$.

Olander, D. R., 1976, Fundamental Aspects of Nuclear Reactor Fuel Elements, TID-26711-P1, U. S. Department of Energy, Washington, D. C.

Oliver, B. M., G. S. Klinger, J. Abrefah, S. C. Marschman, P. J. MacFarlan, and G. A. Ritter, 1998a, Drying Results of K-Basin Fuel Element 0309M (Run 3), PNNL-11820, Pacific Northwest National Laboratory, Richland, Washington. 
HNF-4165, Rev. 1

Oliver, B. M., G. S. Klinger, J. Abrefah, S. C. Marschman, P. J. MacFarlan, and G. A. Ritter, 1998b, Drying Results of K-Basin Fuel Element 1164M (Run 6), PNNL-11896, Pacific Northwest National Laboratory, Richland, Washington.

Oliver, B. M., G. S. Klinger, J. Abrefah, S. C. Marschman, P. J. MacFarlan, and G. A. Ritter, 1998c, Drying Results of K-Basin Fuel Element 6513U (Run 8), PNNL-11969, Pacific Northwest National Laboratory, Richland, Washington.

Pajunen, A. L., 1998, Design Basis for Hydrogen Generation in the Cold Vacuum Drying Facility, HNF-2458, Rev. 0A, COGEMA Engineering Corporation, Richland, Washington.

Piepho, M. G., 2000, Thermal Analysis of Cold Vacuum Drying of Spent Nuclear Fuel, HNF-SD-SNF-CN-023, Rev. 2, Fluor Federal Services, Richland, Washington.

Plys, M. G., and D. R. Duncan, 2000, Fuel Fracture (Crumbling) Safety Impacts (OCRWM), SNF-5488, Rev. 1, Fluor Hanford, Richland, Washington.

Praga, A. N., 1998, MCO Loading and Cask Loadout Technical Manual, HNF-2169, Rev. 0, Duke Engineering and Services Hanford, Richland, Washington.

Reilly, M. A., 1998, Spent Nuclear Fuel Project Technical Databook, HNF-SD-SNF-TI-015, Rev. 6, Duke Engineering and Services Hanford, Richland, Washington.

Ritchie, A. G., 1981, A Review of the Rates of Reaction of Uranium with Oxygen and Water Vapour at Temperatures up to $300^{\circ} \mathrm{C}$, Journal of Nuclear Materials, 102 (1981), 170-182.

Ritchie, A. G., R. C. Greenwood, and S. J. Randles, 1986, The Kinetics of the Uranium-OxygenWater Vapour Reaction between 40 and $100^{\circ} \mathrm{C}$, Journal of Nuclear Materials, 139 (1986), 121-136.

Ritter, G. A., S. C. Marschman, P. J. MacFarlan, and D. A. King, 1998, System Design Description for the Whole Element Furnace Testing System, PNNL-1 1807, Pacific Northwest National Laboratory, Richland, Washington.

Smith, R. J., 2000, Safety Analysis Report for Packaging (Onsite) Multi-Canister Overpack Cask, HNF-SD-TP-SARP-017, Rev. 2, Waste Management Technical Services, Richland, Washington.

Thurgood, M. J., 1997, Bounding Temperatures and Gas Generation Rates During CSB Staging, HNF-SD-SNF-CN-005, Rev. 0, John Marvin, Inc., Richland, Washington.

Trimble, D. J., 1998a, Reaction Rate Constant for Dry Air Oxidation of K Basin Fuel, HNF-SD-SNF-CN-019, Rev. 0, Duke Engineering and Services Hanford, Richland, Washington.

Trimble, D. J., 1998b, Reaction Rate Constant for Uranium in Water and Water Vapor, HNF-2853, Rev. 0, Duke Engineering and Services Hanford, Richland, Washington. 


\section{HNF-4165, Rev. 1}

Trimble, D. J., 2000, Oxidation Kinetics of K-Basin Fuel, HNF-4206, Rev. 1, Duke Engineering and Services Hanford, Richland, Washington.

Trimble, D. J., and T. L. Welsh, 1998, Statistical Analysis of Oxidation Rates for K Basin Fuel in Dry Air, HNF-SD-SNF-CN-035, Rev. 1, Duke Engineering and Services Hanford, Richland, Washington. 
HNF-4165, Rev. 1

\subsection{APPENDICES}

\subsection{N Reactor Fuel Characterization Shipping Observations}

The attached letter report (Briggs and Roe, 1997) summarize N Reactor Fuel shipping observations obtained during the transfer of fuel samples to the laboratory. The following table of reaction rates, derived from the observations, is taken from Praga (1998).

Table 10-1. Oxidation Rate Estimates from Element Shipping Observations

\begin{tabular}{|c|c|c|c|c|c|c|c|}
\hline \multirow{2}{*}{ SFEC } & \multirow{2}{*}{ Gas Rate } & \multicolumn{2}{|c|}{$\begin{array}{l}\text { Basin Water } \\
\text { Temperature }\end{array}$} & \multirow{2}{*}{$\begin{array}{l}\text { Hydrogen } \\
\text { Generation } \\
\text { (gmol/hr) }^{(1)}\end{array}$} & \multicolumn{2}{|c|}{ Picture/Estimated Reaction Area } & \multirow{2}{*}{$\begin{array}{c}\text { Apparent } \\
\text { Weight Gain, } \\
\left(\mathrm{mg} / \mathrm{hr}-\mathrm{cm}^{2}\right)^{(3)}\end{array}$} \\
\hline & & ${ }^{\circ} \mathrm{F}$ & ${ }^{\circ} \mathrm{C}$ & & Reference Figure Number & Area ${ }^{(2)}$ & \\
\hline 9-94-18 & $10 \mathrm{ml} / 96 \mathrm{hr}$ & 69 & 20.6 & $6.2 \times 10^{-6}$ & 4 & $1 / 2$ of $1 / 2$ inch $\Rightarrow 12.3 \mathrm{~cm}^{2}$ & $8.0 \times 10^{-3}$ \\
\hline $12-96-1$ & $30 \mathrm{ml} / 96 \mathrm{hr}$ & 69 & 20.6 & $1.9 \times 10^{-5}$ & 6 & 5 inch $\Rightarrow 245 \mathrm{~cm}^{2}$ & $1.2 \times 10^{-3}$ \\
\hline $12-96-2$ & $5 \mathrm{ml} / 116 \mathrm{hr}$ & 71 & 21.7 & $2.6 \times 10^{-6}$ & 12 & No Estimate & - \\
\hline $12-96-9$ & $60 \mathrm{ml} / 116 \mathrm{hr}$ & 71 & 21.7 & $3.1 \times 10^{-5}$ & 14 & 10 inch $\Rightarrow 490 \mathrm{~cm}^{2}$ & $1.0 \times 10^{-3}$ \\
\hline $12-96-3$ & $40 \mathrm{ml} / 96 \mathrm{hr}$ & 69 & 20.6 & $2.5 \times 10^{5}$ & 5 & No Estimate & - \\
\hline $12-96-5$ & $20 \mathrm{ml} / 116 \mathrm{hr}$ & 71 & 21.7 & $1.0 \times 10^{-5}$ & 11 & $1 / 2$ of $1 / 2$ inch $\Rightarrow 12.3 \mathrm{~cm}^{2}$ & $1.3 \times 10^{-2}$ \\
\hline $12-96-7$ & $5 \mathrm{ml} / 116 \mathrm{hr}$ & 71 & 21.7 & $2.6 \times 10^{-6}$ & 13 & No Estimate & - \\
\hline
\end{tabular}

Notes:

(1) $\mathrm{H}_{2}$ generation based on pressure of $15 \mathrm{ft} \mathrm{H}_{2} \mathrm{O}$, gage and basin water temperature such that $\dot{\mathrm{n}}=\frac{(\mathrm{ml} / \mathrm{hr})(1.44 \mathrm{~atm})}{(82.06) \mathrm{T}}$

(2) Areas based on dimensions of an outer element outside surface area. Area $/ \mathrm{L}=\pi \mathrm{D}=\pi(6.15 \mathrm{~cm})=19.3 \mathrm{~cm} / \mathrm{cm}$.

(3) $\mathrm{H}_{2}$ generation converted to $\mathrm{mg}$ wt gain/hr by stoichiometry $\mathrm{U}+2 \mathrm{H}_{2} \mathrm{O} \rightarrow \mathrm{UO}_{2}+2 \mathrm{H}_{2}$. 
DE\&S Hanford, Inc.

A Duke Engineering \& Services Company

From: $\quad$ Spent Nuclear Fuel Evaluations

Phone: $\quad 376-9408$ HO-4O/376-5564 HO-4C

Date: $\quad$ May 2, 1997

Subject: TRANSMITTAL OF THE MONITORING E:S IN 105-K WEST BASIN REPORT

To: R. P. Omberg HO-40

\section{cc: Distribution}

Attached is the highlight repor: covering observations made during the 105-K West Basin gas moniteririg activities conducted as part of the $K$ West Basin Characterization Fhase II. This narrative describes observations made during the gas monitoring phase of the sludge and fuel containers pric: to the four shipments. from $K$ Basins to the 300 Area for ar $31 y$ sis. The significance of this report was that gas generation ias observed during preparations for shipments three and four witich. has not been observed in any previous $K$ East or $K$ West ship-ents.

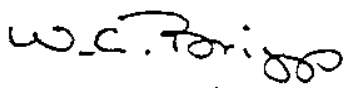

W. A. Briggs

jmn

Attachment

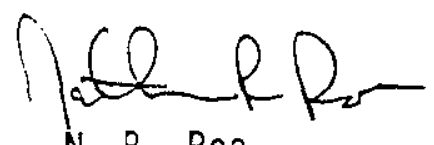

N. R. Roe 
HNF-4165, Rev. 1

\section{ATTACHMERT}

Monitoring Gas in 10E-K Mest Basin

Consisting of $2 \xi p a g e s$,

Including cove: $p a g e$ 
HNF-4165, Rev. 1

\title{
MONITORING GAS IN 10E-K HEST BASIN
}

\author{
W. A. Briggs ane N. R. Roe
}

May $19:^{-}$

Duke Engineering \& Serices Finford, Inc. Spent Nuclear Fuel E, ミlustichs (2T650) 


\section{CONTENTS}

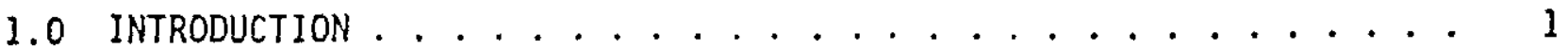

2.0 DESCRIPTION OF TEST, TEST METHOD, AND TEST EQIJPMENT . . . . . . 1

3.0 TEST RESULTS . . . . . . . . . . . . . . . 2

3.1 FIRST SHIPMENT (FIRST MONITORING EVOLUTION) . . .... 5

3.2 SECOND SHIPMENT (SECOND MONITORIFI EVOLUTION) . . .... 5

3.3 THIRD SHIPMENT (THIRD MONITORING EVOLUTION) ....... 5

3.4 FOURTH SHIPMENT (FOURTH MONITORILI EVOLLTION) $\ldots \ldots . \ldots 6$

3.5 RELATED OR SIMILAR TESTS .............. 6

3.6 PHOTOGRAPHIC DOCUMENTATION . . . . . . . . . . . 6

4.0 CONCLUSIONS AND RECOMMENDATIONS .............. 6

4.1 GAS GENERATION RATES ................. 7

5.0 REFERENCES .......................... 7 


\section{LIST OF FIGLRES}

1. In-Basin Gas Monitors on Single Fuel Eienent Canisters

Prior to Shipment ................ 9

2. Gas Monitor Number 1 (Single Fuel Eler:nt

Canisters 9-94-18 and 12-96-3) ............. 10

3. Gas Monitor Number 3 (Single Fuel Ele-ent Canisters 12-96-1) . . . . 11

4. Outer Element Number $6(6743 M) \ldots 12$

5. Outer Element Number $6(6743 U) \ldots \ldots 13$

6. Outer Element Number $4(5744 U) \ldots . . . \ldots 14$

7. In-Basin Gas Monitors on Single Fuel Ble-ent Canisters

Prior to Shipment Number 4............... 15

8. Gas Monitor Number 1 (Single Fuel Ele-en:

Canisters 12-96-5 AND 12-96-2) . . . . . . . . . . . 16

9. Gas Monitor Number 2 (Single Fuel Ele-2n:

Canisters 12-95-7) . . . . . . . . . . . . . 17

10. Gas Monitor Number 3 (Single Fuel Ele-ar: Caristers 12-95-9) . . . 18

11. Outer Element Number $3(2667 \mathrm{U}) \ldots . . \ldots 19$

12. Outer Element Number $2(0161 \mathrm{M}) \ldots . . . . . . .20$

13. Outer Element Number 1 (1164U) . . . . . . . . . . . . 21

14. Outer Element Number $6(2660 \mathrm{M}) \ldots \ldots 22$

\section{LIST OF THELES}

1. K West Gas Monitoring Data and PEsuT:: . . . . . . . . . . 3 


\title{
MONITORING GAS IN 105-K WEST BASIN
}

\subsection{INTRODUCTION}

\begin{abstract}
Spent nuclear fuel (SNF) and fuel canister sludge was sampled from sealed canisters in the 105-K West Basin (KW), as part of the Spent Nuclear Fuel Evaluations (SNFE) Phase II Characterization. The samples were stored in $\mathrm{KW}$ for short periods of time, then transported to the Postirradiation Testing Laboratories (PITL) at the 327 Building facility (300 Area). Once at the PITL, the samples were removed from the Chem Nuc Cask, and the fuel analyzed. The sludge was transported from the PITL to the Analytical Chemistry Laboratory (ACL) at the 325 Building facility (300 Area) for final characterization.
\end{abstract}

The Department of Transportation (DOT), and the regulations associated with the Chem Nuc Cask (Reference 1), required preliminary data concerning gas generation rates prior to accepting/allowing shipments. The SNFE was responsible for sampling, recording, and documenting such information prior to loading the Chem Nuc Cask at the KW facility. In-basin gas monitoring was performed for all containers prior to shipment. Complete transport of samples from $\mathrm{KW}$ to PITL required four shipments (four monitoring evolutions) from December 23, 1996 to March 3, 1997.

\subsection{DESCRIPTION OF TEST, TEST METHOD, AND TEST EQUIPMENT}

The total volume of gas (assumed to be hydrogen) released from a particular sample container was collected over a known period of time. The gas was monitored underwater, by placing an inverted (flooded) $1000 \mathrm{ml}$ graduated cylinder on each of six sample containers (Figure 1). Each inverted cylinder was attached to a stainless steel shell. The outer shell provided structure and stability for the Gas Sampler (Reference 2). The Gas Samplers (Monitors) were installed so that the top of the graduated cylinder. was approximately 34 in. above the top of the sample containers, or 64 in. above the basin floor (Reference 2). The pressure exerted on gas collected near the top of a given cylinder was approximately 19.5 psi, absolute.

Monitoring occurred at the staging area located in the South West corner of KW. The sample containers, both Sludge Sample Containers (SSC) (Reference 3) and Single Fuel Element Canisters (SFEC) (Reference 4), were constructed of 304 stainless steel tubes 6 in. and 4 in. diameters, respectively. Both types of containers were approximately $30 \mathrm{in}$. in length, excluding the attached bails. Each type of container was designed with venting capabilities. During sample staging, the vent valves or ports allowed any gas produced inside the container to be released and captured in the monitoring device. It was assumed the inverted graduated cylinders were completely successful in capturing all gasses released from the containers. 
The theory for gas detection was to quantify the amount of gas released from a container by measuring the water displaced in each graduated cylinder. A time lapse VCR was used to record the gas generation in the cylinders for at least 4 days, but not to exceed 12 days. The basis for the monitoring time interval was determined by evaluating previous data from the PITL.

For shipping calculations, each volume of gas observed in the cylinders was assigned an uncertainty of $100 \mathrm{ml}$. This value was determined because each graduation on a particular monitoring device was not clearly visible when all three monitors (one monitor contains two inverted graduated cylinders) were viewed by the underwater camera simultaneously. It was necessary to record six containers during one monitoring evolution to facilitate the Chem Nuc Cask loading (six containers per shipment).

Gas was collected from SFECs or SSCs containing fuel or sludge sampled from 14 different fuel storage canisters (Table 1). These canisters were selected as sample candidates upon completion of a Data Quality Objective (DQO) process. The sample candidate canisters were documented in letters from B. J. Makenas to R. P. Omberg (Reference 5) and from R. B. Baker to R. P. Omberg (Reference 6 ), for fuel and sludge respectively.

One of the significant "test parameters" apparent during gas monitoring for Phase II Characterization was the progressively increasing basin water temperature. According to basin protocol, the water temperature normally ranges from 45 to $50^{\circ} \mathrm{F}$. Due to $\mathrm{KW}$ Basin chiller failure, the water temperature during the second, third, and fourth gas monitoring evolutions rose a maximum of $22^{\circ} \mathrm{F}$. Each monitoring evolution, and the corresponding water temperatures, will be identified and examined in the following section, Test Results.

\subsection{TEST RESULTS}

The following data (organized according to shipment) was collected over a 3 month period of time. Although final gas volume readings were recorded in the Phase II Logbook (Reference 7) upon monitoring completion (cask loading) only, other data was recorded daily. Video recorded data (Reference 8 ), Test Engineer observations, and water temperatures (Reference 7 ) were recorded on a day-to-day basis.

Due to the aforementioned uncertainty involved, $100 \mathrm{ml}$ of gas generation was assumed for each container for shipping purposes. The $100 \mathrm{ml}$ assumption was used as a bounding value, illustrating compliance with applicable fuel or sludge shipment requirements. Although recorded data included gas volumes for every container, most are calculated values (uncertainties) and not "real" quantities. "Real" quantities are those volumes of gas observed in the field. It was those values which provided the most significant scientific data. Only the containers which produced "real" quantities of gas were examined, in detail, for this report. 
Table 1. K West Gas Monitoring Data and Results.

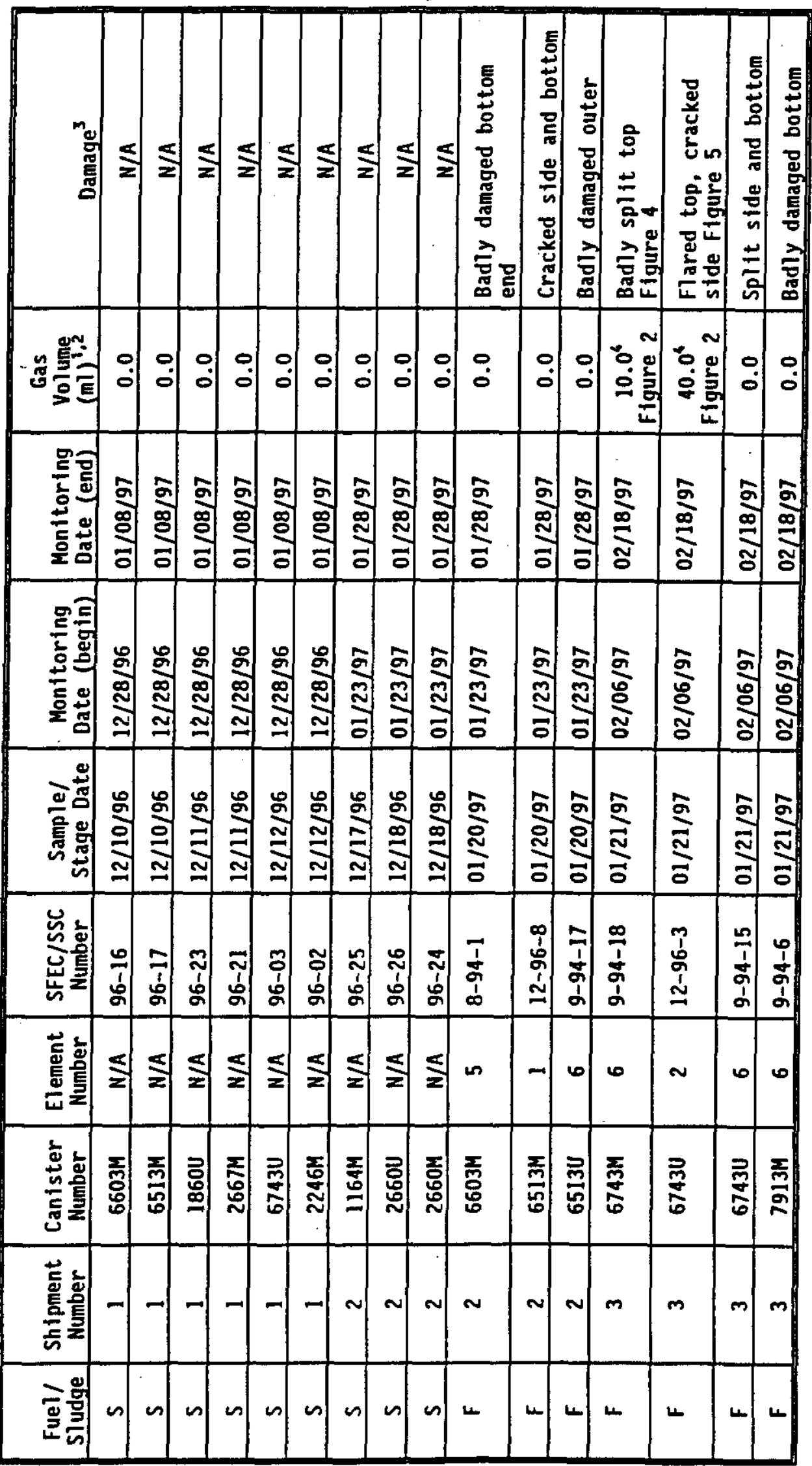


Table 1. K West Gas Monitoring Data and Results.

(Continued)

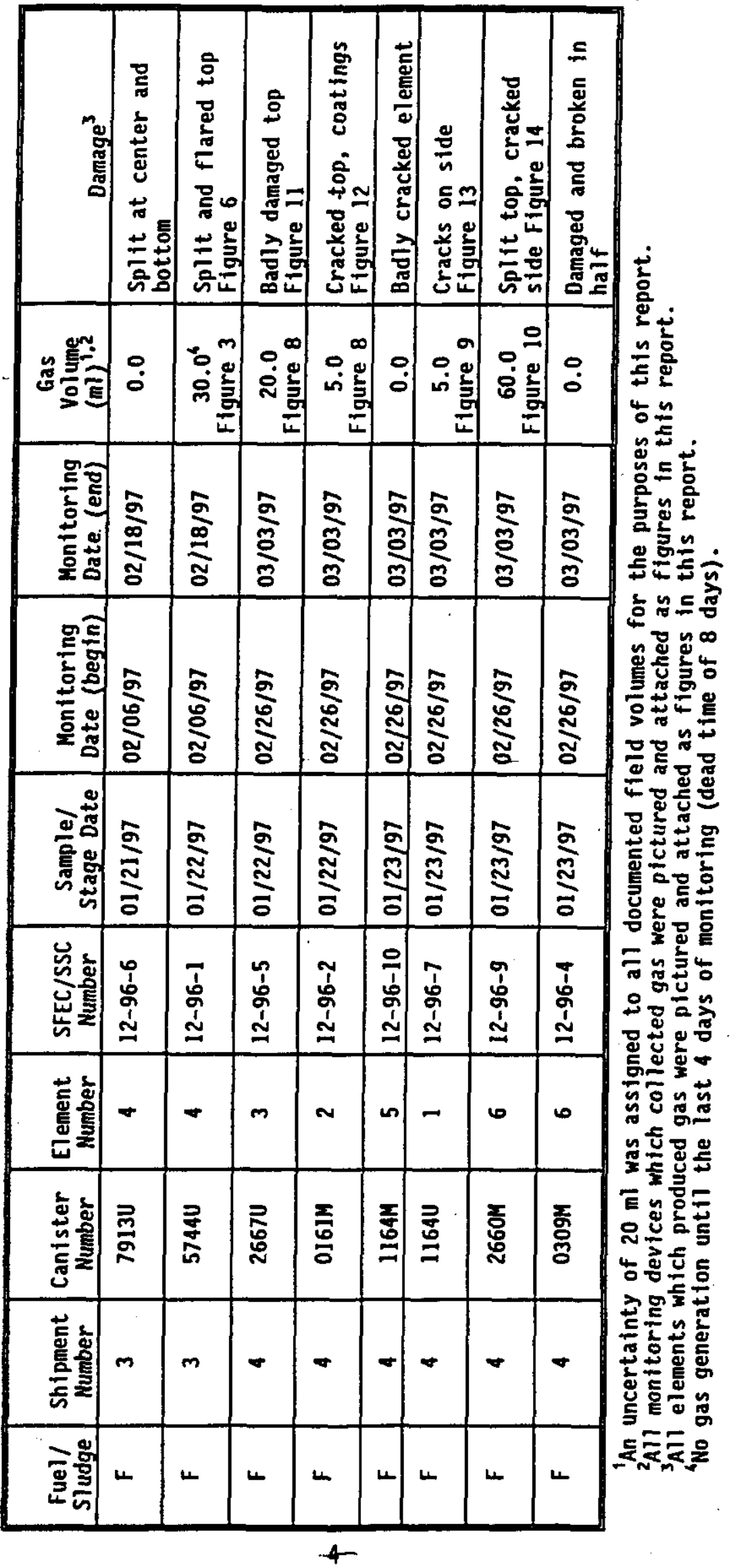


The following data identifies fuel storage canisters by lid serial numbers. Each canister consists of two barrels, one which is marked with the serial number and one which is not. A sample was identified and extracted specific to a barrel not the entire canister. The barrels from which samples were taken were designated as either "marked (M)" or "unmarked (U)". For example, a sample taken from the unmarked barrel of canister 6743 was identified as being taken from $6743 \mathrm{U}$.

\subsection{FIRST SHIPMENT (FIRST MONITORING EVOLUTION)}

Sludge samples were extracted from canisters: 6603M; 6513M; 1860U; 2667M; 6743U; 2246M, and placed into SSCs: 96-16; 96-17; 96-23; 96-21; 96-03; 96-02, respectively. The SSCs were moved to the staging location. Gas generation monitoring was initiated on December 28, 1996 and was completed on January 8, 1997.

The average basin water temperature during this monitoring was $48^{\circ} \mathrm{F}$. No detectible gas was observed in any of the six inverted graduated cylinders covering the six SSCS, included in the first Chem Nuc Cask shipment.

\subsection{SECOND SHIPMENT (SECOND MONITORING EVOLUTION)}

Sludge samples were extracted from canisters: 1164M; 2660U; 2660M, and placed into SSCs: 96-25; 96-26; 96-24, respectively. Fuel samples were taken from canisters: 6603M; 6513M; 6513U, and placed in SFECs: 8-94-1; 12-96-8; 9-94-17, respectively. The SSCS and SFECs were moved to the staging location. Gas generation monitoring was initiated on January 23, 1997 and was completed on January $28,1997$.

The average basin water temperature during this monitoring was $57^{\circ} \mathrm{F}$. No detectible gas was observed in any of the six inverted graduated cylinders covering three SSCS and three SFECs, included in the second Chem Nuc Cask shipment.

\subsection{THIRD SHIPMENT (THIRD MONITORING EVOLUTION)}

Fuel samples were taken from canisters: 6743M; 6743U; 6743U; 7913M; 7913U; 5744U, and placed in SFECs: 9-94-18; 12-96-3;9-94-15;9-94-6; 12-96-6; 12-96-1, respectively. The SFECs were moved to the staging location. Gas generation monitoring was initiated on February 6, 1997 and was completed on February 18, 1997. Although the gas monitors were placed onto containers on February 6, 1997 no gas was apparent until February 15, 1997. There is no clear explanation for this data, however, the results seem to indicate a dormant period before gas generation occurred. This sample population was the only group that exhibited a measurable "dead time" prior to generation.

The average basin water temperature during this monitoring was $69^{\circ} \mathrm{F}$. In-basin gas monitoring for the third shipment resulted in gas production in SFECs: 9-94-18; 12-96-3; and 12-96-1 (Table 1). 


\subsection{FOURTH SHIPMENT (FOURTH MONITORING EVOLUTION)}

Fuel samples were taken from canisters: 2667U; 0161M; 1164M; 1164U; 2660M; 0309M, and placed in SFECs: 12-96-5; 12-96-2; 12-96-10; 12-96-7; $12-96-9 ; 12-96-4$, respectively. The SFECs were moved to the staging location. Gas generation monitoring was initiated on February 26, 1997 and completed on March 3, 1997.

The average basin water temperature during this monitoring was $71^{\circ} \mathrm{F}$. In-basin gas monitoring for the fourth shipment resulted in gas production in SFECS: $12-96-5 ; 12-96-2 ; 12-96-7$; and 12-96-9 (Table 1).

\subsection{RELATED OR SIMILAR TESTS}

In-basin gas generation monitoring has been performed for all sampling campaigns in both KW and 105-K East Basin (KE). A combined total (SSCs and SFECS) of 45 containers were monitored in the same fashion as explained herein. The KE gas monitoring evolutions and staging time intervals were significantly shorter than that at $\mathrm{KW}$. The effects of the change in time intervals were unclear, however, more gas was collected from those KW samples which were monitored longest. Excluding the most recent monitoring evolutions identified as Shipments' 3 and 4 , no gas was ever detected in any monitoring devices. The increased water temperature only existed during Shipments' 3 and 4 .

\subsection{PHOTOGRAPHIC DOCUMENTATION}

Figures 1 through 14 provide photographic illustrations of the related gas monitors and fuel elements.

\subsection{CONCLUSIONS AND RECOMMENDATIONS}

Approximately $170 \mathrm{ml}$ of gas was collected from damaged elements contained in seven SFECS (Table 1). None of the quantities illustrated in Table 1 , if assumed to be hydrogen, were significant to the safety concerning sampling and shipping of SNF or sludge. However, the capture of any gas in the monitors may be significant in analyzing the chemical reactions and gas generation rates which exist in $\mathrm{KW}$.

No distinct differences were determined between any of the seven SFECs which generated gas. Each element's damage, al though different in degree, was not the defining factor which dictated a particular element's gas generation. That is to say, the element with the most damage within a monitoring population did not necessarily produce the most gas. The time interval of gas monitoring was consistent within the required parameters ( 4 to 12 days). No particular arrangement of SFECS in the staging area seemed to have an impact on the gas generation. Other minor aspects of the monitoring process were also consistent throughout the 3 month period. 
Although there were no significant differences between the seven gas generators, there was one predominant difference between those that generated gas and those that did not. Only those staged in the water during the temperature increase produced gas. That is not to say, all SFECs that were exposed to the higher temperatures generated gas. As illustrated in the section, Results, 12 SFECs were monitored while the temperature exceeded $60^{\circ} \mathrm{F}$, and only seven of the 12 emitted gas. It is difficult to draw any definitive conclusions, based on the data, as to why some elements produced gas while others did not. It is apparent however, the increased water temperature seemed to catalyze a reaction that produced gas in some SFECs.

The gas captured in the monitors was not sampled and thus no definitive characterizations were possible as to what gas was collected. Another variable which impacted the accuracy of gas generation monitoring was the inability to measure all the gas generated during a collection evolution. It was determined that in some cases, a portion of gas was trapped under a small surface in the gas monitors. This trapped gas was not captured in the monitors until the collectors were jarred prior to removal. The entire volume of gas collected in a cylinder, in some cases, was not realized until the end of the monitoring period. Obviously, a specific generation rate was difficult to identify. Due to the aforementioned collection problems and because the monitors could not be viewed "up close" during the entire evolution, it was impossible to account for a volume increase per hour. Upon review of the video tapes (Reference 8 ), it was concluded that no individual bubble generation was visible. The only generation rates recorded, with any certainty, equate to the entire gas volume $(\mathrm{ml})$ for the entire monitoring evolution (hr).

\subsection{GAS GENERATION RATES}

Considering all the data, the following rates were identified:

SFEC 9-94-18 - $10 \mathrm{ml} / 96 \mathrm{hr}$

SFEC $12-96-1-10 \mathrm{ml} / 96 \mathrm{hr}$

SFEC 12-96-3 - $40 \mathrm{ml} / 96 \mathrm{hr}$

SFEC 12-96-2 - $5 \mathrm{ml} / 116 \mathrm{hr}$

SFEC 12-96-5 - $20 \mathrm{ml} / 116 \mathrm{hr}$

SFEC 12-96-9 - $60 \mathrm{ml} / 116 \mathrm{hr}$

SFEC 12-96-7 - $5 \mathrm{ml} / 116 \mathrm{hr}$

\subsection{REFERENCES}

1. S. R. Crow, 1996, Safety Evaluation for Packaging for the $N$ Reactor/Single Pass Reactor Fuel Characterization Shipments, WHC-SD-TP-SEP-028, Rev. 1, Westinghouse Hanford Company, Richland, Washington.

2. Drawing, H-1-81563, Rev. 0, "K Basin Gas Sampler Drawings," March 20, 1996.

3. Drawing, H-1-81459, Rev. 1, "K Basin Sludge Sample Container Assembly," December 13, 1995. 


\subsection{REFERENCES (Continued)}

4. Drawing, H-1-80394, Rev. 1, "Single Fuel Element Canister Tube Assembly," August 1995.

5. Internal Memo, B. J. Makenas to R. P. Omberg, "Recommended $K$ West Basin Canisters for Fuel Element Retrieval (Second Campaign)," January 15, 1997.

6. Internal Memo, R. B. Baker to R. P. Omberg, "Recommended $K$ West Basin Canisters for Sludge Sampling," December 6, 1996.

7. Logbook, WHC-N-297, "KW Basin Characterization Phase II, "Spent Nuclear Fuel Evaluations, October 25, 1996.

8. Video Tapes, "Nuclear Fuel Evaluations Video Tape Inventory, Tape Log Numbers: 230; 232; and 235," February and March 1997. 
Figure 1. In-Bly Prior to Shipment \#3

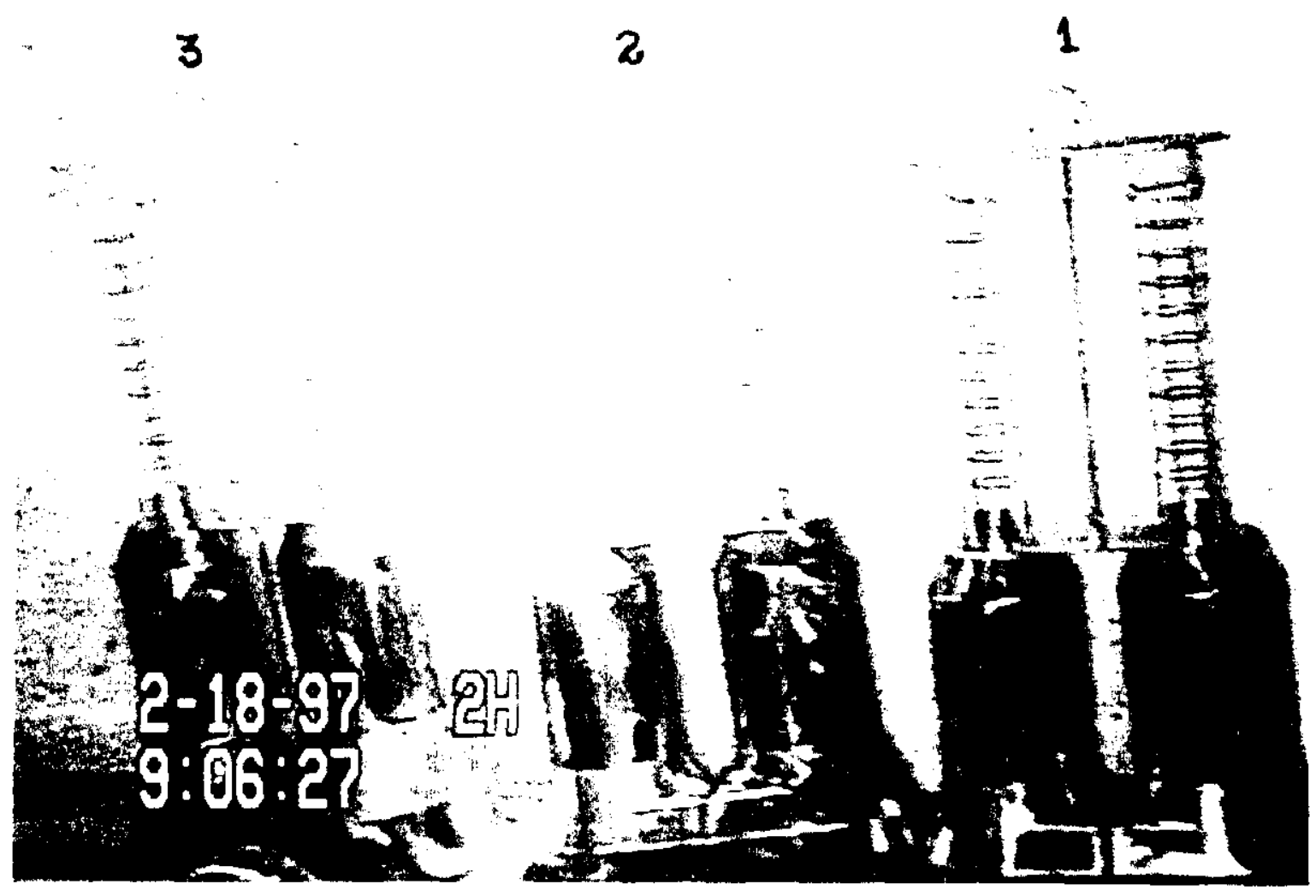

Figure 2. Gas Monitor \#1

L SFEC 12-96-3, R SFEC 9-94-18
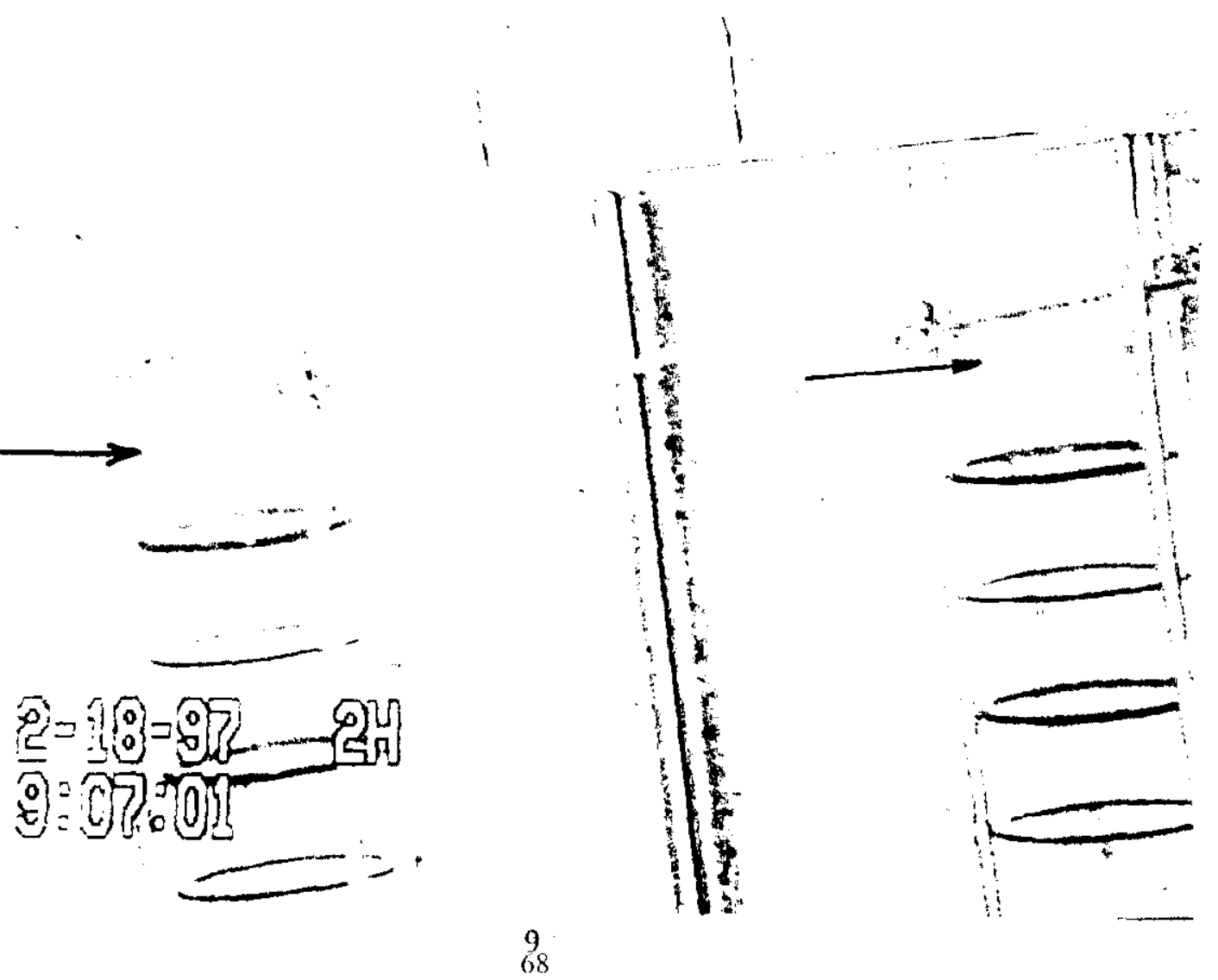
Figure 3. Gas Monitor \#3 L SFEC 12-96-1

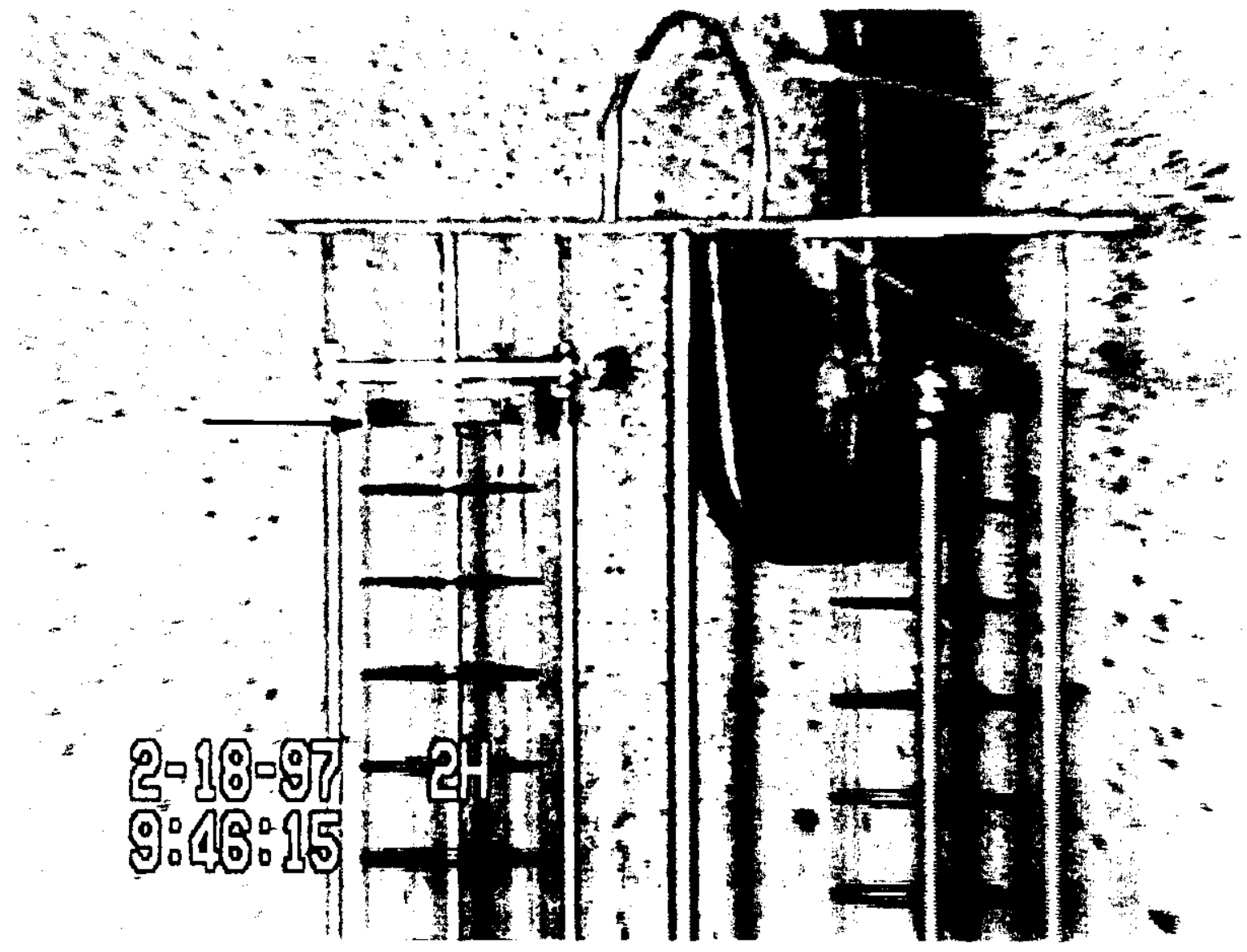




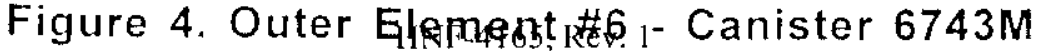
SFEC $9-94-18$

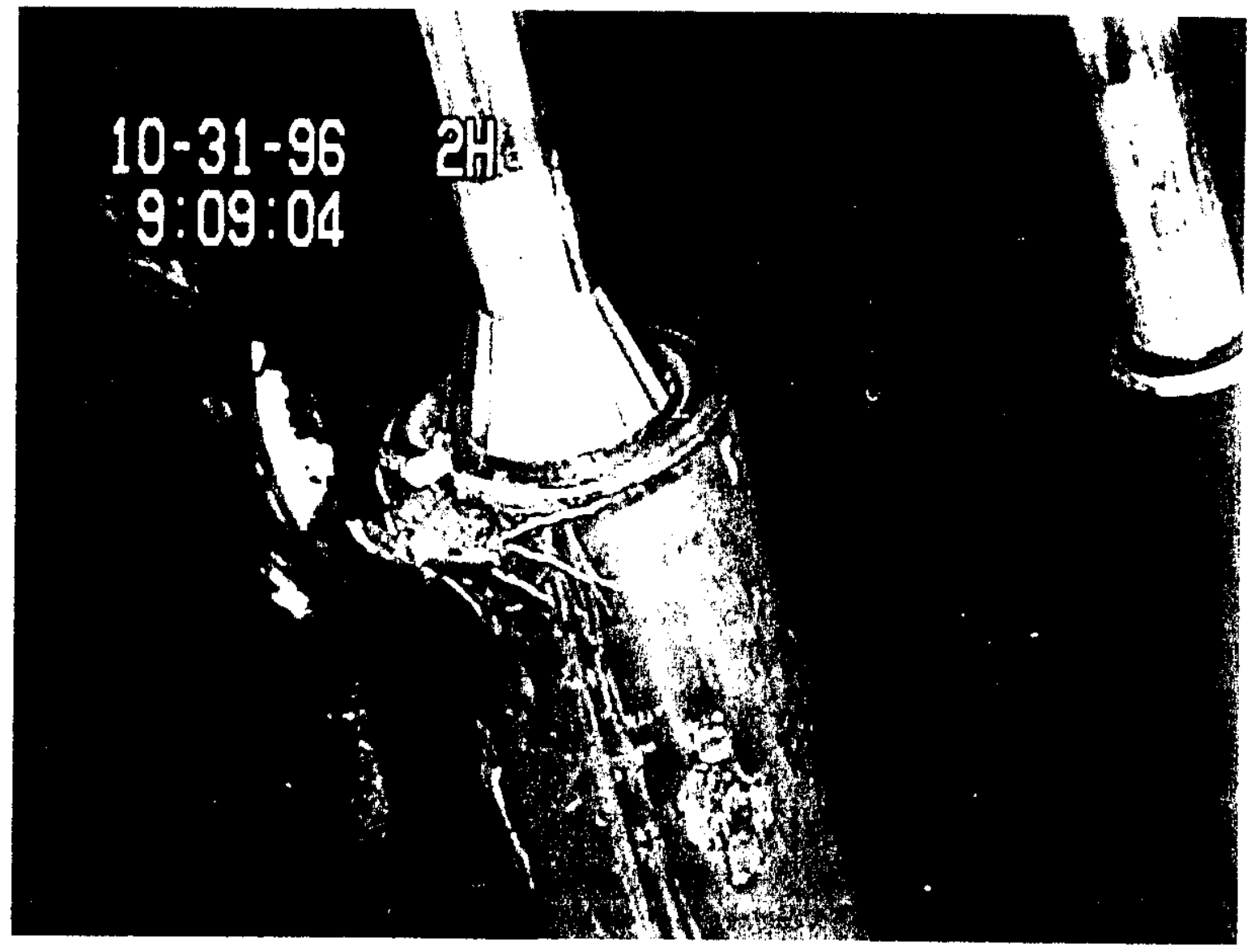

Figure 5. Outer Element \#6 - Canister $6743 \mathrm{U}$ SFEC 12-96-3

\section{0-31-96 래 $10: 25: 44$}

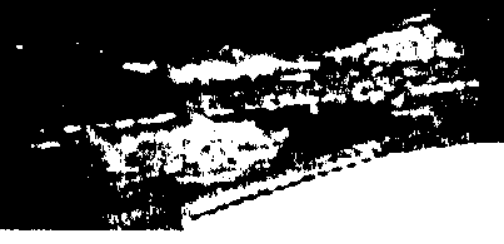

is

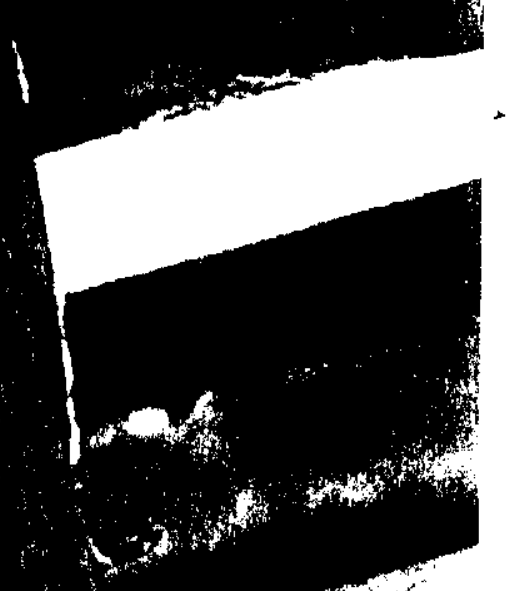


Figure 6. Outer Element \#4 - Canister $5744 U$ SFEC 12-96-1

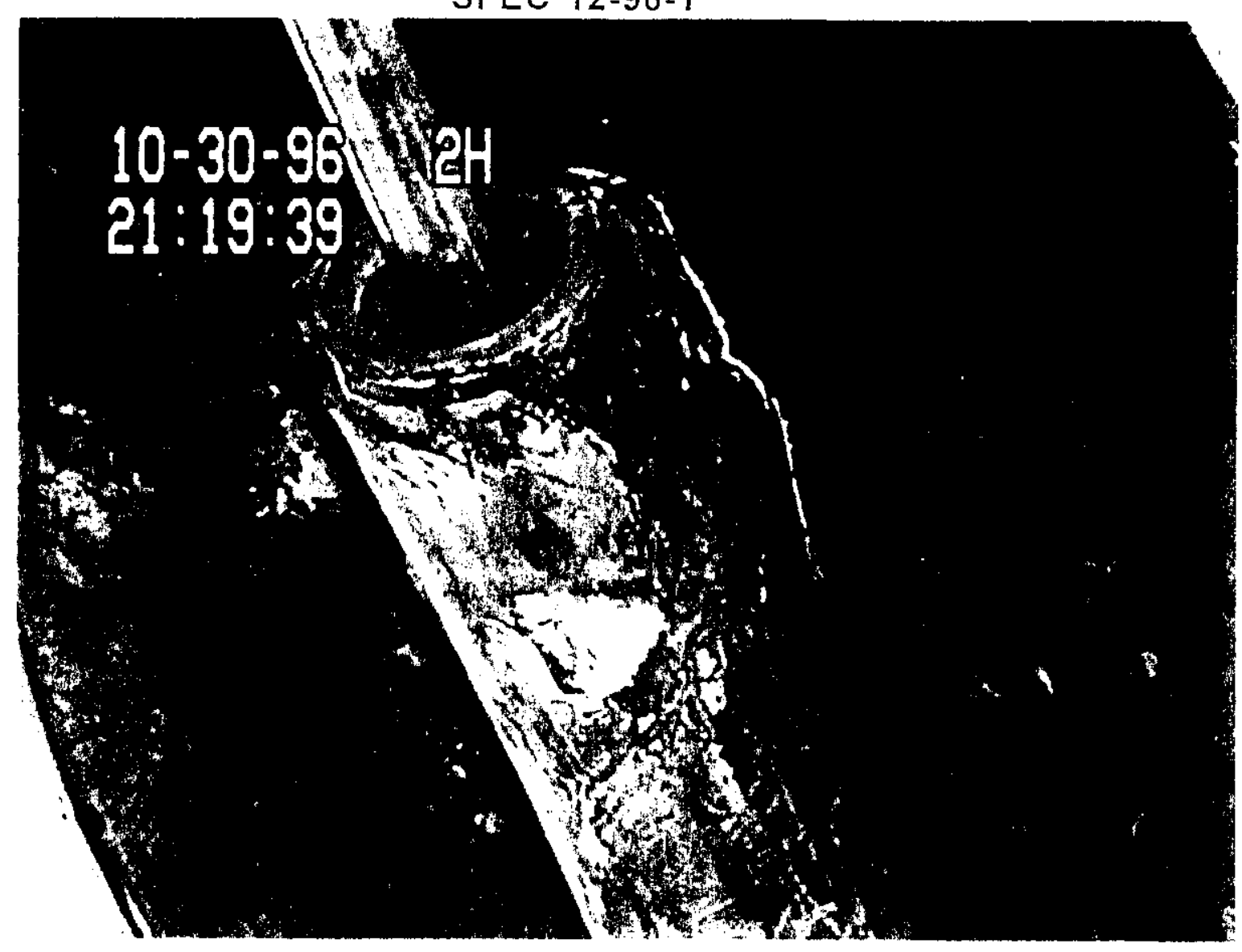


Figure 7. In-Basiff-4t65. Rqubnitors on SFEC's Prior to Shipment \#4

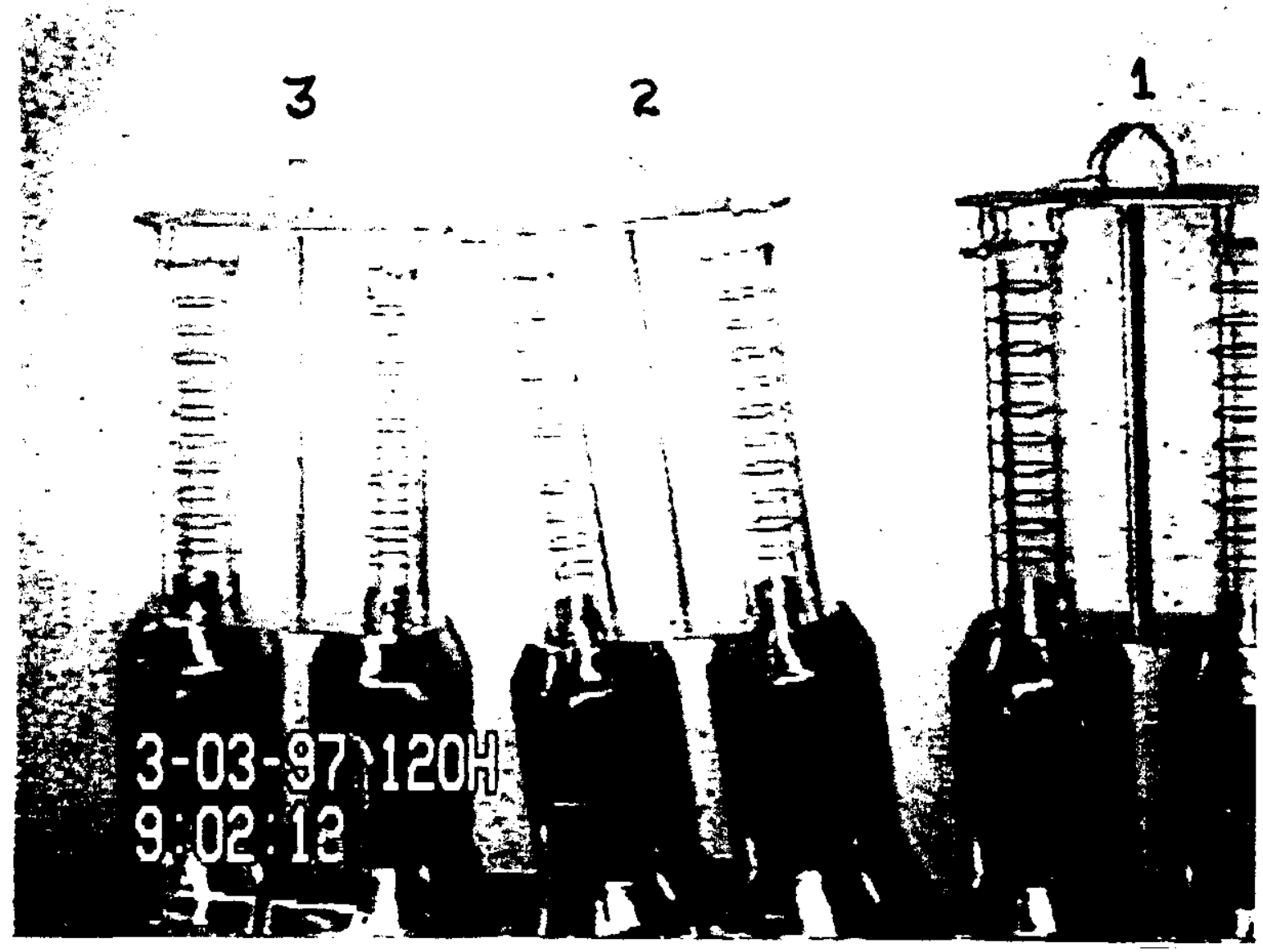

Figure 8. Gas Monitor \#1

L SFEC 12-96-2, R SFEC 12-96-5

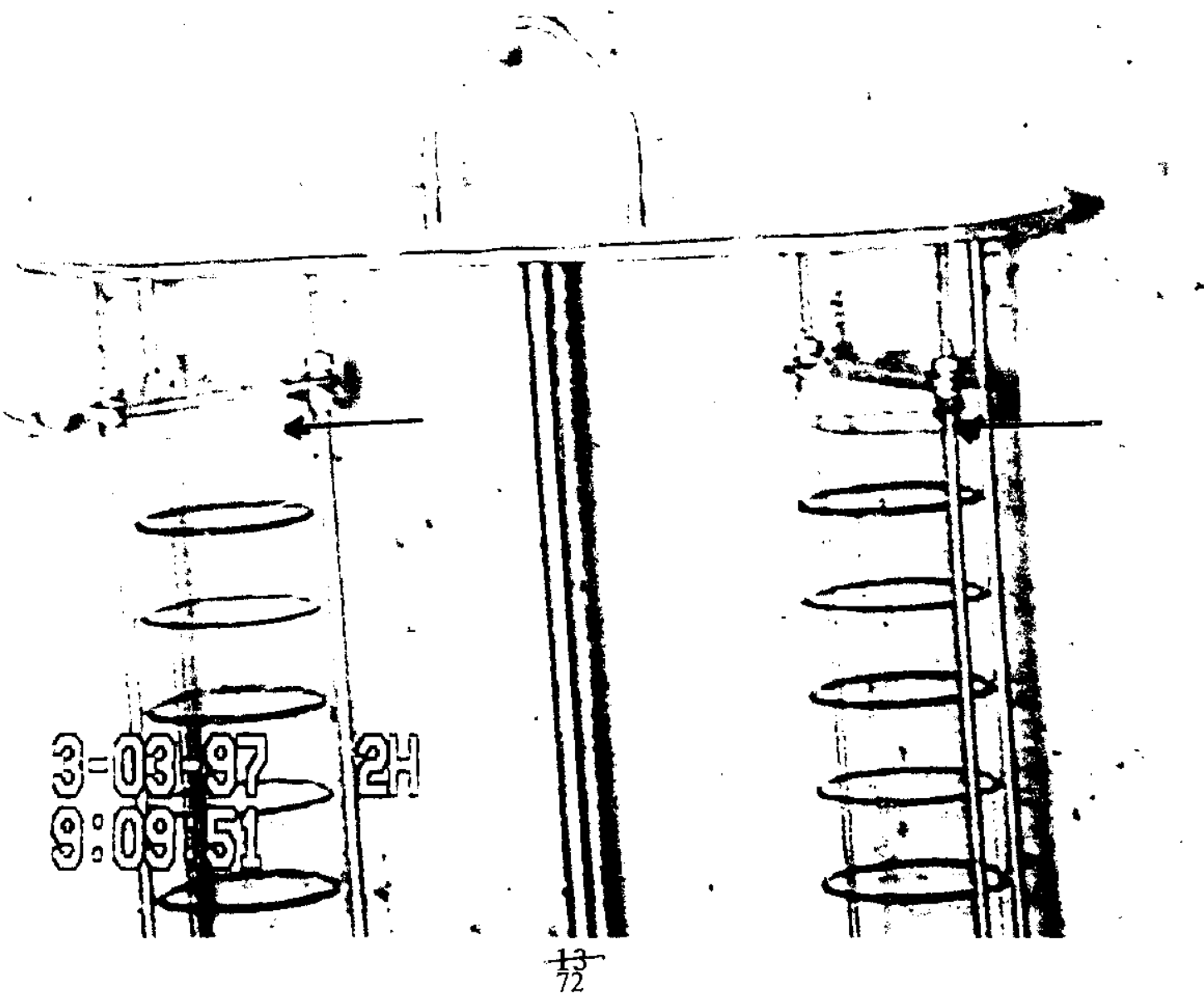




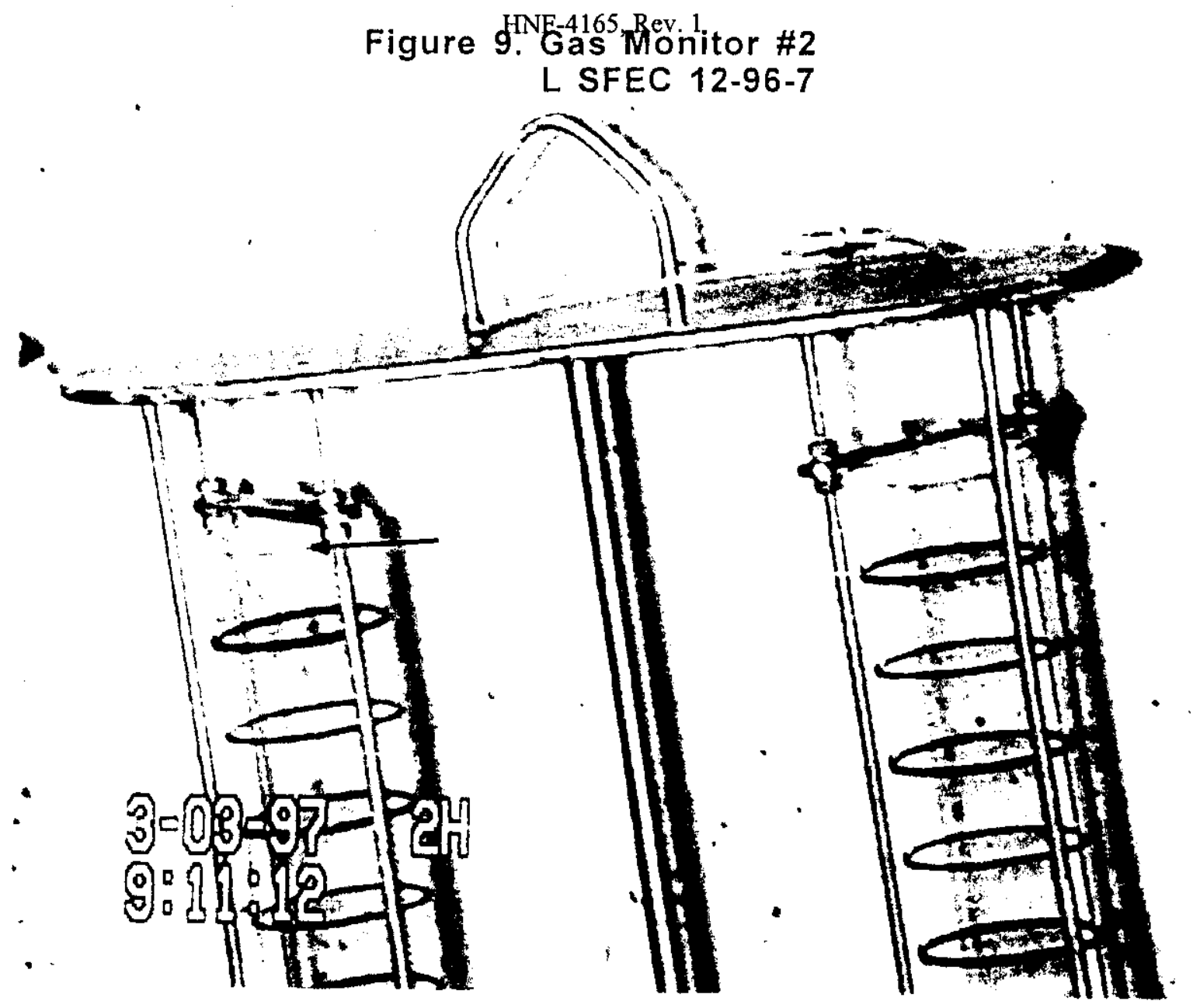

Figure 10. Gas Monitor \#3

$R$ SFEC 12-96-9

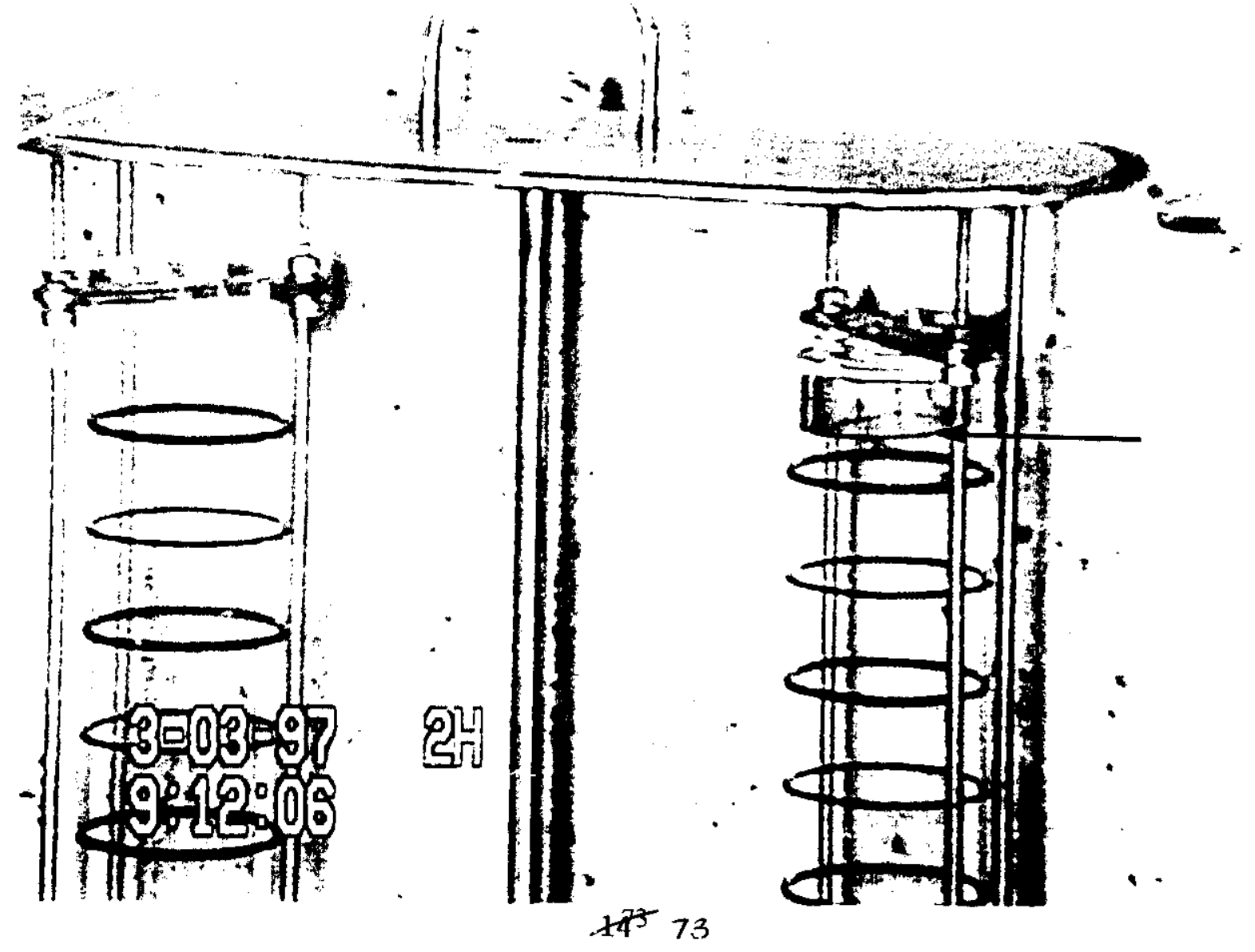


Figure 11. Outer Element $\# 3$ - Canister $2667 \mathrm{U}$ SFEC $12-96-5$

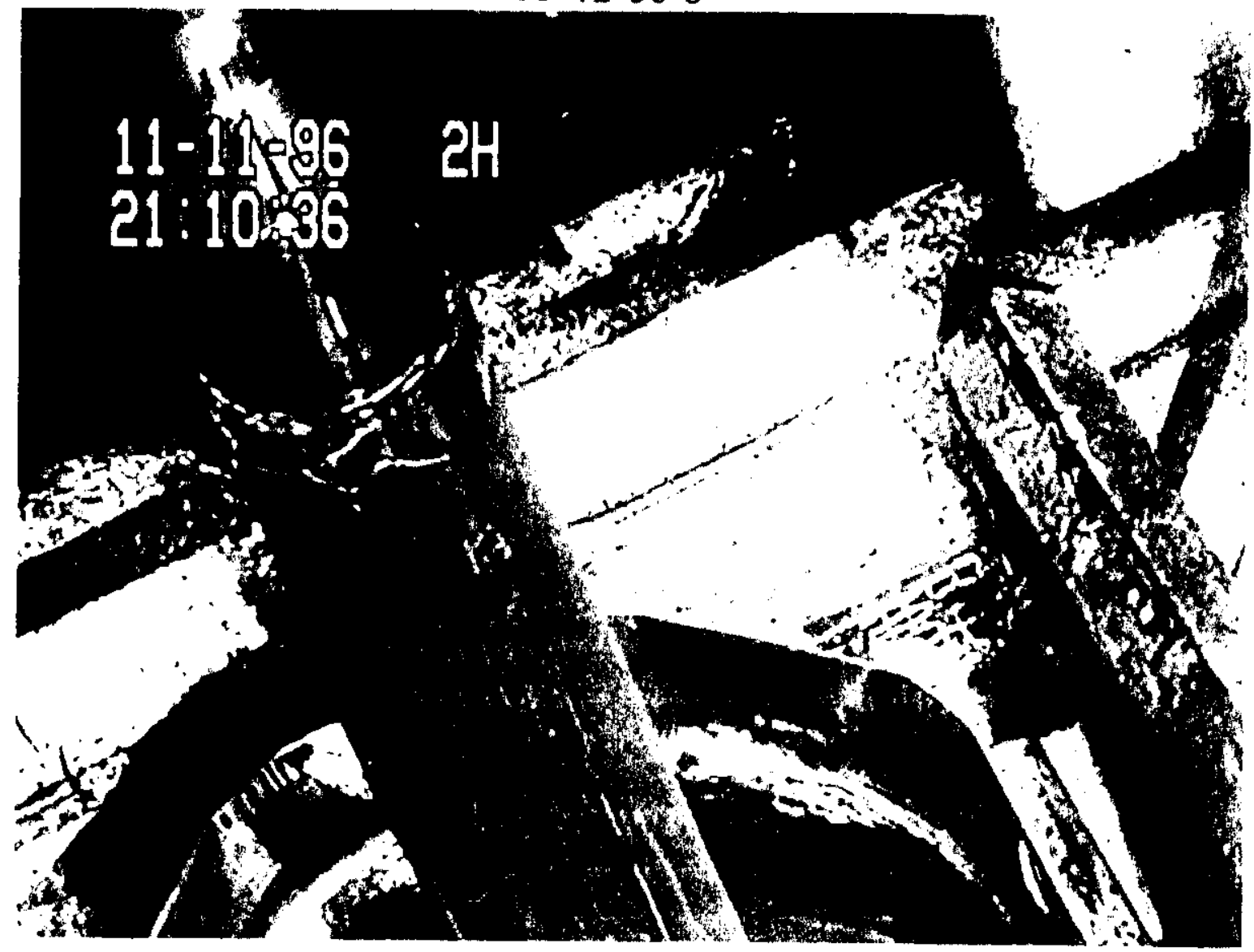

Figure 12. Outer Element \#2 - Canister 0161M SFEC 12-96-2

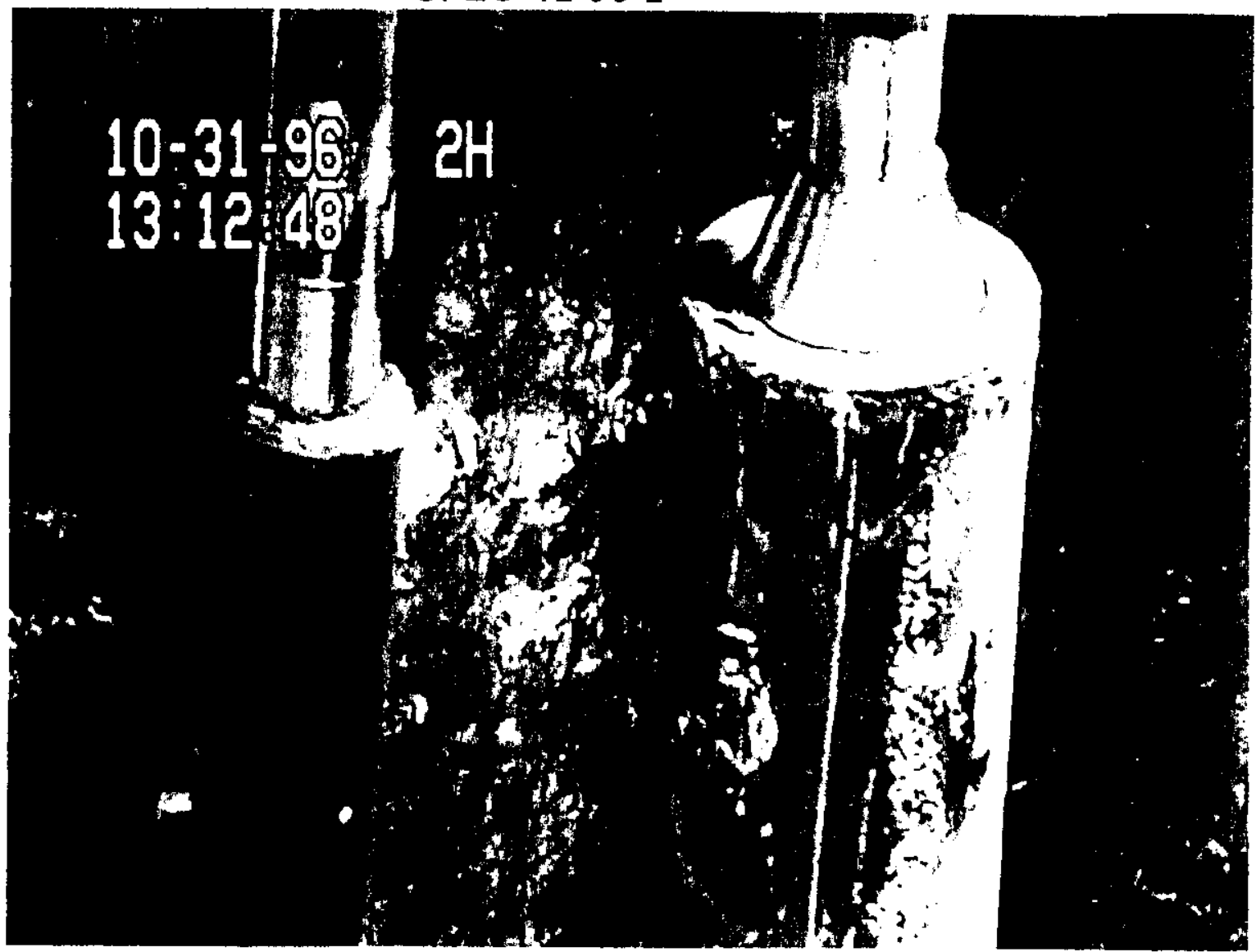


Figure 13. Outer Element SFEC 12-96-7

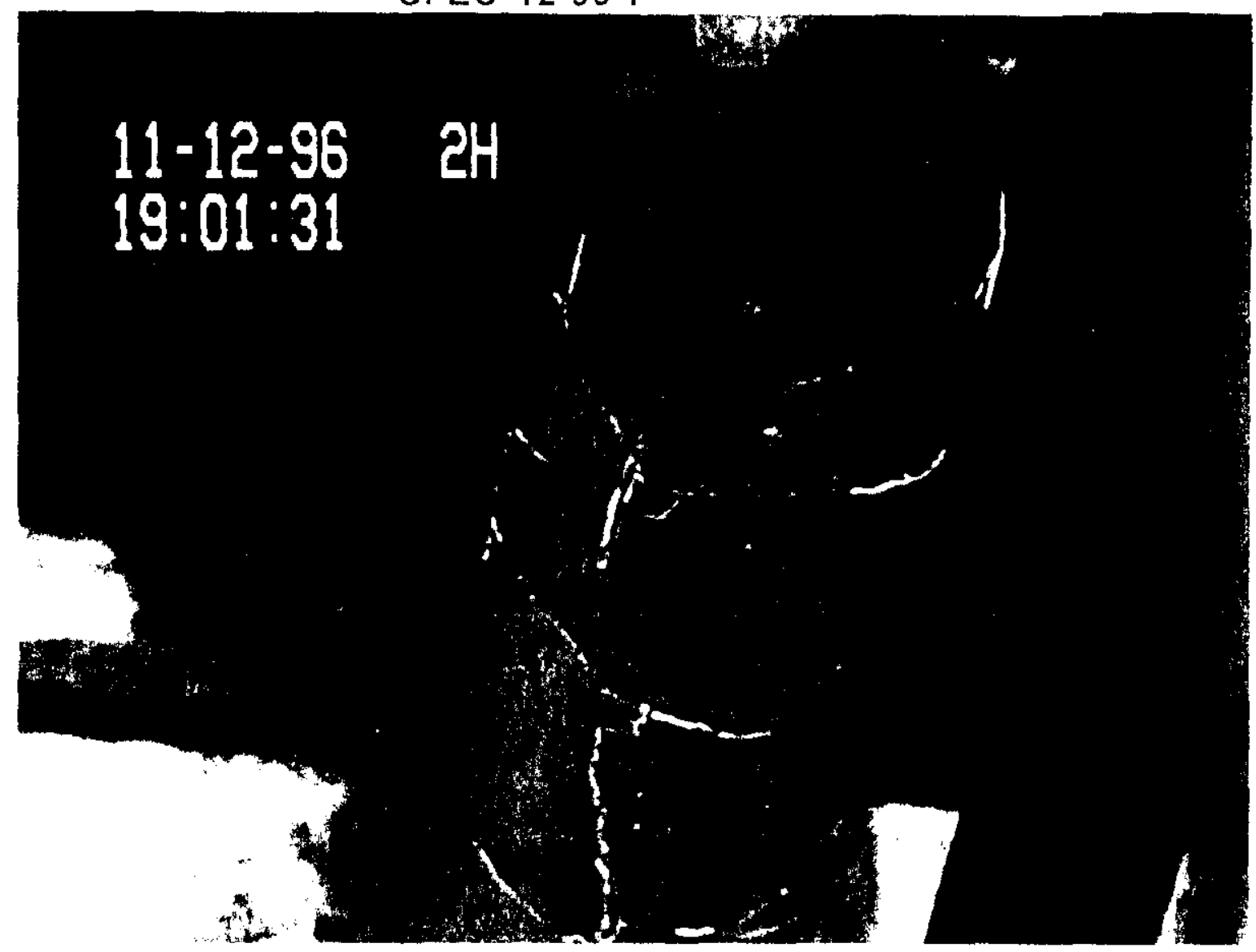

Figure 14. Outer Element \#6 - Canister 2660M SFEC 12-96-9

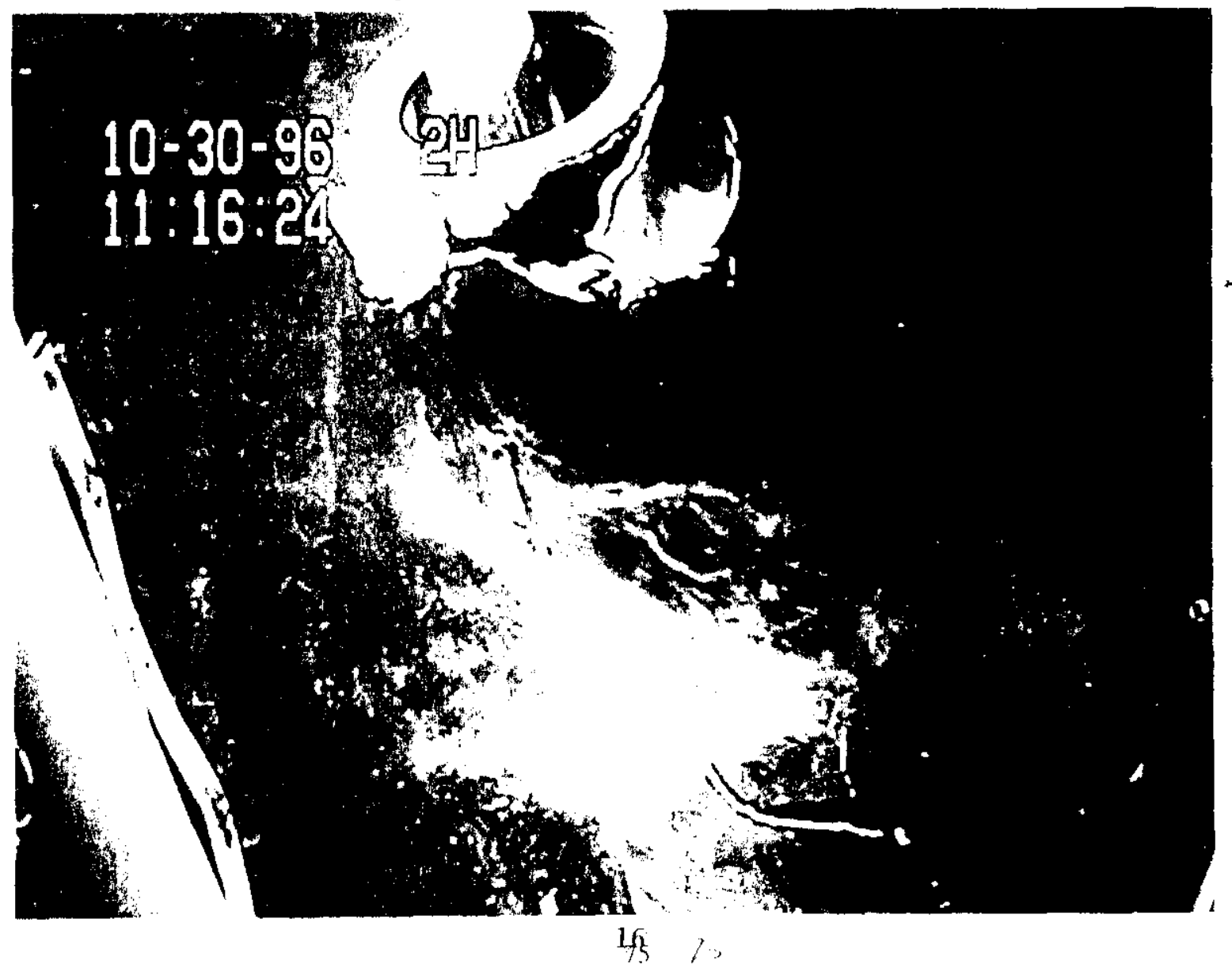




\subsection{Sensitivity Analysis of MCO Thermal Stability in Dry Air}

Insufficient data are available to conclusively demonstrate that the $\mathrm{N}$ Fuel dry air reaction is more rapid than low temperature literature data. However, a sensitivity analysis was completed to show that the MCO would be thermally stable during air ingress events assuming the Pacilific Northwest National Laboratory (PNNL) dry air reaction rates. Two issues were evaluated: the fuel temperature increase from a sudden air ingress and the stability of an MCO in a flowing air (no reactant depletion) configuration.

\subsubsection{Air Ingress}

The implications of an air ingress (e.g., single pipe break during vacuum operation) were evaluated by estimating the adiabatic fuel temperature rise for complete reaction of the entering air. The MCO is assumed to have a void volume of approximately $500 \mathrm{~L}$ and contain about $6,000 \mathrm{~kg}$ of fuel. Assuming the MCO is at vacuum and the air ingress returns the system to atmospheric conditions,

$$
\text { Total } \mathrm{O}_{2} \text { available to react }=\frac{(500 \mathrm{~L})(1 \mathrm{~atm}-0 \mathrm{~atm})}{\left(0.082 \frac{\mathrm{atm}-\mathrm{L}}{\mathrm{gmol}-\mathrm{K}}\right)(298 \mathrm{~K})} \times 0.21=4.3 \mathrm{gmol} \mathrm{O}_{2}
$$

Assuming the reaction (heat of reaction based on heat of formations from Dean [1979]):

$$
\mathrm{U}+\mathrm{O}_{2} \rightarrow \mathrm{UO}_{2}-\Delta \mathrm{H}_{\mathrm{r}}^{0}=270 \mathrm{kcal} / \mathrm{mol}
$$

Maximum heat produced by air reaction is

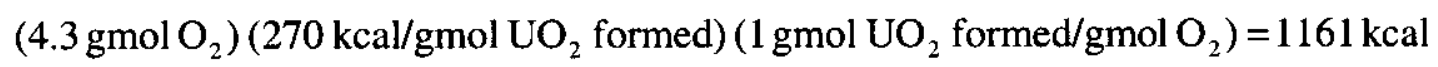

Assuming adiabatic heat absorption by $6,000 \mathrm{~kg}$ of fuel (neglecting temperature increases in baskets and the MCO shell), the fuel temperature rise is estimated.

$$
\Delta \mathrm{T}=\frac{\mathrm{Q}}{\mathrm{mC}_{\mathrm{p}}}=\frac{(1161 \mathrm{kcal})(3.9685 \mathrm{BTU} / \mathrm{kcal})}{(6000 \mathrm{~kg})(2.2 \mathrm{lb} / \mathrm{kg})\left(0.03 \mathrm{BTU} / \mathrm{lb}-{ }^{\circ} \mathrm{F}\right)}=11.6^{\circ} \mathrm{F} \approx 6.4^{\circ} \mathrm{C}
$$

The adiabatic temperature rise calculation depends on the mass of uranium heated by the air reaction. If all reaction heat were concentrated in a single element, the adiabatic temperature rise would be much greater than predicted above. This could occur if the oxidation rate of fuel near the air entry point is sufficient to react all oxygen as it enters an MCO. If air enters an $\mathrm{MCO}$ with a scrap basket at the top position, the bounding surface area available for reaction is $45,000 \mathrm{~cm}^{2}$. In addition, conservatively assuming a scrap fuel temperature of $100^{\circ} \mathrm{C}$ results in a reaction rate estimate of $0.472 \mathrm{mg} w \mathrm{wain} / \mathrm{hr}-\mathrm{cm}^{2}$ from Equation (6-5) and an enhancement factor of 12. This produces an estimated reaction rate of $21,240 \mathrm{mg}$ wt gain/hr in the scrap basket, consuming $0.66 \mathrm{gmol} \mathrm{O}_{2} / \mathrm{hr}$. It would take approximately 6.5 hours at this oxygen 
consumption rate to deplete the 4.3 gmol of oxygen associated with a sudden air ingress. The time would be reduced to 2.4 hours if all the fuel in a bounding MCO, containing $120,000 \mathrm{~cm}^{2}$ of surface area, were reacting with the incoming oxygen. Based on the relatively long time periods to react, compared to a sudden air ingress, it was considered reasonable to evaluate the adiabatic temperature rise using the total fuel mass in an $\mathrm{MCO}$.

The specific area of fuel in a bounding MCO can be used to estimate more conservative estimates for the adiabatic temperature rise of fuel. Assuming all uranium surfaces react at the same rate, the bounding $\mathrm{MCO}$ will generate:

$$
\frac{(1161 \mathrm{kcal})(3.9685 \mathrm{BTU} / \mathrm{kcal})}{\left(120,000 \mathrm{~cm}^{2}\right)}=0.0384 \mathrm{BTU} / \mathrm{cm}^{2}
$$

A scrap basket, based on bounding estimates, will contain up to $\left(45,000 \mathrm{~cm}^{2} / 980 \mathrm{~kg}\right)$ $45.9 \mathrm{~cm}^{2} / \mathrm{kg}$, while a bounding fuel basket will contain up to $6.23 \mathrm{~cm}^{2} / \mathrm{kg}$ $(7900 \mathrm{~cm} 2 / 54$ assemblies $/ 23.48 \mathrm{~kg} /$ assembly). This results in the following adiabatic temperature rise estimates for fuel is a scrap or fuel basket.

$$
\begin{aligned}
& \left.\Delta \mathrm{T}\right|_{\text {scrap }}=\frac{\left(45.9 \mathrm{~cm}^{2} / \mathrm{kg}\right)\left(0.0384 \mathrm{BTU} / \mathrm{cm}^{2}\right)}{(2.2 \mathrm{lb} / \mathrm{kg})\left(0.03 \mathrm{BTU} / \mathrm{lb}-{ }^{\circ} \mathrm{F}\right)}=26.7^{\circ} \mathrm{F} \approx 15^{\circ} \mathrm{C} \\
& \left.\Delta \mathrm{T}\right|_{\text {fuel }}=\frac{\left(6.23 \mathrm{~cm}^{2} / \mathrm{kg}\right)\left(0.0384 \mathrm{BTU} / \mathrm{cm}^{2}\right)}{(2.2 \mathrm{lb} / \mathrm{kg})\left(0.03 \mathrm{BTU} / \mathrm{lb}-{ }^{\circ} \mathrm{F}\right)}=3.6^{\circ} \mathrm{F} \approx 2^{\circ} \mathrm{C}
\end{aligned}
$$

Therefore, it is concluded that an air ingress event will not result in an initial temperature rise of more than 2 to $15^{\circ} \mathrm{C}$, depending on the specific surface area of fuel in the MCO. After reacting this initial volume of air, oxygen must diffuse through the hypothetical pipe breach to continue to supply reactant to the system. If the MCO is thermally stable for a flow of air through the MCO (flow sufficient to preclude reactant depletion), then the air ingress event can be considered thermally stable. Thermal stability for this situation is demonstrated in Section 10.2.2.

\subsubsection{Comparative MCO Thermal Stability}

Since the adiabatic fuel temperature rise developed in Section 10.2.1 is modest during an air ingress event, the MCO can only become thermally unstable if a continuing supply of reactant is available. Conceptually, the worst case configuration could be described by some type of double pipe break scenario sufficient to supply oxygen such that the air reaction rate limits heat generation in an MCO. 
Plys suggests a comparison method for determining if the MCO is thermally stable during an air ingress event if the reaction rates are based on the PNNL dry air reaction rates (see attached letter). The basis for the comparison is that MCO thermal stability has been demonstrated for transient models of systems using the water vapor reaction. Sensitivity studies were conducted indicating that the MCO is thermally stable in the water vapor system with enhancement factors of up to 50. A comparison of thermal properties (relative heat generation rate and resistance to heat transfer) will indicate if the air system would also be stable.

Based on the suggested comparison method, the water vapor system has been shown to be stable, the air system will be stable if

$$
\frac{\dot{\mathrm{H}}_{\mathrm{A}}}{\mathrm{C}_{\mathrm{A}}}<\frac{\dot{\mathrm{H}}_{\mathrm{W}}}{\mathrm{C}_{\mathrm{W}}}
$$

where: $\dot{\mathrm{H}}=$ the heat generation rate from reactions

$\mathrm{C}=$ the system thermal conductance

$\mathrm{A}=$ air system

$\mathrm{W}=$ water vapor system

The reaction heat generation rate is:

$$
\dot{\mathrm{H}}=\xi \text { (oxidation rate) } \Delta \mathrm{H}_{\mathrm{r}}
$$

The system thermal conductance is characterized by the MCO gas thermal conductivity and conduction path lengths.

$$
\mathrm{C}=\frac{\mathrm{R}}{\mathrm{L}}
$$

where: $\mathrm{R}=$ thermal conductivity

$$
\mathrm{L}=\text { thermal conduction path length }
$$

The conduction path lengths in an MCO are not modified by replacing one gas with another. Therefore, the change in conductance is related to the change in gas thermal conductivity.

$$
\frac{\mathrm{C}_{\mathrm{W}}}{\mathrm{C}_{\mathrm{A}}}=\frac{\mathrm{R}_{\mathrm{W}}}{\mathrm{R}_{\mathrm{A}}}
$$

The air system will be stable compared to a stable water vapor system if

$$
\begin{array}{r}
\frac{\dot{\mathrm{H}}_{\mathrm{A}}}{\dot{\mathrm{H}}_{\mathrm{W}}} \frac{\mathrm{R}_{\mathrm{W}}}{\mathrm{R}_{\mathrm{A}}}<1 \\
\left(\frac{\xi_{\mathrm{A}}}{\xi_{\mathrm{W}}}\right)\left(\frac{\text { rate }_{\mathrm{A}}}{\text { rate }_{\mathrm{W}}}\right)\left(\frac{\Delta \mathrm{H}_{\mathrm{r}, \mathrm{A}}}{\Delta \mathrm{H}_{\mathrm{r}, \mathrm{W}}}\right)\left(\frac{\mathrm{R}_{\mathrm{W}}}{\mathrm{R}_{\mathrm{A}}}\right)<1
\end{array}
$$


The rate equation for dry air based on the $\mathrm{N}$ Fuel observations is taken from Abrefah, et al. (1998a). The water vapor reaction rate used to model the thermal stability is as shown by Equation (4-5). Both reaction rate correlations are based on the geometric area of the reacting surface and the weight gain represents the same molar quantity of uranium reacted for either reaction. Therefore,

$$
\begin{aligned}
& \text { rate }_{A}=(60)\left(475 \mathrm{e}^{-\frac{10000}{1.987 \mathrm{~T}}}\right) \mathrm{mg} \mathrm{wt} \text { gain } / \mathrm{hr}-\mathrm{cm}^{2} \\
& \operatorname{rate}_{\mathrm{w}}=\left(2.14 \times 10^{4}\right) 10^{-2144 / \mathrm{T}} \sqrt{\mathrm{P}} \mathrm{mg} \mathrm{wt} \text { gain } / \mathrm{hr}-\mathrm{cm}^{2}
\end{aligned}
$$

The dry air reaction rate correlation represents actual $\mathrm{N}$ Fuel such that no adjustment of the rate is required to address differences in alloy, surface roughness, etc. However, the potential for rapid reaction of inclusions must still be considered. Therefore, the enhancement factor implemented with the dry air reaction rate is $\xi_{A}=12$. Heat of reactions are listed in Sections 4.0 and 6.0. The attached letter provides estimates of gas thermal conductivity. Therefore, the above inequality becomes:

$$
\begin{array}{r}
\left(\frac{12}{\xi_{\mathrm{w}}}\right)\left(\frac{60 \times 475 \mathrm{e}^{-5032.7 / \mathrm{T}}}{2.14 \times 10^{4} 10^{-2144 / \mathrm{T}} \sqrt{\mathrm{P}}}\right)\left(\frac{270}{143.7}\right)\left(\frac{0.096}{0.028}\right)<1 \\
\left(\frac{103}{\xi_{\mathrm{w}} \sqrt{\mathrm{P}}}\right)\left(\frac{\mathrm{e}^{-5032.7 / \mathrm{T}}}{10^{-2144 / \mathrm{T}}}\right)<1 \\
\left(\frac{103}{\xi_{\mathrm{w}} \sqrt{\mathrm{P}}}\right)\left(10^{-2185.7 / \mathrm{T}+2144 / \mathrm{T}}\right)<1 \\
\left(\frac{103}{\xi_{\mathrm{w}} \sqrt{\mathrm{P}}}\right)\left(10^{-41.7 / \mathrm{T}}\right)<1
\end{array}
$$

Rearrangement of the inequality leads to:

$$
\begin{aligned}
\log \left(\frac{103}{\xi_{\mathrm{w}} \sqrt{\mathrm{P}}}\right)-\frac{41.7}{\mathrm{~T}} & <0 \\
\log \left(\frac{103}{\xi_{\mathrm{w}} \sqrt{\mathrm{P}}}\right) & <\frac{41.7}{\mathrm{~T}} \\
\mathrm{~T} & <\frac{41.7}{\log \left(\frac{103}{\xi_{\mathrm{w}} \sqrt{\mathrm{P}}}\right)}
\end{aligned}
$$

This indicates that the air system will be stable when below a temperature that depends on the partial pressure of water and enhancement factor used in the model of a water vapor system that was shown to be stable. Figure 10-1 indicates the variation of stable temperatures for the air system as a function of water vapor pressure and enhancement factor used in a model of the water vapor system that is shown to be stable. 
HNF-4165, Rev. 1

Figure 10-1. Temperature Limit for Stable Air System Assuming Dry Air Reaction Rates from N Reactor Fuel TGA Tests

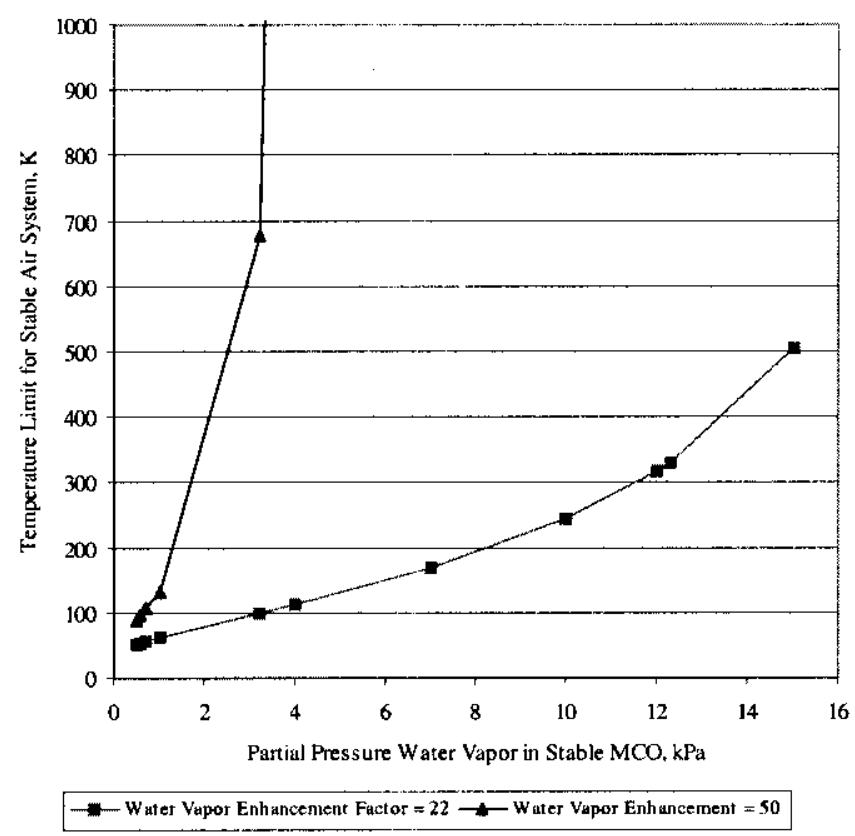

The air system would be stable at all temperatures if the water vapor system model was shown to be stable at conditions such that:

$$
\begin{aligned}
\frac{103}{\xi_{W} \sqrt{\mathrm{P}}} & \leq 1 \\
\xi_{\mathrm{W}} & \geq \frac{103}{\sqrt{\mathrm{P}}}
\end{aligned}
$$

Figure 10-2 indicates the variation of water system enhancement factor with partial pressure of water vapor. 


\section{Figure 10-2. Water Vapor Partial Pressure and Enhancement Factors Indicating Air System is Stable at Any Temperature}

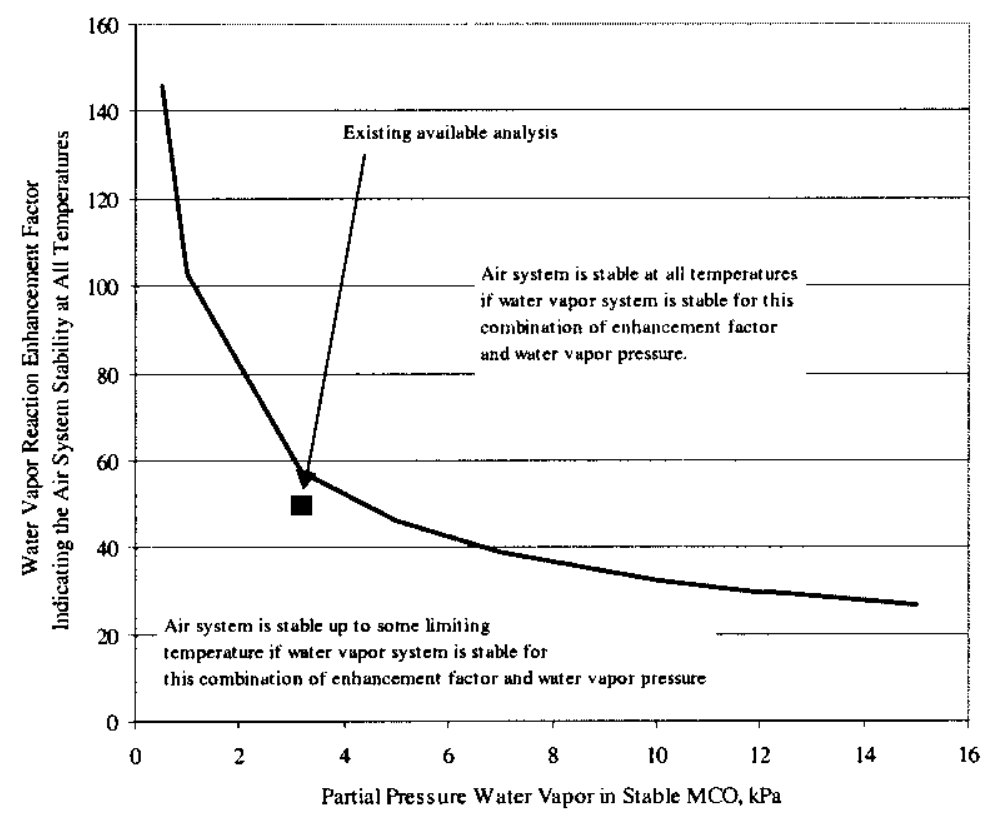

Duncan and Plys (1998) includes a sensitivity case (VC1AR50W) based on vacuum drying in helium with one scrap basket the was thermally stable with $\xi_{w}=50$. This case produced higher temperatures than a similar case with two scrap baskets. Conditions varied during the transient model, but the predominant reaction conditions are approximated by a steam mole fraction of 0.4 and total pressure in the MCO of $8 \mathrm{kPa}$. Therefore, conditions shown to be stable are at a partial pressure of water of $\mathrm{P}=0.4 \times 8=3.2 \mathrm{kPa}$.

An MCO in an air system, reacting at rates estimated from the data in Abrefah, et al. (1998a), would be stable so long as the temperature is less than

$$
\mathrm{T}<\frac{41.7}{\log \left(\frac{103}{50 \sqrt{3.2}}\right)}=680 \mathrm{~K}=407^{\circ} \mathrm{C}
$$

It would be possible to conclude that the MCO with the air reaction scenario would be stable for all temperatures if the water vapor system was stable with

$$
\xi_{w} \geq \frac{103}{\sqrt{3.2}}=57.6 \text { or } \sim 60
$$

This assumes the MCO would be thermally stable and the dominant conditions remain at $-3.2 \mathrm{kPa}$ water vapor for a modeling run with a reaction enhancement factor of 60 . 
HNF-4165, Rev. 1

Duncan and Plys (1998) indicate the peak fuel temperature observed in the water vapor system is $107^{\circ} \mathrm{C}$. The air ingress configuration is predicted to be stable at temperatures up to $407^{\circ} \mathrm{C}$. Therefore, it is concluded that an MCO would remain thermally stable during a flowing air scenario in an MCO even if the higher dry air reaction rate data were used to characterize N Fuel oxidation. 


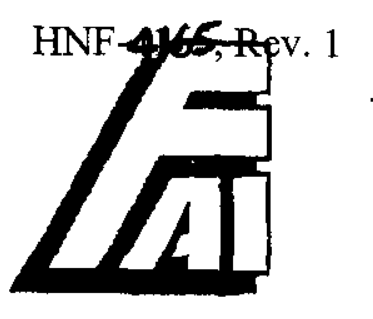

Fauske \& Associates, Inc.

DATE: January 6, 1999

TO: $\quad$ Darrel Dunkan, Jim Frederickson, and $\mathrm{Nl}$ Pajunin, DE\&SH;

FROM: Marty Plys $\mathrm{Mmath}$

SUBJECT: MCO Air Ingress Thermal Stability vs Normal Vacuum Cycle

MCO relativc thermal stability during air ingress versus during normal vacuum cycle can be deduced to a good approximation without transient simulations. You asked about the relativic thermal stability vs normal operation if the reaction rates given by the PNNL dry air oxidation data prevailed during air ingress, assuming the same rate law multiplier used in our standard analyses. When all other factors are the same, the ratio of Frank-Kamenetskii (F-K) parameters provides the relative measurc:

$$
\frac{R_{2}}{R_{1}} \frac{\dot{m}_{1}^{\prime \prime}}{\dot{m}_{2}^{\prime \prime}}
$$

where $R$ is the thermal resistance, $\dot{m}^{\prime \prime}$ is tic reaction rate, and subscripts indicate the two situations. The thermal resistance change is bounded by (and is less than) the change in gas thermal conductivities.

From IFANSF calculations, the gas thermal conductivity is about $0.096 \mathrm{~W} / \mathrm{m} / \mathrm{K}$ during vacuum cycle with $25 \%$ water vapor in heliurn, and it is about 0.028 for air. From HNF-2256 Figure $3-1$, at $60^{\circ} \mathrm{C}$, the Pearce oxygen-frce reaction rate is about $6 \times 10^{-8} \mathrm{~kg} / \mathrm{m}^{2} / \mathrm{s}$, and the PNNL dry air correlation for $N$-reactor fuel is about $2 \times 10^{-8} \mathrm{~kg} / \mathrm{m}^{2} / \mathrm{s}$. The value of the ratio is therefore about 1.14, i.e. a slight increase in the F-K parameter using the PNNL correlation and dry air thermal propertics. The value of the ratio would be closer to 1.0 and probably less than 1.0 if a rigorous evaluation of the effective heat transfer resistance - which includes rue! conductivity and thermal radiation - were performed. We know from HNF-2256 that we have al least a factor of two margin in this ratio, i.e. a rate law multiplier of 50 from a sensitivity case is still stable vs a rate law multiplier of 22 used for base cases.

Therefore, MCO air ingress scenarios are thermally stable even when the PNNI. dry air correlation is used.

CC: $\quad$ Sung Jin Lce, Boro Malinovic 


\subsection{Alternate Method of Evaluating Transitions Between Reactions}

The original version of this document described the following method for evaluating oxidation rate at conditions between defined correlations. Section 7.0 now presents a simplified method for evaluating oxidation rates. However, the original method was found to produce similar results and is described in this appendix to support prior evaluations.

\subsubsection{Alternate Transition Description}

Linear interpolations between correlations are used to describe transitions between oxygen-free water vapor, dry air, and moist air correlations. Figure 10-3 shows a comparison of the dry air and moist air oxidation rates. The alternate method developed for estimating oxidation rates at conditions in the transition regions of temperature and RH is based on Figures 10-3 and 10-4. The interpolation method ensures that reaction rates are bounded by the appropriate correlations and the transitions are continuous functions. The results are summarized as follows:

- For temperature less than $305 \mathrm{~K}$, oxidation rates are estimate by:

- the dry air correlation for $\mathrm{RH}<75 \%$

- linear interpolation between dry air and $100 \% \mathrm{RH}$ air correlations for $75 \% \leq \mathrm{RH} \leq 100 \%$.

- For temperatures between $305 \mathrm{~K}$ and $368 \mathrm{~K}$, oxidation rates are estimated by:

- linear interpolation between dry air and $10-75 \% \mathrm{RH}$ air correlations for $\mathrm{RH}<10 \%$

- the $10-75 \% \mathrm{RH}$ correlation for $10 \% \leq \mathrm{RH} \leq 75 \%$

- linear interpolation between $10-75 \% \mathrm{RH}$ air and $100 \% \mathrm{RH}$ air correlations for $75 \%<\mathrm{RH}$ $\leq 100 \%$

- For temperatures between $368 \mathrm{~K}$ and a $\mathrm{RH}$ dependent transition temperature (see Appendix 10.3) oxidation rates are estimated by:

- linear interpolation between the dry air and $100 \%$ RH air correlations for $\mathrm{RH}<10 \%$

- the $100 \% \mathrm{RH}$ air correlation for $\mathrm{RH} \geq 10 \%$

- For temperatures greater than the transition temperature defined in Appendix 10.3, oxidation rates are estimated by correlations described in Reilly (1998) [these temperatures are greater that the process conditions of interest].

- For partial pressures of oxygen between $0.001 \mathrm{kPa}$ and $0.01 \mathrm{kPa}$, linearly interpolate between the oxygen-free water vapor and moist air correlations at constant partial pressure of water vapor. 
Figure 10-3. Basis for Alternative Transitions between Air Oxidation Reactions

$($ Enhancement Factor $=1)$

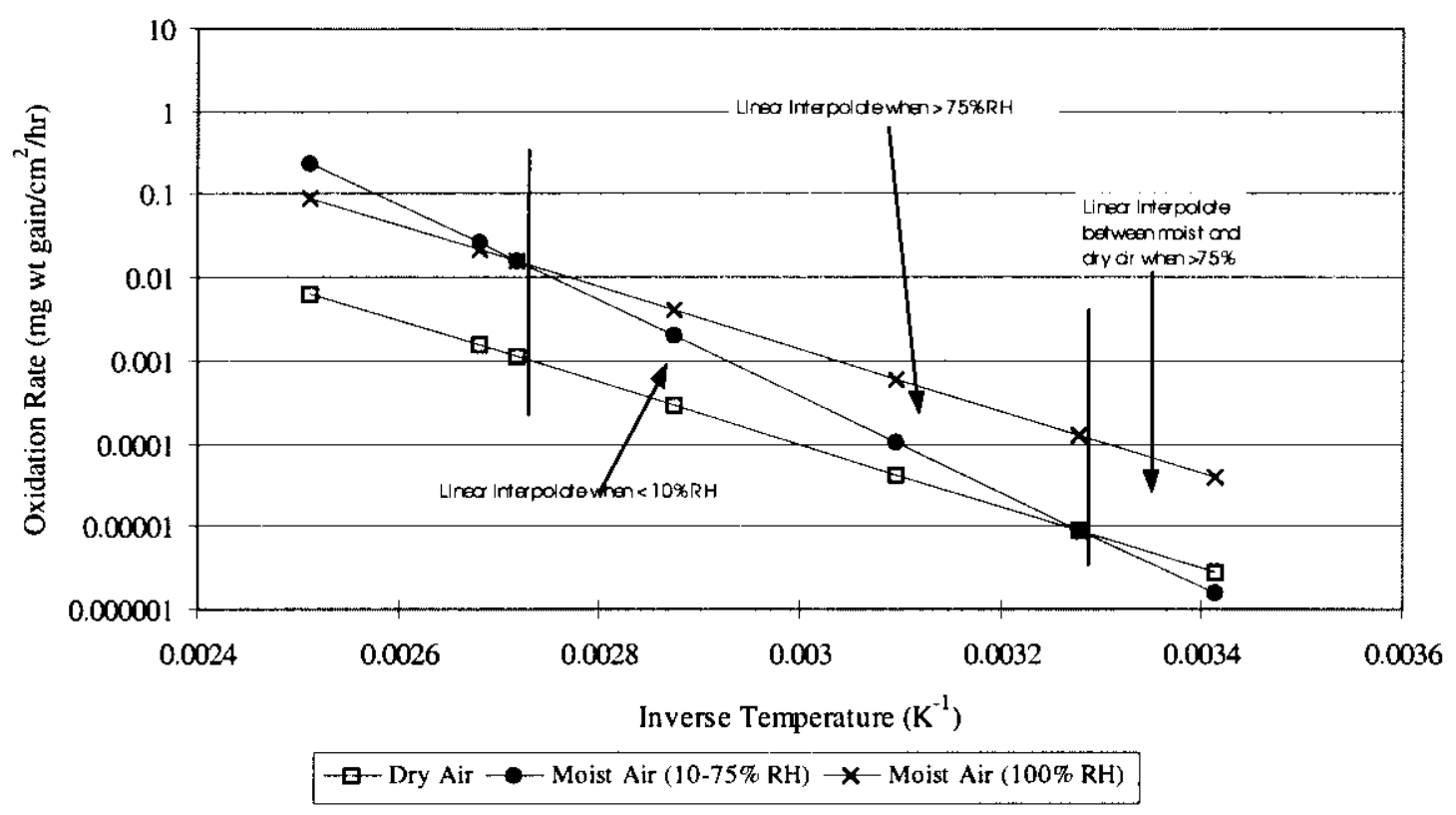

Figure 10-5 indicates the variation of uranium oxidation rate with temperature at constant water vapor partial pressures predicted by the interpolating method described above. Assuming the $10 \mathrm{kPa}$ water vapor system as an example, the system starts at $100 \% \mathrm{RH}$ air when the temperature is approximately $322 \mathrm{~K}\left(49^{\circ} \mathrm{C}\right)$. As the system temperature is increased and water vapor pressure maintained constant, $\mathrm{RH}$ decreases to $75 \% \mathrm{RH}$. Reaction rates are estimated by interpolating between the $100 \% \mathrm{RH}$ air and $10-75 \% \mathrm{RH}$ air correlations. As the system temperature is increased further, the RH enters the range of 10 to $75 \%$ and the correlation specific to these conditions is used for estimating oxidation rates until the temperature reaches $368 \mathrm{~K}$. At $368 \mathrm{~K}$, the $10-75 \% \mathrm{RH}$ air and $100 \% \mathrm{RH}$ air correlations predict equivalent oxidation rates. The $100 \% \mathrm{RH}$ air correlation is used to predict oxidation rates until the temperature reaches approximately $375 \mathrm{~K}(\mathrm{RH}=10 \%$ for water vapor pressure of $10 \mathrm{kPa})$. Between $375 \mathrm{~K}$ and $417 \mathrm{~K}$ (from Figure 10-7), oxidation rates are estimated by linear interpolation between dry air and $100 \% \mathrm{RH}$ air correlations. Above $417 \mathrm{~K}$, oxidation rates are based on the high temperature correlations in Reilly (1998). 
Figure 10-4. Composition Basis for Alternative Transitions between Oxidation Reactions

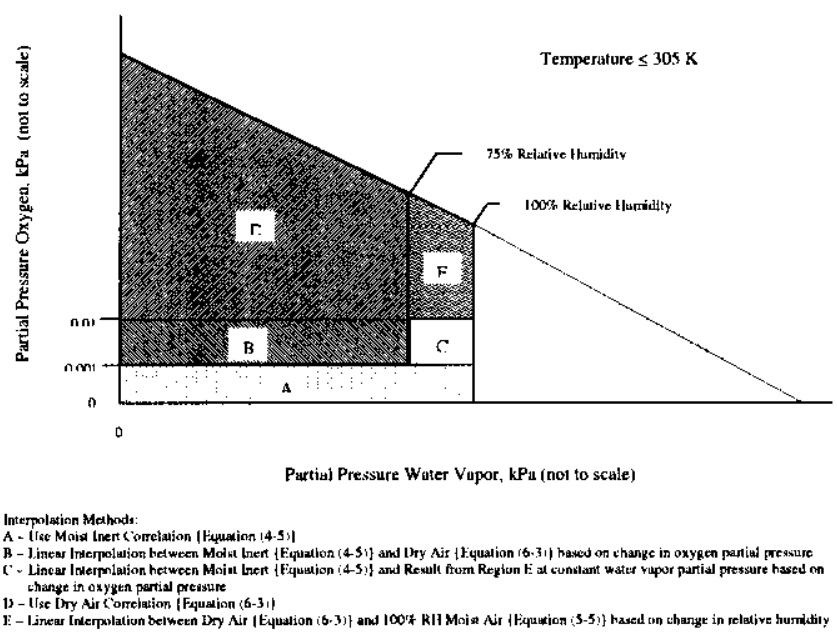

(a) Temperature $\leq 305 \mathrm{~K}$

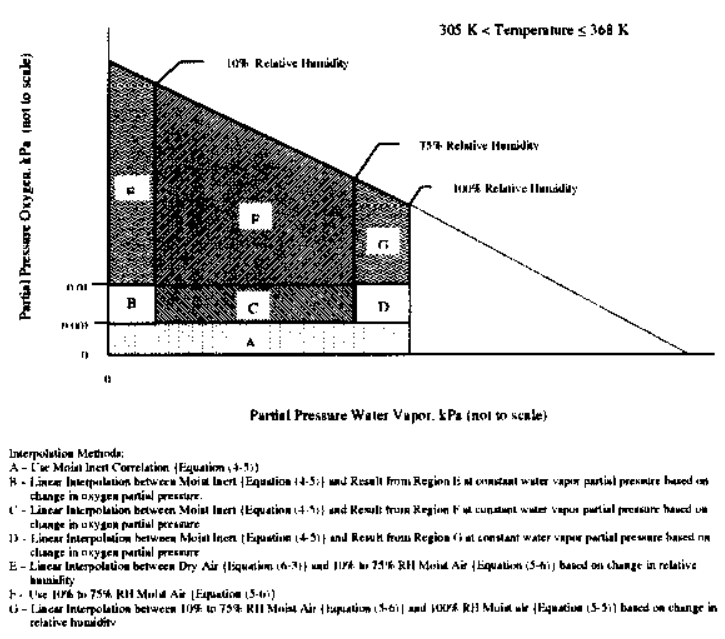

(b) $305 \mathrm{~K}<$ Temperature $\leq 368 \mathrm{~K}$

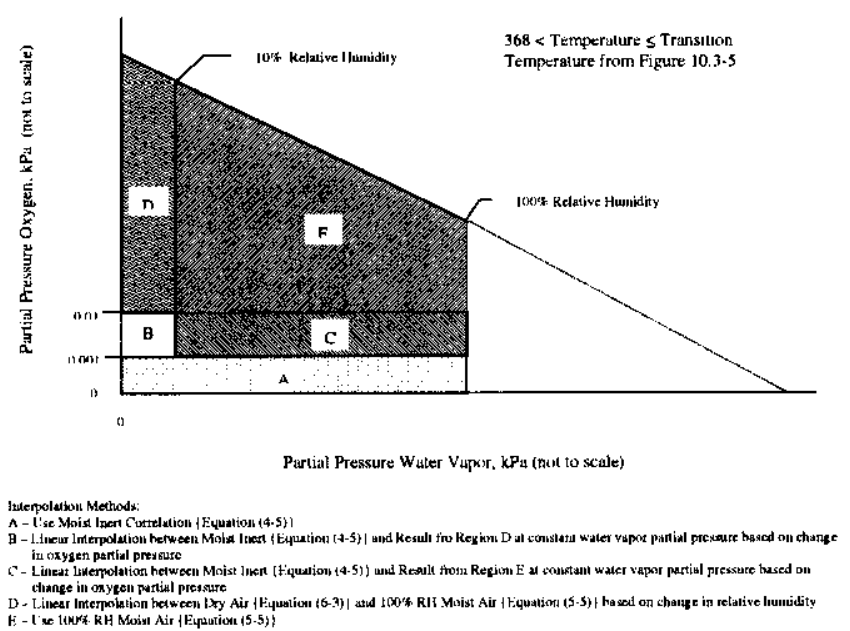

(c) $368 \mathrm{~K}<$ Temperature $\leq$ Transition Temperature from Figure 10.3-5 
Figure 10-5. Variation of Moist Air Uranium Oxidation Rate Based on Interpolations (Enhancement Factor $=1$ )

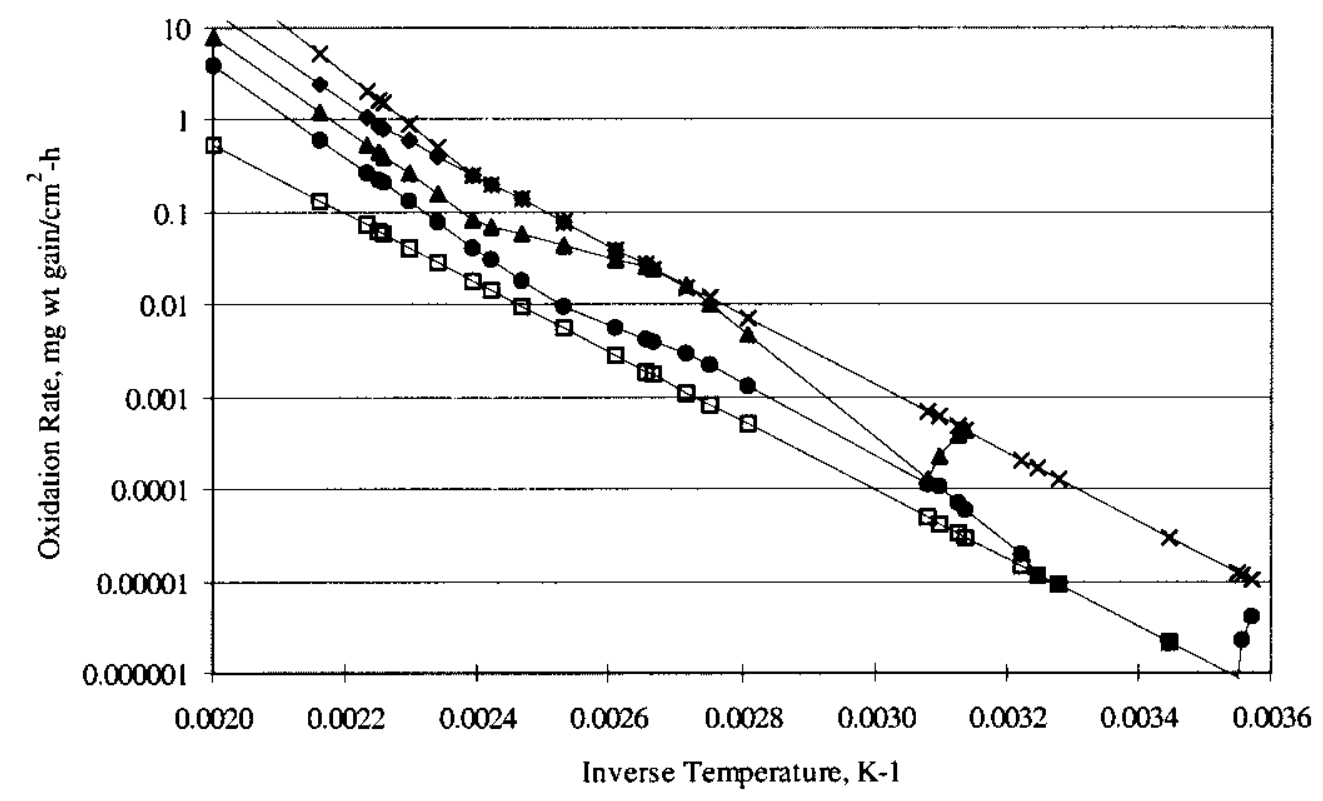

๑- Dry Air $-x$ Moist Air At 100\% RH $\bullet$ Water Vapor $=1 \mathrm{kPa}-\downarrow-$ Water Vapor $=10 \mathrm{kPa} \multimap-$ Water Vapor $=100 \mathrm{kPa}$

\subsubsection{Transition Temperatures for Alternate Linear Interpolations}

Estimates of moist air reaction rates are based primarily on data correlations. Since the reaction rate estimates are used to support computer calculations of transient processes, a method of creating continuous functions from the correlations is required as reactant concentrations change. The basis for transitions between oxygen free water vapor and air oxidation correlations is based on a straight forward linear interpolation between water vapor and air reaction rates as the oxygen partial pressure varies between $0.001 \mathrm{kPa}$ and $0.01 \mathrm{kPa}(10$ and $100 \mathrm{ppm}$ for total system pressure of $1 \mathrm{~atm}$ ). The transition between moist air and dry air is more complex and described in detail below. It is emphasized that this interpolation method was developed to support consistent estimates of reaction rates. It is not based on a reaction mechanism or theory. The oxidation rate correlations to experimental data form the actual basis for the validity of the reaction rate estimates.

Figures 10-3 and 10-4 provide the general description of air reaction interpolations. The overall concept is that moist air reaction rates cannot exceed the correlation of $100 \% \mathrm{RH}$ air data nor be slower than the dry air reaction rate. The correlation of rate data between $10 \%$ and $75 \% \mathrm{RH}$ air intersects both of these correlations. Intersection temperatures are found mathematically by equating predicted oxidation rates from the following correlations. 
Dry air rate: $\quad \log K=7.19-3732 / \mathrm{T}$

$10-75 \%$ RH air rate: $\log \mathrm{K}=13.8808-5769.9 / \mathrm{T}$

100\% RH air rate: $\quad \log \mathrm{K}=8.333-3730 / \mathrm{T}$

where: $\mathrm{K}=$ rate constant, $\mathrm{mg}$ wt gain $/ \mathrm{hr}-\mathrm{cm}^{2}$

$\mathrm{T}=$ temperature, $\mathrm{K}$

Dry air $-10-75 \% \mathrm{RH}$ air intersection temperature:

$$
\begin{aligned}
7.19-3732 / \mathrm{T}=\log \mathrm{K}=13.8808-5769.9 / \mathrm{T} \\
\frac{2037.9}{\mathrm{~T}}=6.6908 \\
\mathrm{~T}=305.6 \text { or } 305 \mathrm{~K}
\end{aligned}
$$

10-75\% RH air - $100 \% \mathrm{RH}$ air intersection temperature:

$$
\begin{aligned}
13.8808-5769.9 / \mathrm{T} & =\log \mathrm{K}=8.333-3730 / \mathrm{T} \\
5.5508 & =\frac{2039.9}{\mathrm{~T}} \\
\mathrm{~T} & =367.5 \text { or } 368 \mathrm{~K}
\end{aligned}
$$

Therefore, for temperatures below $305 \mathrm{~K}$, air system reaction rates are based on Equation (10.3-1) when the $\mathrm{RH}<75 \%$. For RH between $75 \%$ and $100 \%$, the reaction rate is based on a linear interpolation between Equations (10.3-1) and (10.3-3). Between $305 \mathrm{~K}$ and $368 \mathrm{~K}$, reaction rates for systems with $\mathrm{RH}$ between $0 \%$ and $10 \%$ are obtained by linear interpolation between Equation (10.3-1) and (10.3-2). Systems with RH between $10 \%$ and $75 \%$ are based on Equation (10.3-2). Systems with RH between $75 \%$ and $100 \%$ are based on linear interpolation between Equations (10.3-2) and (10.3-3).

Above $368 \mathrm{~K}$, the interpolation method is adjusted to ensure continuity with the higher temperature moist air correlation in Reilly, 1998. This correlation (Equation 10.3-4) is based on the partial pressure of water in the system.

For $373 \mathrm{~K}<\mathrm{T}<463 \mathrm{~K}: \log \mathrm{K}=10.566-4990 / \mathrm{T}+0.3 \log \mathrm{P}$

where: $\mathrm{P}=$ partial pressure water, $\mathrm{kPa}$

Transition temperatures are defined based on equating reaction rate predictions from Equations (10.3-3) and (10.3-4) when the system RH is greater than 10\%. For systems with RH between rate predictions by Equation (10.3-4) with a linear interpolation between Equation (10.3-1) and (10.3-3). To support evaluation of the transition temperature, a correlation of the water vapor saturation pressure was developed. The correlation is shown as Equation (10.3-5) and compared to data in Figure 10-6.

$$
\log P_{\text {sat }}=7.6726-2126.5 / T
$$

where: $\mathrm{P}_{\mathrm{sat}}=$ saturation pressure of water vapor, $\mathrm{kPa}$ 
This allows relating the partial pressure of water, temperature and RH. At $10 \% \mathrm{RH}$, the partial pressure of water can be found for a given temperature:

$$
\begin{aligned}
\frac{\mathrm{P}_{\mathrm{RH}=10 \%}}{\mathrm{P}_{\text {sat }}} & =0.1 \\
\mathrm{P}_{\mathrm{RH}=10 \%} & =(0.1) 10^{7.6726-2126.5 / \mathrm{T}} \\
& =10^{6.6726 \cdot 2126.5 / \mathrm{T}}
\end{aligned}
$$

Alternatively, the temperature can be found for a given water vapor pressure:

$$
\mathrm{T}_{\mathrm{RH}=10 \%}=\frac{2126.5}{6.6726-\mathrm{P}}
$$

Figure 10-6. Correlation for Predicting Water Vapor Saturation Pressure

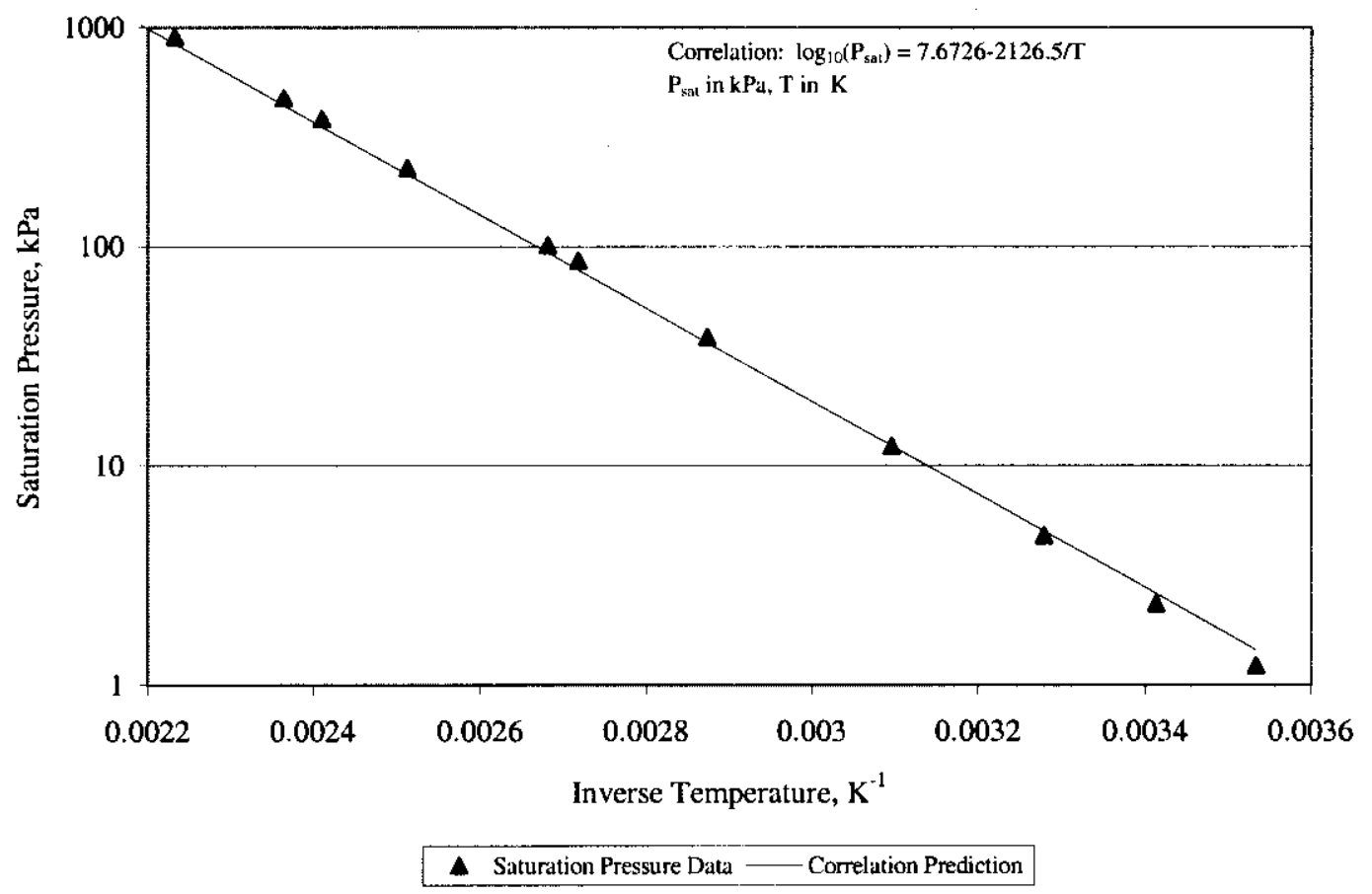


When the $\mathrm{RH}>10 \%$, the transition temperature between reaction rate correlations is defined by equating Equations (10.3-3) and (10.3-4).

$$
\begin{gathered}
8.333-3730 / \mathrm{T}_{\mathrm{I}}=\log \mathrm{K}=10.566-4990 / \mathrm{T}_{\mathrm{I}}+0.3 \log \mathrm{P} \\
\frac{1260}{\mathrm{~T}_{\mathrm{I}}}=2.233+0.3 \log \mathrm{P} \\
\mathrm{T}_{1, \mathrm{RH}>10 \%}=\frac{1260}{2.233+0.3 \log \mathrm{P}}
\end{gathered}
$$

For $\mathrm{RH} \geq 10 \%$, Equation (10.3-3) is used to estimate the oxidation rate between $368 \mathrm{~K}$ and

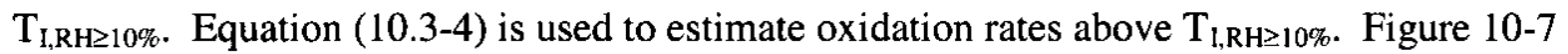
indicates the transition temperature for $\mathrm{RH} \geq 10 \%$ as it varies with the partial pressure of water vapor.

When the $\mathrm{RH}<10 \%$, the transition temperature between reaction rate correlations is found by equating Equation (10.3-4) with the linear interpolation between Equations (10.3-1) and (10.3-3). Noting that $0 \leq \mathrm{P} / \mathrm{P}_{\text {sat }}<0.1$ for $\mathrm{RH}<10 \%$. Therefore, the transition temperature is found by the following.

$$
\left\{10^{7.19-3732 / \mathrm{T}}\right\}+(\mathrm{P} / 0.1 \mathrm{Psat})\left\{10^{8.333-3730 / \mathrm{T}}-10^{7.19-3732 / \mathrm{T}}\right\}=\mathrm{K}=10^{10.566-4990 / \mathrm{T}+0.3 \log \mathrm{P}}
$$

\section{Figure 10-7. Transition Temperature between Moist Air Oxidation Correlations}

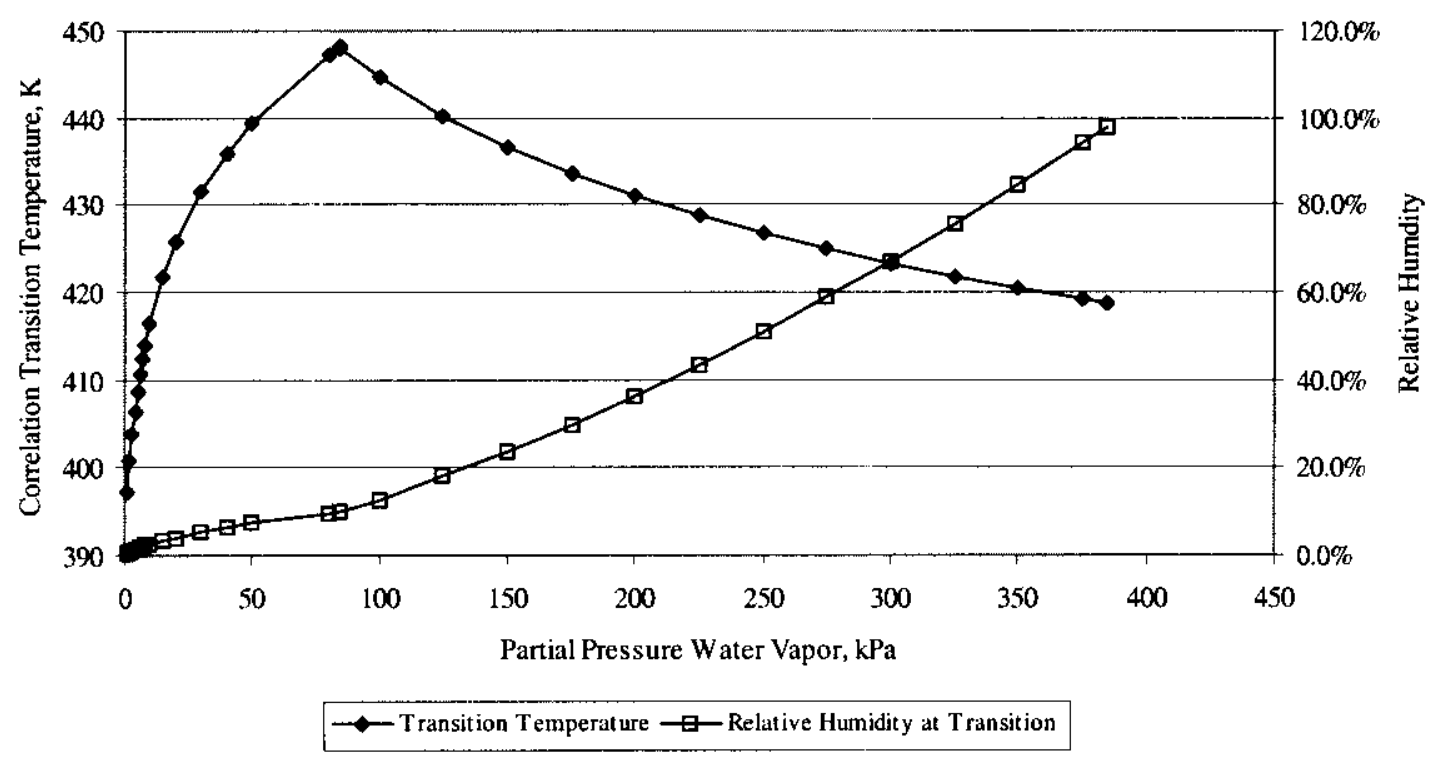


This can be simplified to the following:

$$
\begin{aligned}
& \left\{10^{7.19 \cdot 3732 / \mathrm{T}}\right\}+\frac{\mathrm{P}}{10^{6.6726-2126.5 / \mathrm{T}}}\left\{10^{8.333-3730 / \mathrm{T}}-10^{7.19-3732 / \mathrm{T}}\right\}=10^{10.566-4990 / \mathrm{T}+0.3 \log \mathrm{P}} \\
& \left\{10^{7.17-3732 / \mathrm{T}}\right\}+\mathrm{P}\left\{10^{1.6604-1603.5}-10^{0.5174-1605.5 / \mathrm{T}}\right\}=10^{10.566-4990 / \mathrm{T}+0.3 \log \mathrm{P}} \\
& \log \left[\left\{10^{7.19-3732 / \mathrm{T}}\right\}+\mathrm{P}\left\{10^{1.6604-1603.5 / \mathrm{T}}-10^{0.5174-1605.5 / \mathrm{T}}\right\}\right]-10.566+4990 / \mathrm{T}-0.3 \log \mathrm{P}=0
\end{aligned}
$$

This can be solved implicitly for $\mathrm{T}$, given the system water vapor partial pressure, to yield the transition temperature $\mathrm{T}_{\mathrm{l}, \mathrm{RH}<10 \%}$. Figure 10-7 indicates the transition temperature variation with the partial pressure of water. When $\mathrm{RH}<10 \%$, the oxidation rate is predicted by linear interpolation between Equations (10.3-1) and (10.3-3) for temperatures between $368 \mathrm{~K}$ and $\mathrm{T}_{\mathrm{I}, \mathrm{RH}<10 \%}$. Equation (10.3-4) is used for temperatures above $\mathrm{T}_{\mathrm{I}, \mathrm{RH}<10 \%}$.

\subsubsection{Comparison of Oxidation Rate Predictions in Transitions}

Section 7.0 describes a reaction rate prediction method in transition regions of relative humidity based on McGillivray (1994). The approach described in Section 7.0 is recommended for future work because it represents the latest proposed reaction mechanism and a simple method of interpolating between applicable rate correlations.

Project calculations, to date, have been based on the interpolation method described in Sections 10.3.1 and 10.3.2. Figures 10-8, 10-9, and 10-10 compare oxidation rate predictions from the interpolation method in Section 7.0 (McGillivray) with the method described in Section 10.3 (Databook). Water vapor partial pressures of $1 \mathrm{kPa}, 10 \mathrm{kPa}$, and $50 \mathrm{kPa}$ are assumed for the three comparison plots, respectively. Literature data obtained at conditions near the comparison plot conditions are also indicated.

The comparison plots indicate:

- both interpolation methods produce similar oxidation rate predictions,

- the difference between oxidation rates predicted by the two methods is within the variation observed in literature data, and

- any difference between the alternate oxidation rate predictions is more than compensated for by a reaction rate enhancement factor of 3 to 10 .

Therefore, it is concluded that either method of oxidation rate prediction can be used in project analyses. 
Figure 10-8. Comparison of Moist Air Oxidation Rate Predictions at 1 kPa Water Vapor

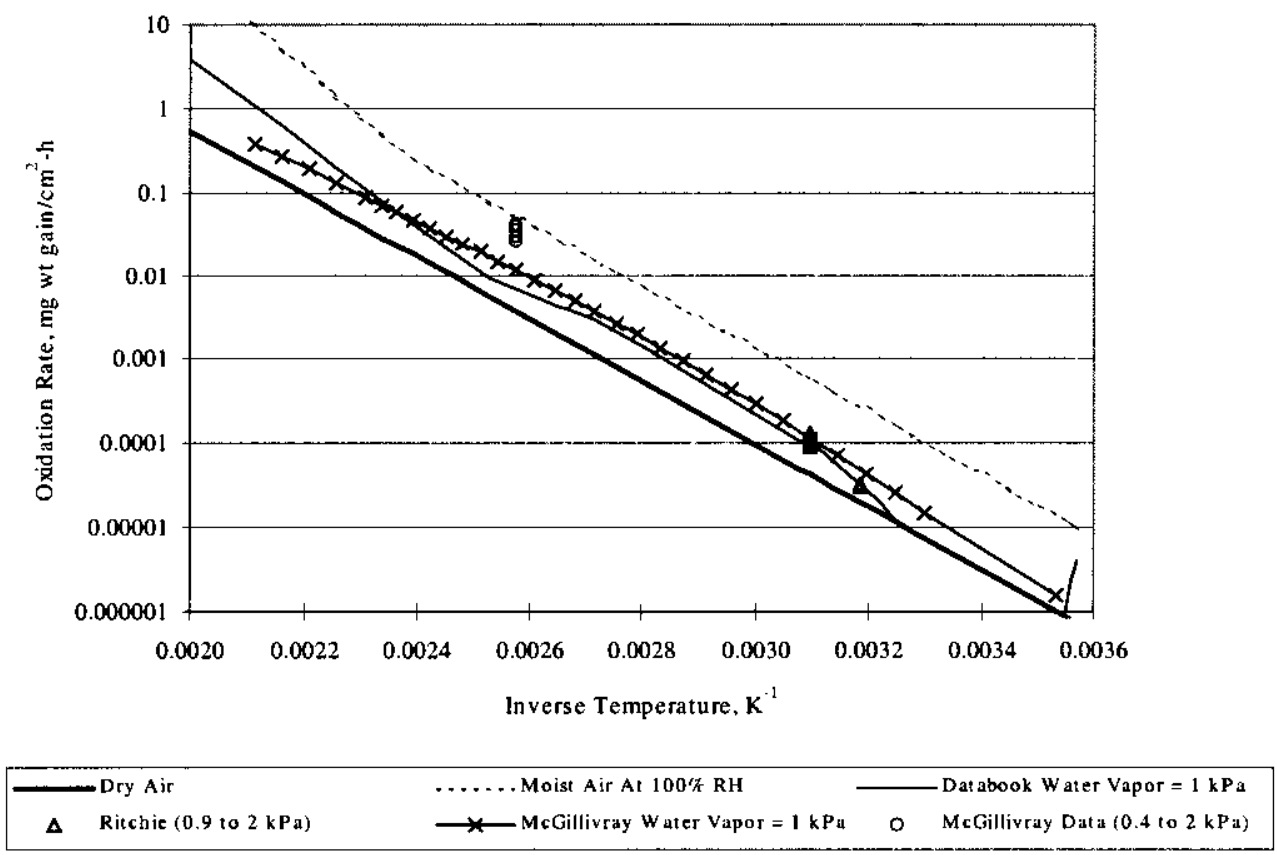

Figure 10-9. Comparison of Moist Air Oxidation Rate Predictions at $10 \mathrm{kPa}$ Water Vapor

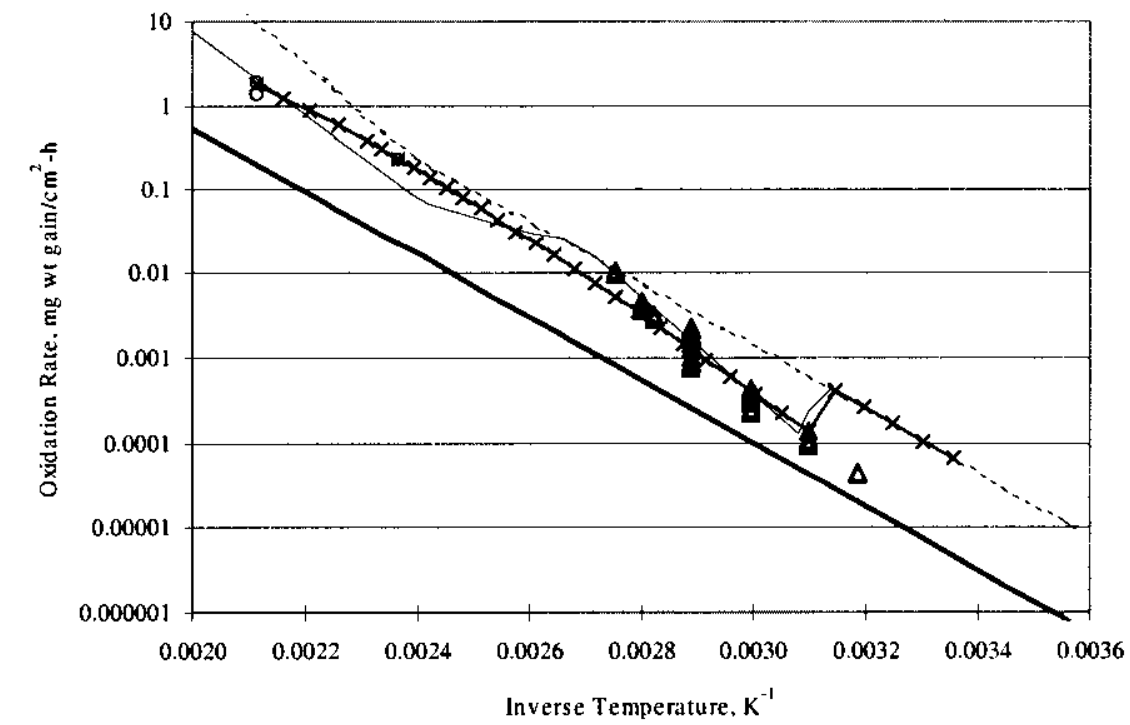

$\begin{array}{lll}\text { Dry Air } & \ldots \text { - Moist Air At 100\% RH } & \text { Databook Water Vapor }=10 \mathrm{kPa} \\ \Delta \quad \text { Ritchie }(6 \text { to } 15 \mathrm{kPa}) & \longrightarrow \text { McGillivray Water Vapor }=10 \mathrm{kPa} \quad 0 \quad \text { McGilliv ray Data }(6 \text { to } 15 \mathrm{kPa})\end{array}$


HNF-4165, Rev. 1

Figure 10-10. Comparison of Moist Air Oxidation Rate Predictions at $50 \mathrm{kPa}$ Water Vapor

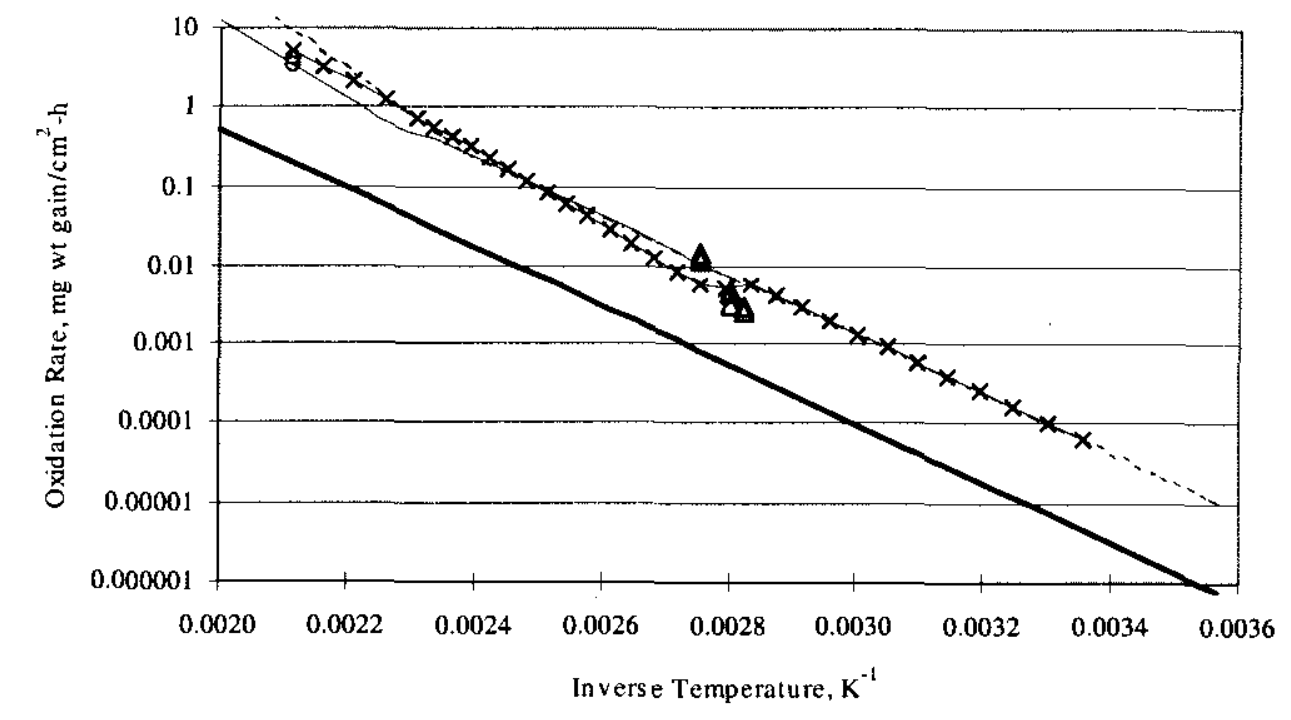




\subsection{Uncertainty Estimates for Enhancement Factors from Single Element Drying Tests}

Oxidation rate enhancement factors are estimated for each single element drying test run from the data in Table 4-1. The experimental rate is compared to rates estimated by the literaturebased correlation described by Equation (4-4). Table 10-2 presents the variation in enhancement factor estimates, depending on whether the experimental rate was based on the high or low element surface area estimate. Enhancement factor estimates range from 3 to 170 .

Table 10-2. Water Vapor Oxidation Rate Enhancement Factor Estimates for N Reactor Fuel from Single Element Drying Tests

\begin{tabular}{|c|c|c|c|c|c|c|c|}
\hline & \multirow{2}{*}{\multicolumn{2}{|c|}{$\begin{array}{l}\begin{array}{l}\text { Experiment Rate Constant, } \\
\mathrm{k}_{\text {expt }}\end{array} \\
\mathrm{mg} \text { wt gain } / \mathrm{cm}^{2} / \mathrm{h} / \mathrm{kPa}^{\mathrm{I}}\end{array}$}} & \multirow{2}{*}{\multicolumn{2}{|c|}{$\begin{array}{c}\text { Effective } \\
\text { Enhancement } \\
\text { Factor, } \mathrm{k}_{\text {expl }} / \mathrm{k}_{\mathrm{lit}} \\
\text { Dimensionless }\end{array}$}} & \multirow{3}{*}{$\begin{array}{c}\begin{array}{c}\text { Literature Rate Constant, } \\
\mathrm{k}_{\mathrm{lit}}\end{array} \\
\mathrm{mg} \mathrm{wt} \text { gain } / \mathrm{cm}^{2} / \mathrm{h} / \mathrm{kPa}^{1 / 2} \\
\end{array}$} & \multicolumn{2}{|c|}{$\begin{array}{c}\text { Enhancement } \\
\text { Factor } \\
\text { Uncertainty }\end{array}$} \\
\hline & & & & & & & \\
\hline \multirow{2}{*}{ Run No. } & Low & High & Low & High & & Low & High \\
\hline & 0.16 & 1.94 & 11 & 131 & 0.015 & 0 & 1030 \\
\hline $\begin{array}{c}4 \\
\text { PNNL-11821 } \\
\end{array}$ & 0.20 & 2.48 & 13 & 168 & 0.015 & 0 & 1219 \\
\hline \multirow{2}{*}{$\begin{array}{c}5 \\
\text { PNNL-1 } 1841 \\
\end{array}$} & 0.05 & 1.24 & 3 & 84 & 0.015 & 0 & 1108 \\
\hline & 0.05 & 1.31 & 4 & 88 & 0.015 & 0 & 1136 \\
\hline \multirow{2}{*}{$\begin{array}{c}6 \\
\text { PNNL- } 11896 \\
\end{array}$} & 0.13 & 1.90 & 9 & 129 & 0.015 & 0 & 1216 \\
\hline & 0.13 & 2.02 & 9 & 137 & 0.015 & 0 & 1145 \\
\hline \multirow{4}{*}{$\begin{array}{c}7 \\
\text { PNNL-11897 }\end{array}$} & 0.02 & 0.24 & 4 & $\overline{48}$ & 0.005 & 0 & 311 \\
\hline & 0.02 & 0.26 & 4 & 53 & 0.005 & 0 & 344 \\
\hline & 0.09 & 1.04 & 6 & 70 & 0.015 & 0 & 463 \\
\hline & 0.07 & 0.80 & 4 & 54 & 0.015 & 0 & 364 \\
\hline \multirow{4}{*}{$\begin{array}{c}8 \\
\text { PNNL- } 11969\end{array}$} & 0.02 & 0.20 & 4 & 40 & 0.005 & 0 & 247 \\
\hline & 0.02 & 0.28 & 5 & 57 & 0.005 & 0 & 349 \\
\hline & 0.11 & 1.30 & 8 & 88 & 0.015 & 0 & 560 \\
\hline & 0.12 & 1.39 & 8 & 94 & 0.015 & 0 & 647 \\
\hline
\end{tabular}

Notes:

(1) Enhancement Factor $=\left(k_{\text {expt }} \pm \Delta k\right) / k_{\text {lit }}$. $k_{\text {expt }}$ from Table 4-1. $k_{\text {lit }}$ from Equation (4-4).

A large range of uncertainty is estimated for the enhancement factors, ranging from 0 to approximately 1200 . This large range is estimated from the uncertainty in the experimental rate constant, which is derived from an error propagation analysis. Table 10-3 summarizes the error propagation calculation, with the basis equations indicated in the table notes. The error propagation estimate requires input of the uncertainty in rate (hydrogen production rate), surface area, water vapor pressure at each point where the reaction rate is reported. The hydrogen production rate uncertainty was not precisely developed, but estimated at $1 \%$ of the reported rate. The area uncertainty was estimated at one-half the difference in high and low surface area estimates. The water vapor uncertainty was estimated in Table 10-4 based on the dew point instrument error and the correlation used to convert dew point measurements to water vapor pressure. 
HNF-4165, Rev 1

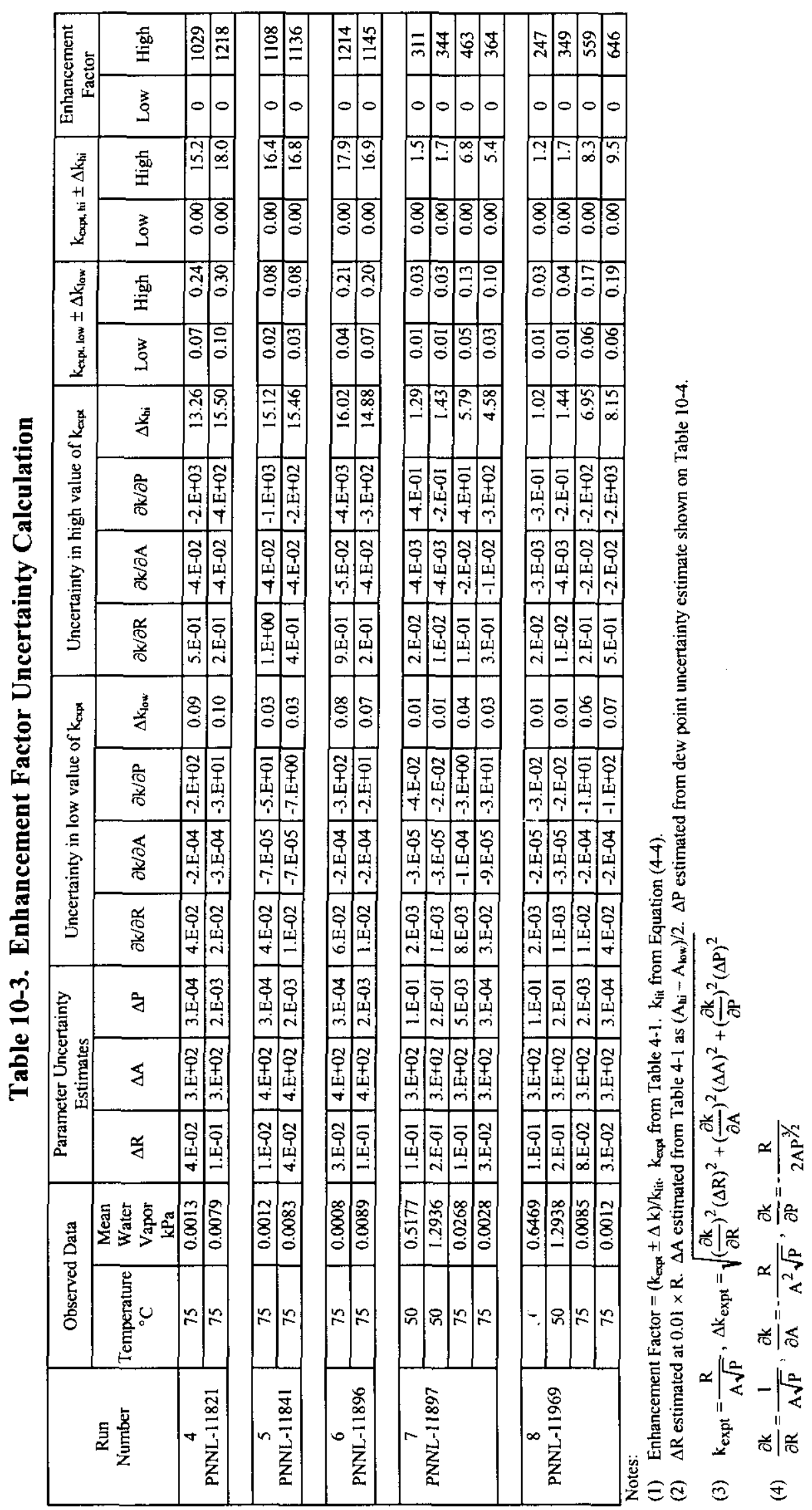


HNF-4165, Rev 1

Table 10-4. Uncertainty Estimate for Partial Pressure Water Measurements in Single Element Drying Tests.

\begin{tabular}{|c|c|c|c|c|c|c|}
\hline \multicolumn{7}{|c|}{ Uncertainty Estimate for Water Vapor Analysis in Single Element Drying Tests } \\
\hline \multicolumn{7}{|c|}{$\begin{array}{l}\text { Partial pressure water based on correlation of dew point measurement and following correlation of water vapo } \\
\text { pressure from dew point in Marschman, et al., 1998. }\end{array}$} \\
\hline \multicolumn{7}{|c|}{$\log _{10}(P$, in torr $)=A x^{6}+B x^{5}+C x^{4}+D x^{3}+E x^{2}+F x+G$} \\
\hline \multicolumn{2}{|c|}{$\mathrm{A}=-6.73 \mathrm{E}-12$} & \multicolumn{2}{|c|}{$\mathrm{D}=-7.26 \mathrm{E}-06$} & \multicolumn{2}{|l|}{$G=0.66043$} & \\
\hline \multicolumn{2}{|c|}{$\mathrm{B}=-1.73 \mathrm{E}-09$} & \multicolumn{2}{|c|}{$\mathrm{E}=-2.97 \mathrm{E}-04$} & \multicolumn{2}{|l|}{$\mathrm{x}$ in $\operatorname{deg} \mathrm{C}$} & \\
\hline \multicolumn{2}{|c|}{$C=-1.71 E-07$} & \multicolumn{2}{|c|}{$F=3.44 \mathrm{E}-02$} & & & \\
\hline \multicolumn{7}{|c|}{$\begin{array}{l}\Delta \mathrm{P} \sim \mathrm{dP} / \mathrm{dx} \times \Delta \mathrm{x} . \\
\text { The dew point monitor uncertainty is } \Delta \mathrm{x}=2^{\circ} \mathrm{C} \text {, from Ritter, et al., } 1998 \text {. } \\
\mathrm{dP} / \mathrm{dx}=\mathrm{P} \operatorname{Ln}(10)\left(6 \mathrm{Ax}^{5}+5 \mathrm{Bx}^{4}+4 \mathrm{Cx}^{3}+3 \mathrm{Dx^{2 }}+2 \mathrm{Ex}+\mathrm{F}\right)\end{array}$} \\
\hline \multicolumn{7}{|c|}{ Variation of Water Vapor Uncertainty } \\
\hline $\mathrm{x}, \mathrm{C}$ & P, torr & $\mathrm{dP} / \mathrm{dx}$ & $\Delta \mathrm{P}$, torr & & $\mathrm{P}, \mathrm{kPa}$ & $\Delta \mathrm{P}, \mathrm{kPa}$ \\
\hline 10 & $9.24 \mathrm{E}+00$ & $5.43 \mathrm{E}-01$ & $1.09 \mathrm{E}+00$ & & $1.23 \mathrm{E}+00$ & $1.45 \mathrm{E}-01$ \\
\hline 0 & $4.58 \mathrm{E}+00$ & $3.63 \mathrm{E}-01$ & $7.25 \mathrm{E}-01$ & & $6.10 \mathrm{E}-01$ & $9.67 \mathrm{E}-02$ \\
\hline-35 & $1.68 \mathrm{E}-01$ & $1.82 \mathrm{E}-02$ & $3.64 \mathrm{E}-02$ & & $2.24 \mathrm{E}-02$ & $4.85 \mathrm{E}-03$ \\
\hline-45 & $5.43 \mathrm{E}-02$ & $6.42 \mathrm{E}-03$ & $1.28 \mathrm{E}-02$ & & $7.23 \mathrm{E}-03$ & $1.71 \mathrm{E}-03$ \\
\hline-60 & $8.11 \mathrm{E}-03$ & $1.10 \mathrm{E}-03$ & $2.20 \mathrm{E}-03$ & & $1.08 \mathrm{E}-03$ & $2.93 \mathrm{E}-04$ \\
\hline
\end{tabular}

